\title{
The Fundamental Institutions of China's Reforms and Development ${ }^{1}$
}

\author{
This version: May 2010 \\ Chenggang $\mathrm{Xu}$ \\ University of Hong Kong
}

\begin{abstract}
China's economic reforms have resulted in spectacular growth and poverty reduction. However, China's institutions look ill-suited to achieve such a result, and they indeed suffer from serious shortcomings. To solve this "China puzzle" this paper analyses China's institution - a regionally decentralized authoritarian system. The central government has control over personnel, whereas sub-national governments run the bulk of the economy; and they initiate, negotiate, implement, divert and resist reforms, policies, rules and laws. China's reform trajectories have been shaped by regional decentralization. Spectacular performance on the one hand and grave problems on the other hand are all determined by this governance structure.
\end{abstract}

Keywords:

Institution, economic development, economic reform, China, decentralization, political economics, authoritarianism, federalism

JEL Classifications:

D02, D86, E02, E62, G20, G30, H11, H70, K00, O10, O53, P36

\footnotetext{
${ }^{1}$ An early version of this paper was titled "The Institutional Foundations of China's Reforms and Development." Comments from participants in conferences and seminars at the CEIBS, Chicago, Chinese U (HK), City U (HK), IEA Round Tables (Beijing), IPD (Columbia/Manchester), Macau, Peking, Seoul (SNU), Singapore (SNU), Tsinghua and UNU-WIDER are greatly appreciated. I am grateful for helpful discussions and comments from three anonymous referees, Masahiko Aoki, Pranab Bardhan, Lauren Brandt, Hongbin Cai, Chun Chang, Jiahua Che, Ronald Coase, Athar Hussain, Garry Jefferson, Yasheng Huang, Janos Kornai, James Kung, Hongbin Li, Justin Yifu Lin, Lawrence Lau, Eric Maskin, James Mirrlees, Katharina Pistor, Gerard Roland, Yumin Sheng, Joseph Stiglitz, Zhigang Tao, Daniel Treisman, Shaoguang Wang, Christine Wong, Jinglian Wu, Dali Yang and Lian Zhou. Special thanks go to the editor, Roger Gordon, for his guidance and insightful comments on different versions of the paper. The usual disclaimer applies. Linfeng Chen, Xiaoya Dou, William Organek and Jin Wang served as excellent research assistants. Financial support from the World Economy \& Finance Research Program of the ESRC (UK), the WCU program through the Korea Science and Engineering Foundation funded by the Ministry of Education, Science and Technology (grant R32-2008-000-20055-0), HKUST and HKU are sincerely acknowledged.
} 
Table of Contents

$\underline{1 . \text { Introduction }}$

2. The Fundamental Institution: Regionally Decentralized Authoritarianism

2.1 Decentralized Economic Governance: Regional Decentralization

$\underline{2.2 \text { Centralized Political Governance }}$

2.2.1 Evolved Decision-making Process of the Central Leadership

2.2.2 Personnel Control and Cadre Management

2.3 Central-Regional Relationship

$\underline{2.4 \text { General Remarks }}$

3. Regional Competition and Sub-national Governments' Incentives for Reforms

3.1 The Institutional Foundation for Regional Tournament Competition

$\underline{3.2 \text { Evidence }}$

$\underline{3.3 \text { Chinese Regional Competition and the Debate on Fiscal Federalism }}$

4. Regional Institutional Experiments

4.1 The Institutional Foundation for Regional Experiments

4.2 Regional Experiments on Land Reform and Special Economic Zones

4.3 Incentives of Experimenting

5. Regional Competition and Regional Experiments in Some Major Reforms

5.1 The Township-Village Enterprises (TVEs) and the Non State Sector

5.2 State Sector Reform: Centrally Sponsored Local Experiments

5.3 Privatization: Locally Initiated Reform Experiments

5.4 The Impacts of Regional Decentralization on Growth

6. Tradeoffs of Regional Decentralization

6.1 Law and Regulation

6.2 Regional Protection

6.3 Regional Disparity

6.4 Resolving China's Institutional Problems

7. Concluding Remarks 


\section{Introduction}

Chinese economic reforms, which have been in flux for three decades, have more than doubled China's economic growth, from an average of 4.4 percent annually before 1978 to an average of 9.5 percent after 1978. Even more impressively, the contribution of TFP to the growth has increased from 11 percent before 1978 to more than 40 percent afterwards (Perkins and Rawski, 2008). This process has transformed the world's largest developing country from a centrally-planned economy into a mixed market economy, while simultaneously reducing poverty at a scale unparalleled in world history (World Bank, 2002). During the reform period the Chinese per capita GDP increased by almost eight-fold, and China has transformed from one of the poorest countries in the world ${ }^{2}$ into a major economic power. Today's China is the world's largest producer and largest consumer of many conventional industrial staples and high-tech products, such as steel, cars, TV sets, personal computers, cell phones and internet usage, etc. (NSB, 2005) and has the world's largest foreign reserves. The current size of the Chinese economy, in terms of GDP, is larger than the sum of 83 countries in Eastern Europe, the CIS and all of Africa (the author's calculation based on Maddison, 2003). This makes a research on China more imperative for understanding the world economy.

Table 1. Annual Growth of China's GDP, Fixed Capital, Labor, and TFP, 1952-2005

\begin{tabular}{|c|c|c|c|c|c|c|c|c|}
\hline \multirow{3}{*}{ Period } & \multirow{3}{*}{ GDP } & \multicolumn{3}{|c|}{ Average Growth of Inputs } & \multirow{3}{*}{$\begin{array}{c}\text { Average } \\
\text { TFP } \\
\text { Growth }\end{array}$} & \multirow{2}{*}{\multicolumn{3}{|c|}{$\begin{array}{c}\text { Percentage Shares of GDP } \\
\text { Growth Attributable to }\end{array}$}} \\
\hline & & \multirow[b]{2}{*}{$\begin{array}{l}\text { Fixed } \\
\text { Capital }\end{array}$} & \multicolumn{2}{|c|}{ Labor Input } & & & & \\
\hline & & & $\begin{array}{l}\text { Raw } \\
\text { Labor }\end{array}$ & $\begin{array}{l}\text { Education } \\
\text { Enhanced }\end{array}$ & & $\begin{array}{l}\text { Fixed } \\
\text { Capital }\end{array}$ & $\begin{array}{l}\text { Education } \\
\text { Enhanced }\end{array}$ & TFP \\
\hline & & $\mathrm{K}$ & $\mathrm{L}$ & $\mathrm{H}$ & & $\mathrm{K}$ & Labor H & \\
\hline $1952-2005$ & 7.0 & 7.7 & 1.9 & 2.6 & 2.1 & 47.7 & 21.4 & 30.9 \\
\hline $1952-1978$ & 4.4 & 5.8 & 1.9 & 2.5 & 0.5 & 56.3 & 32.7 & 11.0 \\
\hline 1952-1957 & 6.5 & 1.9 & 1.2 & 1.7 & 4.7 & 12.7 & 14.9 & 72.4 \\
\hline 1957-1978 & 3.9 & 6.7 & 2.0 & 2.7 & -0.5 & 73.7 & 39.7 & -13.4 \\
\hline 1957-1965 & 2.4 & 5.2 & 1.5 & 2.1 & -1.0 & 93.1 & 49.5 & -42.6 \\
\hline $1965-1978$ & 4.9 & 7.7 & 2.4 & 3.1 & -0.2 & 67.7 & 36.7 & -4.4 \\
\hline $1978-2005$ & 9.5 & 9.6 & 1.9 & 2.7 & 3.8 & 43.7 & 16.2 & 40.1 \\
\hline 1978-1985 & 9.7 & 9.2 & 3.4 & 4.5 & 3.2 & 40.6 & 26.6 & 32.8 \\
\hline 1985-1990 & 7.7 & 6.9 & 2.5 & 2.9 & 3.1 & 38.8 & 21.5 & 39.7 \\
\hline 1990-1995 & 11.7 & 9.1 & 1.4 & 1.9 & 6.7 & 33.3 & 9.5 & 57.3 \\
\hline $1995-2000$ & 8.6 & 10.5 & 0.9 & 1.6 & 3.2 & 52.7 & 10.5 & 36.8 \\
\hline 2000-2005 & 9.5 & 12.6 & 1.0 & 1.8 & 3.1 & 57.1 & 10.6 & 32.3 \\
\hline
\end{tabular}

Source: Perkins and Rawski, 2008.

However, in sharp contrast to this spectacular performance, it has been reported that from the viewpoint of standard wisdom, such as the Washington Consensus or the recent empirical literature of cross-country studies, Chinese institutions in government, corporate governance, law and finance, look notoriously weak. Moreover, Chinese reform policies are often unconventional and sometimes even look diametrically opposed to 'standard' policy suggestions (Weitzman and

\footnotetext{
${ }^{2}$ At the outset of the reform, China's per capita GDP was about the same as that of Zambia, which was lower than half of the Asian average or lower than two-thirds of the African average, and its size was about one half of the Soviet Union (Maddison, 2003). Moreover, it had almost no trade with other countries.
} 
Xu, 1994; Rodrik, 2006). ${ }^{3}$

According to conventional wisdom, the government should protect private property rights, enforce contracts, and separate itself from business (North, 1981; Acemoglu and Johson, 2005; Rodrik, 2006). Yet, the Chinese government is deeply involved in business, and there is no clear separation between government and business. Using commonly-applied standards, China is in general below-average on most measurements of the application of the rule of law or for governance quality (Allen et al., 2005); and is among the most corrupt countries in the world. ${ }^{4}$ Moreover, throughout most of the three-decade reform process there was no constitutional protection of private property rights until recently (the 2004 constitutional amendment). To summarize, China's weak institutions are ill-suited to achieve economic development. Thus, the Chinese reforms pose great challenges to standard economic theories. Can economic theory explain China's reforms? Is the Chinese reform a miracle? This paper will tackle these challenges through a unified conceptual framework which synthesises existing literature.

Recently, a growing amount of literature on institutions and reforms demonstrate a general consensus among economists and policy makers that a set of institutions must be in place to make markets function well. Therefore, a market-oriented reform should focus mainly on institution-building to protect property rights. Nevertheless, a vital challenge faced by all transition economies and developing economies is how to build these requisite institutions, and how to carry out the reforms. A simplistic, yet fairly popular view is that markets will form as long as private property is well-protected through proper institutions. However, lessons drawn from numerous historical and contemporary cases show that markets and economic development do not develop spontaneously; ownership protection is not created independent of market development; and private ownership alone is insufficient for the market economy to function (Coase, 1992; Smith, 1763, 1776). Without government functioning beyond the protection of property rights, markets often do not develop; even worse, disorder can destroy markets as easily as dictators. Yet, failures of market-oriented reforms launched by governments are ubiquitous. This is a fundamental dilemma faced by any institution-building reform, and echoes Coase's famous question: what is the boundary of the firm? (Coase, 1937). As I argue in this paper, the lessons of China's reforms suggest that an answer to this fundamental question is ultimately determined by the tradeoffs between costs and benefits of different forms of the government. The trajectory of China's reforms, reform strategies, outcomes, achievements and problems, are mainly determined by China's political and economic institutions.

Following the theoretical literature of institutional analysis (Coase, 1992; Stiglitz, 2002; Hurwicz, 2007), in this paper the word 'institution' refers to those basic and stable mechanisms which govern the incentives of agents and coordinate activities in major political and economic games. Thus, 'institutional foundations' in this paper refer to those basic and stable mechanisms that determine the incentives of the most important players in China's reform and development. ${ }^{5}$

\footnotetext{
${ }^{3}$ In comparing Chinese and Indian reforms with Washington Consensus policies, Rodrik (2006) said: “...their policies remained highly unconventional. With high levels of trade protection, lack of privatization, extensive industrial policies, and lax fiscal and financial policies through the 1990s, these two economies hardly looked like exemplars of the Washington Consensus. Indeed, had they been dismal failures instead of the successes they turned out to be, they would have arguably presented stronger evidence in support of Washington Consensus policies."

${ }^{4}$ China has a "Corruption Perception Index" level of 5, which is similar to Indonesia, Iraq, Myanmar, Nigeria, Sudan and Somalia etc. (Svensson, 2005).

${ }^{5}$ These mechanisms are endogenous in that they are created through the strategic interactions of agents. Thus, institution may also be regarded as the equilibrium of the game in the economic and political world (Greif, 2006). A popular definition of institution is given by North (1990) that "institutions are the rules of the game in a society or,
} 
Based on a large body of literature, I argue that China's fundamental institution that deeply affects executives' incentives and behaviors, which in turn impact society, is what I call the regionally decentralized authoritarian ( $R D A$ ) regime (Section 2 ). The $\mathrm{RDA}$ regime is characterized as a combination of political centralization and economic regional decentralization. On the one hand, the national government's control is substantial in that the Chinese political and personnel governance structure has been highly centralized. Sub-national government officials are appointed from above, and the appointment and promotion of sub-national government officials serve as powerful instruments for the national government to induce regional officials to follow the central government's policies. This feature fundamentally distinguishes the Chinese RDA regime from federalism, where governors or mayors are elected, and they are supposed to represent and be accountable to their constituents. On the other hand, the governance of the national economy is delegated to sub-national governments. Regional economies (provinces, municipalities, and counties) are relatively self-contained, and sub-national governments have overall responsibility for initiating and coordinating reforms, providing public services, and making and enforcing laws within their jurisdictions. This feature qualitatively differentiates the Chinese economy from a typical centrally-planned economy.

China's RDA regime evolved before and during the post-Mao reforms, and some of its important features can be traced back to much earlier in China's history. There are two critical historical factors that make China's RDA regime somewhat unique. First, China is the only country in the world that has more than two thousand years of imperial history, which had a unique governance structure, and today's RDA regime inherits some important elements from this governance structure. Second, the Cultural Revolution is unique in the history of world communist movements. The ensuing destruction of the communist institutions and society led to disillusion with the communist ideology and a change of the legitimacy base of the Chinese Communist Party, weakened resistance to reforms, and has shaped the basic characteristics of the RDA regime, paving the road for the post-Mao reforms.

In the RDA regime, sub-national governments have influence or even direct control rights over a substantial amount of resources, such as land, firms, financial resources, energy, raw materials, and others. ${ }^{6}$ Sub-national governments are major players in the bulk of the Chinese economy. Under the supervision of the central government they initiate, negotiate, implement, divert and resist reforms, policies, rules and laws. They drive, influence or hamper regional/national economic development, macroeconomic conditions, environmental conservation or degradation, social stability, etc. China's reform trajectories have been shaped by centrally-controlled regional decentralization. Spectacular performance on the one hand and grave problems on the other hand are all created or closely associated with this governance structure.

At the early stages of the reforms, the central government delegated more autonomous power and provided stronger incentives to sub-national governments, in order to encourage them to try out reforms and promote economic growth. Thus, regional competition has been a major component of China's three decades of reform (Section 3). When a region has a higher growth rate than others, the head of the region will enjoy greater power and will be more likely to be

more formally, are the humanly devised constraints that shape human interaction." However, this definition is too abstract to be operational.

6 "In effect, it is the sub-national levels of Government that implement China's national development agenda. Nearly 70 percent of total public expenditure in China takes place at the sub-national level (i.e. provincial, prefecture, county, and township), of which more than 55 percent takes place at sub-provincial levels" (The World Bank, 2002). 
promoted. One of the most important initiatives taken by many sub-national governments was the development of non-state firms, including FDI and indigenous firms (e.g. the townshipvillage enterprises), which has been the most important engine of China's economic growth since the mid-1980s.

Chinese sub-national governments not only compete against quantifiable targets, such as GDP growth rate; but, they also often compete in initiating or testing new reform policies, i.e. regional reform experiments (Section 4). They have been given considerable responsibility for regional coordination, and such decentralized coordination has facilitated regional reform experiments; since sub-national governments are closer to experimenting sites, they are much better-informed about local information than the central government, and therefore can coordinate more effectively. Regionally-based coordination makes economy-wide coordination failures less likely when there are external shocks. This also makes it easier to experiment with institutional changes locally without causing disruption to the rest of the economy. Most importantly, by incorporating regional experiments as an essential part of the central decisionmaking process, the political risks of advancing reforms are substantially reduced, and political opposition to reforms is significantly weakened (Sections 2 and 4). Indeed, almost all successful reforms in the past three decades were introduced through local experiments (Section 5).

Nevertheless, the intrinsic deficiencies of an authoritarian regime, such as the lack of an independent judiciary, rent-seeking behaviour, and a failure to respond to citizens' preferences, are important parts of the characteristics of China's RDA regime, without exception (Section 6). Although some of these problems might be mitigated when sub-national governments face fierce regional competition, regional competition may lead to other problems, such as regional protection. Moreover, many problems inherent in the RDA regime may be worsened when the effectiveness of regional competition is weakened, e.g. when sub-national governments face multiple tasks, they strategically chose to ignore some tasks in the competition. Also, regional competition may lead to 'races to the bottom' for some tasks, which can be much worse than simply being ignored. China's future depends on how those problems are resolved, and given that they are deficient outcomes of the RDA regime, an ultimate solutions lies in a fundamental transformation of the institution itself.

Although determined by its distinctive history China's RDA regime is itself unique, there are still some general lessons that can be drawn from China's reforms and development for other developing countries. These are discussed in the Concluding section.

One of the major purposes of this paper is to address the so-called "China Puzzle." It is undisputed among economists that the quality of institutions is important for reform and development, because they determine incentives for executives and all the players in an economy. China is regarded in cross-country study literature as having poor institutions, such as poor legal protection of property rights, poor corporate governance, lack of democratic accountability and an absence of the rule of law. The resulting forecast is that Chinese officials will be corrupt, will not work hard, and will not collect and report information correctly, all of which are partly correct empirically. However, much more importantly, this theory would also suggest that, under poor institutions, executives in China would block reforms, therefore preventing economic development. Nevertheless, the overall performance of China's reforms and development appears not only magnificent, but unparalleled in world history in its gigantic scale and prolonged rapid growth. This incredible contrast between "poor" institutions and China's spectacular performance challenges our general understanding of the mechanics of institutions and our understanding of "institutional quality." 
First, there appear to be conceptual misunderstandings about what exactly constitutes an institution in the literature. The so-called institution is sometimes improperly defined or misinterpreted in certain popular empirical or policy studies. One of the most widespread approaches is to label a set of narrowly-defined measurements as the perfect "institution" based on some observed features of developed market economies, e.g. the US. Then, all other countries' practices are measured against this standard to see the imperfections of those countries' institutions. Although the empirical findings that follow from that approach could be useful in a narrow scope, serious problems may arise when this approach is generalized. Without a thorough understanding of the working mechanisms of institutions in developed and developing economies, such mechanical and narrow interpretations of institution ignore the essence of these institutions. This kind of research, to some extent, is not only at odds with the theoretical literature on institutions (a la North, 1990; Coase, 1991; Stiglitz, 2002; Hurwitz, 2007 etc.), ${ }^{7}$ but also can be misleading in general. For instance, the concept of, and the mechanism by which, the rule of law affects economies has been the subject of many debates. However, most of the popular empirical cross-country studies apply a narrow definition of the rule of law and ignore the debates on the subject, such that the US is often taken as the ideal (or almost ideal) model in those studies. Yet, if we look at the widespread financial fraud and the deep corruption from the grassroots to the top executives on Wall Street revealed throughout the 2008 financial crises and the Enron-WorldCom scandal in 2002 etc., the contrast between this illusion and reality is striking.

Moreover, very often the empirical measurements used in cross-country studies are too narrow to capture the functioning of institutions in developing economies, such as in China. As a result, all the functioning institutions that are beyond the scope of those narrow definitions are ignored, as if they did not exist. Consequently, China's performance becomes inexplicable, and it becomes either an outlier to be ignored or a puzzle in cross-country studies.

The empirical study of the protection of private property rights and contract enforcement is a concrete example. It is true that in China there was no formal or constitutional protection of private property until 2004, and commercial codes related to contracts were not enacted until the late 1980s, and moreover remained unimportant until the late 1990s. However, there was semiformal and informal protection of private property, and contract enforcement mechanisms were exercised by some sub-national governments under a special social context in Chinese history or by social norms. Yet, these institutions often are unaccounted for in almost all cross country studies. Even worse, according to some "standard" policy advice, these more informal institutions might be regarded as obstacles that should be replaced by "standard" institutions as quickly as possible, even though setting up "standard" institutions may be very difficult, timeconsuming, or even counter-productive under certain political conditions.

How should a country transform a centrally-planned economy into a market economy? What are the most important and effective reforms for economic development? How can a reform motivate sub-national governments and at the same time coordinate and control them? These subjects have been debated by economists, political scientists, historians, sociologists, and others for decades, both in general and in the context of China. Their viewpoints are, however, scattered, and very often scholars in different disciplines do not talk to each other. This paper attempts to

\footnotetext{
7 "The value of including such institutional factors in the corpus of mainstream economics is made clear by recent events in Eastern Europe. These ex-communist countries are advised to move to a market economy, and their leaders wish to do so, but without the appropriate institutions no market economy of any significance is possible. If we knew more about our own economy we would be in a better position to advise them." (Coase, 1992)
} 
develop a coherent conceptual framework which synthesizes a multi-disciplinary discussion on China's institutions, reforms and development. In addition to improving our understanding of China's reforms and economic development, by doing so, I also hope to deepen our general understanding of political and economic institutions, and on the evolution of these institutions.

This paper is not an attempt of an exhaustive literature survey. A full scale of such a survey would require multiple volumes. Therefore, many important contributions are not covered due to space restrictions and my ignorance on the subject, particularly beyond the field of economics. For this reason, for many very serious problems China is facing, I have discussed only some of them briefly. For many others I have only mentioned them without elaboration, such as problems of election, judiciary, corruption, social security and environment etc.

\section{The Fundamental Institution: Regionally Decentralized Authoritarianism}

Transformation from a centralized economy to a market economy requires both institutional support and institutional change. In addition, developing from an agrarian economy into a modern market economy also entails creating better institutions. However, reforms have never started from an institutional vacuum. All reforms have to begin with existing institutions, and any institutional change has to be initiated and implemented by agents within these existing institutions (even in the case of a revolution, existing institutions still have profound long run impacts). For all of these reasons, historically-inherited institutions have far-reaching impacts on an economy, sometimes long after those institutions have been changed or abandoned (Nelson and Winter, 1982; North, 1990). No major distinctive features of an economy - including reforms and subsequent changes - can be properly understood without understanding the fundamental institutions that underpin the economy; moreover, this is especially true when considering China's spectacular and prolonged growth on the one hand, and its serious socioeconomic problems on the other.

In this section, I introduce the fundamental institution of China, which I call the regionally decentralized authoritarian (RDA) system. ${ }^{8}$ The RDA system is characterized by a highly centralized political and personnel controls at the national level, and a regionally decentralized administrative and economic system. Both decision-making and policy implementations in the RDA regime, from national strategic issues to concrete local matters, are deeply influenced by this combination of political centralization and economic decentralization. These features qualitatively differentiate China's regime from a federal state, a unitary state, and a totalitarian regime.

\subsection{Decentralized Economic Governance: Regional Decentralization}

A salient feature of the Chinese governance structure is the relatively hands-off approach taken by the national government with respect to most of the national economy, while subnational governments deeply involved in the economies within their jurisdiction, including regional firms. The Chinese government consists of a region-based multi-level hierarchy. Below the central government, there are four levels of sub-national governments: provincial level,

\footnotetext{
${ }^{8}$ The concept of regionally decentralized authoritarianism was coined to characterize China's institution in 2006 in the first draft of this paper. In 2009 I read Landry (2008), where he uses the word decentralized authoritarianism. Although looks similar on the surface, the meaning of RDA is substantially different from the words of Landry (2008) just like the extensive differences between this paper and his book.
} 
municipal level (or prefecture level), county level and township level. The central government directly controls only a small proportion of the Chinese economy. The largest economic sector that the central government controls directly is industry, and even within this industry the central government directly employed less than $4 \%$ of all the industrial employees nationwide (NSB, 2006b).

Most government functions are carried out by sub-national governments. Although by constitution China is not a federal state, in many important economic issues Chinese sub-national governments are more powerful than their counterparts in federal countries around the world, since they are responsible for much broader regional matters than simply fiscal issues. Unfortunately, almost all the empirical papers in the literature look at only fiscal decentralization, since there is no well-accepted methodology to measure broadly defined regional decentralization. In the context of China's decentralization, although fiscal decentralization is sometimes a reasonable proxy for decentralization more generally, other times fiscal centralization efforts were compensated by regional decentralization in other dimensions. Thus, focusing on fiscal decentralization alone can be misleading (this will be elaborated in later sections).

China's governance structure does not fit neatly into standard conceptions of authoritarian regimes. According to cross-country studies, fiscal decentralization is closely linked with democracy. However, China's authoritarian regime is one of the fiscally most decentralized countries in the world. Contrasting China's fiscal decentralization with its counterparts in the rest of the world during the early 2000s, the total expenditure of Chinese sub-national governments accounted for about $70 \%$ of the national total, which was far larger than that of the world's largest federal countries such as the U.S. (46\%), Germany (40\%) and Russia (38\%) (Wong, 2006).

The following Figure 1 depicts the governance structure of the Chinese economy. The statistics in the figure reflect the situation in the year 2005, though the structure has been stable throughout the reform era. ${ }^{9}$ This governance structure is the result of a half-century of political development (Perkins, 1977, 1988; Wong, 1985; Granick, 1990; Naughton, 1995; Liu et al., 2006; Wu, 2009); moreover, many important features of it can be traced back to imperial times (to be further discussed later). Not long after a full scale transplantation of the Soviet model in the early 1950s, there were two major campaigns that lead to vast waves of decentralizations at extremely high costs. The first started in the late 1950s (the Great Leap Forward (GLF)), and the second in the late 1960s (the Cultural Revolution) (Shirk, 1993; Liu et al., 2006). ${ }^{10}$

During the GLF campaign, central ministries handed over most centrally controlled SOEs to sub-national governments. As a result, the sub-national governments' tax revenue increased from $20 \%$ of the national total in 1958 to $76 \%$ in 1959 and $79 \%$ in 1961 , much higher than those in the post-Mao reform period (Table 2). Central planning was replaced by regional competition. Subnational governments were encouraged to compete with each other to over-fulfill planning targets, to establish "communes" earlier or at a larger scale, to close down markets, etc. They

\footnotetext{
${ }^{9}$ The total number of central SOEs listed in Fig.1 is 2128, which is from the NSB. However, according to the SASAC (State-owned Asset Supervision and Administration Commission), the number should be less than 170 in 2005 and 151 in 2007 (http://www.sasac.gov.cn/zyqy/qyml/default.htm). The latter is the total number of parent companies controlled directly by the central government, which supervises a large number of subsidiary companies; whereas the former is the total number of all establishments managed by the central government.

${ }^{10}$ The GLF established the People's Commune, thus the Commune-Brigade Enterprises (the predecessor of the TVEs); and expanded local industries under state and collective ownership. An essential part of the human cost of the GLF is the Great Famine (see Lin, 1990 and Li and Yang, 2005).
} 
were also encouraged to try out different commune organizations, different ways of organizing production and collective life (e.g. public canteen systems in communes), etc. The central government's bureaucracy was trimmed; supervision of most state-owned enterprises was delegated from the ministries to provinces and cities, and sub-national governments' responsibilities were substantially enlarged. Reflecting the first wave of decentralization in the late $1950 \mathrm{~s}$, the sub-national fiscal revenue to total national fiscal revenue ratio jumped from $20 \%$ in 1958 to $76 \%$ in 1959 (Table 2). ${ }^{11}$

Fig 1. Regional Governance Structure of Chinese Economy

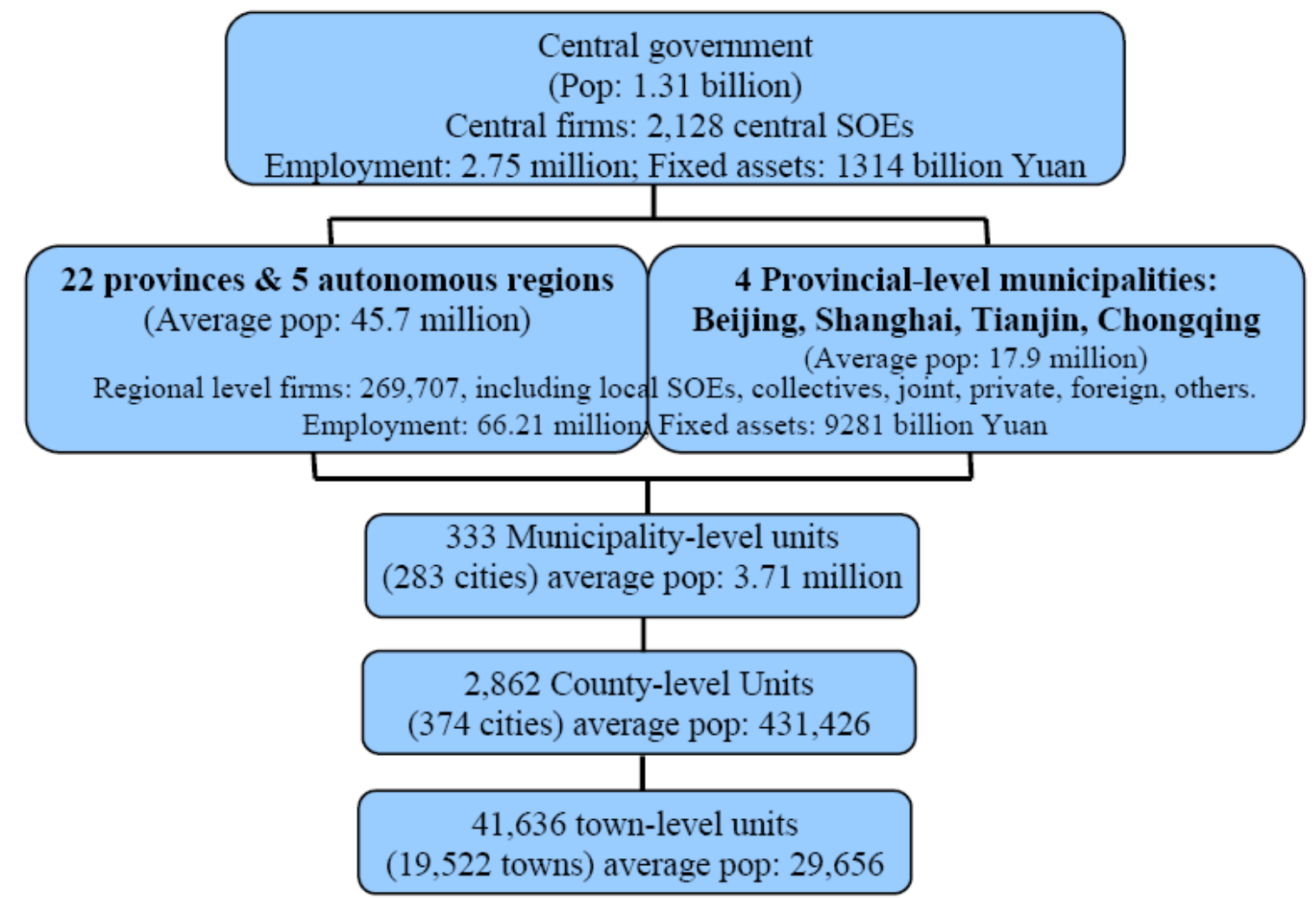

Source: NSB, 2006; 2006b; 2006c.

Corresponding with the second wave of decentralization in the "Cultural Revolution," the sub-national fiscal revenue (expenditure) to national fiscal revenue (expenditure) ratio increased from $65 \%(37 \%)$ in 1966 to $88 \%(50 \%)$ in 1975 (Table 2).

As a result, at the outset of the reforms, China had already established hundreds of relatively self-contained regional economies. The majority of the two thousand counties had SOEs producing agricultural machinery, while 300 counties had steel plants. Small regional SOEs produced $69 \%$ of China's total fertilizer output and $59 \%$ of its total cement. More than 20 provinces had SOEs producing automobiles or tractors (Xu and Zhuang, 1998). This is in sharp contrast to all other formally centralized economies, in which specialization and monopoly are

${ }^{11}$ By disturbing central planning and destroying markets, while simultaneously removing local financial responsibility, these campaigns degenerated into competitions of exaggerations and lies among sub-national officials, which ended up in chaos and eventually created one of the worst catastrophes in world history, in which about 40 million people died of starvation between 1959 and 1961 (MacFarquhar, 1974, 1983, 1993). 
hallmarks. With greatly reduced responsibilities, the Chinese central government was much smaller than its counterparts in other centralized economies. When the Chinese reforms started the number of products directly under the central plan was only 791 (the number was never more than one thousand in Chinese centrally planned system), and the number of ministries at the centre was less than 30 (Qian and $\mathrm{Xu}, 1993) .{ }^{12}$

Table 2. Evolution of Chinese Fiscal Decentralization, 1953 to 2005

\begin{tabular}{|c|c|c|c|c|c|}
\hline Year & $\begin{array}{l}\text { Sub-Natl/ } \\
\text { Tot Rev }\end{array}$ & $\begin{array}{l}\text { Sub-Natl/ } \\
\text { Tot Exp }\end{array}$ & GDP/capita & $\begin{array}{l}\text { GDP/capita } \\
\text { grw }\end{array}$ & $\begin{array}{l}\text { Institutional } \\
\text { Changes }\end{array}$ \\
\hline 1953 & $17.0 \%$ & $26.1 \%$ & 554 & $3.2 \%$ & 1st Five Year Plan \\
\hline 1958 & $19.6 \%$ & $55.7 \%$ & 693 & $8.8 \%$ & \\
\hline 1959 & $75.6 \%$ & $54.1 \%$ & 697 & $0.6 \%$ & $\begin{array}{ll}\text { Great } & \text { Leap } \\
\text { Forward } & \end{array}$ \\
\hline 1961 & $78.5 \%$ & $55.0 \%$ & 673 & $0.0 \%$ & \\
\hline 1966 & $64.8 \%$ & $36.9 \%$ & 753 & $6.7 \%$ & $\begin{array}{l}\text { Cultural } \\
\text { Revolution }\end{array}$ \\
\hline 1975 & $88.2 \%$ & $50.1 \%$ & 874 & $4.5 \%$ & \\
\hline 1978 & $84.5 \%$ & $52.6 \%$ & 979 & $9.4 \%$ & Reform Starts \\
\hline 1980 & $75.5 \%$ & $45.7 \%$ & 1067 & $2.6 \%$ & $\begin{array}{ll}\begin{array}{l}\text { Fiscal } \\
\text { starts }\end{array} & \text { reform } \\
\end{array}$ \\
\hline 1984 & $59.5 \%$ & $47.5 \%$ & 1396 & $10.4 \%$ & \\
\hline 1988 & $67.1 \%$ & $66.1 \%$ & 1816 & $6.4 \%$ & \\
\hline 1993 & $78.0 \%$ & $71.7 \%$ & 2277 & $8.5 \%$ & \\
\hline 1994 & $44.3 \%$ & $69.7 \%$ & 2475 & $8.7 \%$ & $\begin{array}{ll}\begin{array}{l}\text { Fiscal } \\
\text { Rule }\end{array} & \text { Sharing } \\
\end{array}$ \\
\hline 2004 & $45.1 \%$ & $72.3 \%$ & & & \\
\hline 2005 & $47.7 \%$ & $74.1 \%$ & & & \\
\hline
\end{tabular}

Sources for data: China 50 Years' Statistics; GDP/capita: 1990 international dollars, Maddison (2003).

When the reforms took place, after the end of the Cultural Revolution, sub-national governments already de facto controlled a great deal of resources in China. Given this inherited governance structure, for both political and economic reasons, granting more autonomous powers to sub-national governments is one of the major strategies in the post-Mao reforms, particularly during the first fifteen years of the reforms (Deng, 1980, 1986; Shirk, 1993; Liu et al., 2006; Wu, 2009). Sub-national governments were given strong incentives and were directly involved in managing or setting up firms, forming joint ventures with domestic or foreign investors, etc. Many sub-national governments have granted de facto property rights to local SOEs and collectively owned firms (COEs) within their jurisdictions (Granick, 1990), which account for most of the firms in the nation. Moreover, sub-national governments have become more important in all regional affairs, from land allocation, business development, infrastructure construction, and fiscal matters, to law making and law enforcement. Fiscal decentralization

\footnotetext{
${ }^{12}$ As a comparison, in the Soviet Union the central planning system was based on the principle of functional specialization, and the central government directly controlled most of the state-owned enterprises (SOEs). In the late 1970s there were 62 ministries under the Gosplan, which were responsible for 48,000 plan "positions" or 12 million products(Nove, 1983).
} 
reached its peak in 1993, during which time the sub-national fiscal revenue (expenditure) to national fiscal revenue (expenditure) ratio was 78\% (72\%) (Table 2).

To analyze the economic incentive and coordination mechanisms of the Chinese RDA system, the governance structure is modeled as a stylized multi-regional governance form (Mform) (e.g., Qian and Xu, 1993; MQX, 2000; and QRX, 2006, 2007). In the M-form hierarchy, every region is controlled by the central government politically, whereas each region not only enjoys a certain degree of autonomy but also is self-contained in its functions. ${ }^{13}$ Figure 2 depicts a highly stylized Chinese regional governance structure in which each region is self-contained (in contrast to specialization): each sub-national government controls major functions such as personnel, finance, industry and agriculture etc. within its jurisdiction. As a comparison, in other formally centralized economies, specialized ministries control industrial firms and the central government is responsible for coordinating the complementary tasks of various ministries.

Fig. 2. Stylized Governance Structure of China

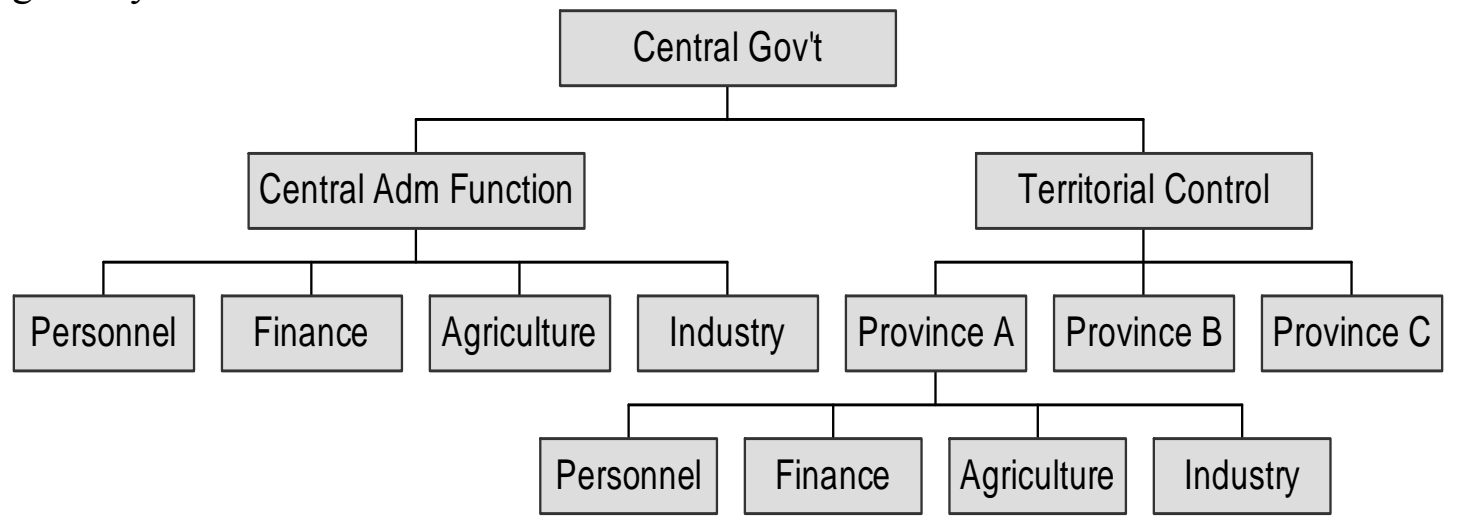

\subsection{Centralized Political Governance}

Although highly decentralized economically, China is neither a de jure nor a de facto federal state. The backbone of China's RDA regime is the Chinese Communist Party (CCP), which controls the personnel matters of sub-national governments and commands high economic sectors (e.g. banking, energy, telecommunication, railway etc.), as well as controlling ideology and the mass media.

The dominant role of the CCP makes the RDA regime of China fundamentally different from a federal system. Firstly, by constitution China is not a federal state. The Chinese constitution has been amended during the reforms, reflecting the changes of Chinese political and economic institutions. However, both the pre-reform version and the latest version of the Constitution stipulate that regions have no inherent power, and regional power is granted by the central authorities. The central government is empowered to delegate power to regions, and also to rescind this power (PRC Constitution, 1978; PRC Constitutional Amendments, 2004).

Secondly, China's RDA regime is not a de facto federal state either. Within the RDA regime, Chinese regional leaders are appointed by upper-level governments through the CCP system not by regional elections - despite devolution of much power over economic matters to the sub-

\footnotetext{
${ }^{13}$ The term M-form was first used by Chandler (1967) and Williamson (1976) to characterize multi-divisional structure of large corporations, where divisions are self-contained and are granted autonomous power, while division chiefs are appointed by the headquarters.
} 
national governments. While sub-national governments obtain highly autonomous economic power, the central government maintains its influence on regional officials' incentives by determining their career paths (Huang, 1996; Landry, 2008). In practice, the central government makes decisions on appointment and removal of provincial leaders, e.g. governors. Similarly, most municipal leaders, e.g. mayors, are directly controlled by corresponding provincial governments. This nested network extends the central government's personnel control to officials of all levels of regions, from provincial to municipal, then to county until the bottom of the hierarchy, township government (Burns, 1994). Moreover, reshuffling and cross-region rotation of regional leaders is a common practice to keep central control over sub-national officials. From 1978 to $2005,80 \%$ of provincial regions have experienced rotation of governors imposed by the central government (Xu et al., 2007). This personnel control approach is the major instrument used to make regional officials comply with the central government's policy, and also to provide incentives for regional experimentation, which I will elaborate on in a later section. Moreover, personnel control allows the central government to achieve some macro control, such as controlling inflation (Huang, 1996). Furthermore, through this mechanism, the central government has maintained considerable influence in consensus-building with sub-national governments in order to push through policies that are favorable to the central government (Naughton and Yang, 2004). Nevertheless, it must be pointed out that, although this approach often worked on high priority issues, it frequently failed on many other important issues (Section 6 further discusses this).

\subsubsection{Evolved Decision-Making Process of the Central Leadership}

In this subsection I will discuss how the decision-making process of the CCP central leadership evolved and how it works. In the post Mao era, China's central leadership sees economic growth as a life and death matter for the regime. It is important to point out that they are not unique among socialist leaders in this aspect. In discussing the general features of socialist systems, Kornai (1992, pp.160-161) explains that the socialist leaders promise to "eliminate the backwardness very quickly." And the promise "rests on a belief that they can catch up with the developed countries quite fast by virtue of the socialist system's superiority. This belief is a major constituent of the official ideology. The leaders insist on fast growth because it will provide further evidence of that superiority." There is a large literature on "forced growth" in former socialist economies (Kornai, 1972, 1992; Ofer, 1987). Indeed, many speeches by Deng (e.g. 1987) and other Chinese central leaders concerning the central importance of growth echo those of Stalin and Khrushehev. ${ }^{14}$ Yet, the promise of fast growing was not fulfilled in the last 15 years of their reforms in former Soviet Union and Central-Eastern Europe until the collapse of the system (Kornai, 1986, 1992). What makes China different is that they have transformed the system into a mixed economy with an overwhelming private sector and integrated into the global economy

However, this transformation evolved and is not designed by anyone. On the surface, China's reform looks like a "pure" economic reform without a major corresponding political

\footnotetext{
${ }^{14}$ Stalin $(1931$ [1947, p.356]) said "One feature of the history of the old Russia was the continual beatings she suffered ...f for her backwardness... We are fifty or one hundred years behind the advanced countries. We must make good this distance in ten years. Either we do it or they crush us." Khrushehev (1959, pp.76-77) claimed that socialist system will outcompete the Western world by faster growth and eventually bury them.
} 
change. ${ }^{15}$ Nevertheless, as a matter of fact, the post-Mao reform started from astonishing political changes, which resulted in the change of the central leadership, and the change of central decision-making process of the CCP. After three decades' evolution, today's RDA regime is fairly different from the CCP regime during the Mao era, although the political changes were restricted to those necessary for enabling economic reform, with focuses on establishing the party rules, on personnel changes to weaken those who might block reforms, and on the selection mechanism of leadership succession.

In the pre-reform era, the central decision-making of the CCP was dominated by a charismatic figure, Mao Zedong. In the revolutionary era, the CCP was fairly decentralized, in that many important decisions were jointly made between central and regional leaders, or made by regional leaders. Regional power was a very strong element in the central decision-making body of the CCP. ${ }^{16}$ Soon after the CCP took power in 1949 a dramatic political centralization took place. Although a region-based organizational structure was kept, the most influential regional leaders were "promoted" as central leaders and were physically moved to Beijing in the early 1950s. ${ }^{17}$ Simultaneously, China transplanted the Soviet central planning regime, and the first five year-plan of China was instituted. This centralization served to establish a centrally planned economy and was welcomed by the CCP elites. As in the Soviet Union, the objective of the CCP was "to build a strong socialist economy" [the $8^{\text {th }}$ National Congress of the CCP, 1956]; and most SOEs were controlled centrally by ministries.

Through significantly weakening regional leadership this centralization substantially strengthened Mao's personal control over the party, from personnel matters to the central decision-making process. ${ }^{18}$ Mao managed to strengthen the cult of his personality by transforming the central decision-making process into a series of political games in which his potential rivals were weakened through fighting with each other. Without any rival at the subnational level, Mao launched campaigns which delegated substantial power to sub-national governments, thus further weakening the power of his rivals in the central government (MacFarquhar, 1974, 1983, 1993). The personal control and campaigns mutually reinforced each other, and the influence of the campaigns was far reaching. In addition to changing the behaviors of the sub-national officials, it deeply affected the governance structure of the party and of the state.

With an extremely ambitious economic growth plan for speeding up China's transition to a Communist society, the Great Leap Forward (GLF) and the People's Commune Campaigns were launched in the late 1950s. Not only did the campaigns once again dramatically decentralize the

\footnotetext{
${ }^{15}$ Given the nature of communist ideology and the radical practice of the CCP in the Mao era, if there was indeed no important political change then China's market reform would indeed look puzzling. "...the Chinese strategy of economic reform without political reform appeared to have worked,..." "The overall economic success of the Chinese economic reform experience is surprising because we usually think of communist political institutions as rigid and hostile to innovation." "We expect communist party and government officials to defend their vested interests in the command economy by blocking market reforms." (Shirk, 1993).

${ }^{16}$ For example, in 1949,8 out of the 15 Politbureau members of the $7^{\text {th }}$ CCP Central Committee were regional leaders.

${ }^{17}$ The most prominent figures include Deng Xiaoping - became the CCP General Secretary and was purged in 1967, Gao Gang - became the vice President of China and was purged/died in 1954, Chen Yi - became vice Premier and was purged in 1967, Xi Zhongxun - became vice Premier and was purged in 1962, and Deng Zihui - became vice Premier and was purged in 1962, etc.

${ }^{18}$ In China's imperial history, during the onset of each dynasty it was typical that a new emperor would centralize power to weaken powerful regional rivals, such as warlords, for the sake of consolidating the regime. Mao discussed this issue many times.
} 
economy as discussed previously, they also changed the central decision-making process. Since then, the Chinese economy has sharply deviated from the classical Soviet central planning model.

The "Cultural Revolution" (CR), launched in 1966, is much more than another wave of decentralization. To a large extent, it unintentionally prepared the necessary political and institutional conditions for post-Mao reforms. The CR campaign mobilized the masses and CCP leaders at all sub-national levels to follow Mao directly to fight against party and government bureaucrats. ${ }^{19}$ There was an anarchy-type of decentralization through which party/government organizations at the central and sub-national levels were replaced by mass organizations. The mobs enforced strict censorship that any idea different from Mao's was absolutely not tolerated. During this period, with the slogan "down with capitalist runners", most of the party apparatuses and central government bureaucracies were dismantled; most party/state/social elites were purged, including the president of the country; regional "revolutionary rebellions," with selfproclaimed loyalty to Mao were supported by Mao's lieutenants and "seized powers (duoquan)" at all levels of sub-national governments from the CCP, sometimes through civil wars (MacFarquhar and Schoenhals, 2006); and finally, sub-national governments became the most important level of government for managing the economy, given that most ministries closed down. ${ }^{20}$ The devastation awakened the majority of the party and social elites and the legitimacy of the CCP was deeply shaken through the CR's overwhelming destruction. All of these paved the road to making major changes, to changing the decision-making rules and the objectives of the CCP after the death of Mao. ${ }^{21}$

The coup d'état of 1976, a few weeks after the death of Mao, in which Madam Mao and her lieutenants were arrested, eliminated those who insisted on continuing the CR from both the central leadership and sub-national levels. Consequently, a large number of CCP high officials, who were purged during the $\mathrm{CR}$ and were keen to make a radical change, returned to power, and propaganda campaigns were launched to change the ideology of the CCP from one of class struggles to one of economic development. ${ }^{22}$ The CCP central leaders forged a new consensus on the following major issues: a) the monopolistic political power of the CCP must not be challenged; b) within the confines of, and to strengthen, condition a), economic development should be interpreted as the essence of socialism, and thus of the utmost importance ${ }^{23}$; c)

\footnotetext{
${ }^{19}$ Two years before launching the CR, Mao warned sub-national officials including county level officials that they should refuse to follow and should resist the revisionist central leadership (Xu, 1995)

${ }^{20}$ The self-contained and self-sufficient regionally decentralized structure was further reinforced in the early 1970 s when most of the counties in the nation were encouraged to setup small industrial firms in five major sectors (Wong, 1987).

${ }^{21}$ A failed attempt to change the central focus of the CCP before Mao's death is more than a prelude of the post 1978 reform. There was a belief among the top CCP leaders that the CR has brought the Chinese economy to the verge of collapse and re-focusing the central task of the CCP to the economy is a matter of life and death to the party (in later years Deng repeated these arguments many times, e.g. 1980, to justify the changing of the central task of the CCP). In 1975 the premier Zhou Enlai together with Deng Xiaoping, a deputy premier after being purged for many years, launched the so-called "Four Modernizations" (modernization of agriculture, industry, science and technology, and defense) campaign. This campaign represented a rising consensus among most CCP elites. More importantly, they underlay a competing legitimacy for the future party leadership. Challenging the revolutionary theme of the CR, this de facto reform incited intensive political fights as part of the succession of the CCP's leadership. Although this reform attempt was crushed politically by the left-wing faction with formidable support from Mao, this aborted agenda became a platform for changing the CCP and it reminded the CCP reformist elites that a pure economic reform would be blocked without political change.

${ }^{22}$ Before Deng Xiaoping returned to power in late 1978, most of the major changes were lead by Hu Yaobang, the minister of the CCP personnel department and the de facto head of the Central Party School (Hu, 2008, 2009).

${ }^{23}$ The following argument of Deng (1987 [1994]) well represents the goal of the CCP: "to build socialism it is
} 
regarding the central decision-making process, personalistic regime should be replaced by party rule, i.e. a consensus-based collective decision-making process (Deng, 1980 [1984]; Zhao, 2009; Li, 2008; Jiang, 2002). This was a watershed period in which the CCP began to transform itself from a personality-ruled party into "a system governed by rules, clear lines of authority, and collective decision-making institutions" (Shirk 1993). Moreover, economic development has become the objective of the party and the state.

These critical personnel and ideological changes were consolidated in the $3^{\text {rd }}$ Plenum of the $11^{\text {th }}$ CCP Central Committee in December 1978. ${ }^{24}$ The communique of this plenum became the official manifesto for political, ideological and economic change. Consequently, the "Four Modernizations," the slogan of the $3^{\text {rd }}$ Plenum of the $11^{\text {th }}$ Central Committee of the CCP, and later "Reform and Open-up," which replaced the "Four Modernizations" after the $13^{\text {th }}$ Congress of the CCP in 1987, emerged as the official objective of the CCP.

To some extent changing the foundation of legitimacy of the CCP to one of economic development does not contradict communist ideology and is not unique to the post-Mao CCP, although this may be at odds with other types of dictatorships. ${ }^{25}$ Perhaps more important than ideology, economic development is regarded as essential for the survival of the regime. Yet, the much more challenging issue is to find a way to fulfill the objective of economic development. Essential issues of how to reform the economy and through which approach the economy should be or can be developed were indeed highly contentious among the top CCP leaders (Zhao, 2009). Should the economy be developed by restoring the Soviet central planning model, as China did in the first five-year plan? Or should it be developed by transforming the economy into a market system? Should the political system be reformed together with economic reforms? What should be the direction for a political reform? There were sharply different views on these issues among the CCP central leaders; more importantly, there were power struggles associated with these differing views. ${ }^{26}$

necessary to develop the productive forces. ... Not until ...we have reached the level of the moderately developed countries, shall we be able to say that we have really built socialism and to declare convincingly that it is superior to capitalism. We are advancing towards that goal."

${ }^{24}$ Although the Third Plenum of the $11^{\text {th }}$ Central Committee of the CCP officially changed the objective of the CCP to economic development under the slogan "the Four Modernizations", reform was not in the agenda of the Plenum (Hu, 2009).

${ }^{25}$ According to Marx, one respect in which socialism is better than capitalism is its higher capacity for advancing "productive forces". Thus, in order to prove the validity of the communist party's doctrine, it is necessary to deliver a higher growth rate than those of capitalist economies. For this reason, most communist leaders in Soviet Union and Eastern Europe, even including Mao in the 1950s, tried hard to make their economies to grow faster, although they all failed eventually. The following argument of Deng (1987 [1994]) well represents the ideology of the post 1978 CCP, "to build socialism it is necessary to develop the productive forces. ... Not until ...we have reached the level of the moderately developed countries, shall we be able to say that we have really built socialism and to declare convincingly that it is superior to capitalism. We are advancing towards that goal." Indeed the multiple decades' unsuccessful reform efforts in Soviet Union and Eastern European countries were all driven by their attempts to regain growth impetus in those economies. The collapse of the Soviet Union and the whole Eastern Bloc made the CCP top leaders feel that continued economic development was crucial for the survival of the regime. For example, former vice premier Tian Jiyun attributed the collapse of Soviet Union and the Eastern Bloc to their decades' failures in improving their productivities (Du M. and Xu Q., 2009). Yet it should be noted that in both communist ideology and policy neither "advancing productive forces" nor pursuing high growth rates implies social welfare maximization in the sense of neo-classical economics. In reality, all socialist economies have substantially smaller shares of consumer consumptions in their GDPs than those of market economies. This indicates that growth maximization of socialist economies is divorced from pursuing social welfare. For further analysis and more details on forced growth in socialist economies see Kornai (1980; 1992).

${ }^{26}$ Deng Xiaoping, Zhao Ziyang and Hu Yaobang etc. shared a pro-market approach whereas Chen Yun, Li Xiannian, 
Given the inherited RDA institution, dealing with political risk and technical uncertainty, a general reform strategy, marked by a local experiment-based collective central decision making process, emerged. Decision-making powers for trying out concrete measures were delegated to sub-national governments whereas the central government kept control of strategic political and economic issues (Deng, 1980 [1984]). This approach makes a consensus building-based decision-making more progressive. ${ }^{27}$ Therefore, most strategic decisions on China's market reform were made "collectively" in the form of compromises among the top CCP leaders in a trial-and-error process. "Collective" here has a broad meaning in that it includes also subnational officials' contributions through their local policy experiments.

Political challenges and resistance to a reform are weakened when a new reform is tried only in a few regions as experiments, such as the special economic zone experiments (to be further discussed in section 4.2). More importantly, for reforms bearing high political risks, the reformist central leaders could be vague without making an explicit decision when local experiments were allowed without an official endorsement, which implies a central leader will not take serious responsibility if something goes wrong with the experiment. The process of the land reform in the early 1980s and privatization in the late 1990s, which were major breakthroughs if we compare them with the two decades' reforms in CEE-FSU before 1989, are illustrations of the advantage of local experimentation (to be elaborated in sections 4.2 and 5.4). It is also pragmatic because the CCP top leaders, including those who pioneered market reform in China, knew little about how to transform the Chinese economy into a market economy (Zhao, 2009). It was much safer for them to follow some successfully tested reform measures than to implement some designed programs.

Moreover, regional competition helps to contain the impact of conservative ideology, and thus is a de facto selection mechanism in local experiment-based central decision-making. Indeed, not all central and sub-national officials are pro-market reformists and not all local experiments are market reform trials. Just as Chinese regions are heterogeneous, there were all kinds of experiments being tried, from egalitarian collectives to private businesses. However, outcomes of market reform experiments often dominated other experiments in regional competitions, and most of the time what matters most in the decision-making process is performance.

This local experiment-based central decision-making process also makes reform progress more stable, since the early reforms created strong interest groups not only among central leaders but also among sub-national officials, particularly those who initiated 'their own experiments'. Through the basic operating mechanisms of the RDA regime, the built-in interests and proreform interest groups among sub-national officials became a valuable stabilizer for the reform policies. Another important decision process, which establishes the continuity of reform policies in long run, is the way the future central and sub-national leaders are selected (I will discuss this

Bo Yibo and Hua Guofeng etc. had a strong view insisting on central planning (Deng, 1980; Zhao, 2009; Li, 2008). On political aspects, Hu and Zhao pushed for political pluralism within the one party system as a part of the reform. Sometimes Chen Yun also proved more amenable to other views for maintaining the party rule rather than promoting political pluralism. However, Deng, Li, Bo and most other elder CCP top leaders had strong views insisting on strict ideological control combined with repression of political dissidents (Zhao, 2009; Li, 2008; Bao, 2009). Here, ideological control is essentially about the compliance to the voice of the CCP central leadership, rather than any particular theory or doctrine.

27 "The Chinese government bureaucracy ... always made decisions by consensus." "Consensus decision making institutions tend to be conservative because radical departures from the status quo are blocked by vetoes from groups who stand to lose." (Shirk, 1993, p.15) 
in next part when I deal with the central-regional relationship). Economic development as the base of legitimacy for the CCP central leadership has been reinforced during decades of reforms. As a result, this objective is codified into the amended constitutions of the Party and the state. Capitalist entrepreneurs are officially regarded as part of "advanced social productive forces" and are recruited into the party (the CPC Constitution, the 16th CPC Congress, 2002) (see Dickson, 2003). The Chinese constitution has also been amended to protect private property rights (Constitutional Amendment, 2004).

\subsubsection{Personnel Control}

Personnel control is a major channel through which the central government controls, coordinates and motivates sub-national officials. With this instrument the Chinese RDA regime implements a centrally-controlled decentralization, in which most tasks of reforms and economic development are carried out by sub-national governments. On the one hand regional officials control huge amounts of resources and they enjoy fairly broad autonomies within their jurisdictions; on the other hand, their career paths are controlled by the central government. Specifically, appointments, promotions and demotions (or more severe punishments, such as imprisonment for serious violations of the rules) of sub-national officials in China are ultimately determined by the central government, and their career paths are tied to the performance of their jurisdictions. This makes Chinese economy fundamentally different from a federal system. ${ }^{28}$

This personnel control system is a nested network in which the centre directly controls the key positions at provincial level and grants each tier of sub-national government the power to appoint key officials one level below it. Each level of sub-national government oversees the appointment, evaluation, promotion and dismissal of its subordinate-level regional leaders.

A set of performance criteria for leading officials at sub-national governments is stipulated by the level of government above it. Regional officials are assessed in accordance with the important tasks and targets laid down by their superior level of governments. Level by level, each level of sub-national government negotiates with their subordinate sub-national government for performance targets. Then, regional officials at different levels sign target responsibility contracts with their superiors. The targets for the tasks to be attained as well as rewards/penalties contingent on the fulfillment of those targets are specified in those contracts (Tsui and Wang, 2004). For example, in a scheme for provincial leading officials, 60 percent of these leaders were assigned to targets related to economic construction (Tsui and Wang, 2004). In general, performance criteria are broader for leading officials at higher level sub-national governments, while the targets set for leading officials at lower level sub-national governments tend to be more precisely defined. According to a handbook issued by the Party, work achievement accounts for 60 to 70 percent of the evaluation of regional officials, while other aspects, such as political integrity, competence and diligence together account for the rest, 30 to 40 percent (Edin, 2003).

It is also documented that county governments control township and village officials by linking their performance to promotion (Whiting, 2000). In field works at township-level governments, it has been found that party secretaries and township heads sign performance contracts with the county level. In these contracts, township officials pledge to achieve targets established by county officials, and are held personally responsible for attaining those targets. Performance targets are ranked in three categories: soft targets, hard targets and priority targets

\footnotetext{
${ }^{28}$ It is interesting to note that this governance structure of Chinese government, i.e. a combination of a centralized personnel control and a decentralized operation/implementation, shares some similarities with the Japanese corporate governance structure, particularly before the 1990s (Aoki, 1990).
} 
with veto power. Hard targets tend to be economic, such as an economic development plan and tax revenue, whereas priority targets are often political, such as keeping social order. Fulfilling hard targets is important for bonuses and for political rewards, whereas completion of priority targets affects personnel decisions (Edin, 2003).

Moreover, competition between regional officials among the same level, such as at the county level or township level, is an essential part of the cadre management system. As discovered in field work in one county, leading cadres of the first three ranked townships in the annual evaluation were recognized as "advanced leaders", whereas the bottom 5 percent of officials on the list were disgraced. To be a top-ranking township leader and to be awarded with the title of "advanced leader" enhances the chances for promotion substantially, and thus it is regarded as a "political bonus." Indeed, some first-ranked township officials were promoted within the county (Edin, 2003).

To enhance the effectiveness of the personnel control system, rotation and cross-region transfer are also deployed. The practice of rotating provincial level officials has always existed, and it has been further institutionalized since the 1990s. The Central Committee of the CCP has issued Party decrees on the rotation system in 1990, 1994, 1999 and 2006. The Party decrees announce that a major purpose of rotating regional officials is to promote economic development through diffusion or duplication of regional reform experiences (Xu et al., 2007). ${ }^{29}$ Directed by this policy, during the period between 1978 and 2005, about $80 \%$ of governors were promoted or transferred from other provinces, i.e. many of them were not promoted within the same province. The average duration of their tenures within a given province is close to four years, while ranging from as little as one year to as many as ten years (Xu et al., 2007).

It has been documented that during the reform era, rotation was often combined with promotion. The rotation/promotion combination was frequently used to promote mayors of successful municipalities to be governors of other provinces, particularly under-performing provinces. This promotion path creates incentives for regional leaders to work hard. Moreover, this may also serve as a mechanism to diffuse successful regional experimentation (in Section 4 we will further discuss regional experiments). For example, between 1998 and 2004 three former party secretaries of Suzhou, one of the best-performing municipalities in China, were promoted to become provincial governors of Jiangsu, Shaanxi and Jilin. Between 1998 and 2002, a former mayor of Wenzhou, another top-performing municipality, was appointed as vice-governor and then governor of Sichuan (Chien and Zhao, 2007).

\subsection{Central-Regional Relationship}

The central-regional (or central-local) relationship has always been one of the most important issues when considering China's governance. Although the formal structure is hierarchical between central and regional governments, the authority of the central government is endogenized insofar as the power of the national leadership depends on the collective support of the regional leaders as well. This sophisticated structure plays important roles in the operation of the RDA regime, such as continuing effective national macroeconomic policies, encouraging regional initiatives, and balancing central-local interests.

One of the most important governance mechanisms of the RDA regime is the selection

\footnotetext{
${ }^{29}$ Historically rotation was a common practice in the Chinese Empire to prevent regional officials from cultivating strong political power bases within their jurisdictions.
} 
process for the future central and sub-national leaders. The process includes nominations and approvals. Nomination by top leaders is necessary for anyone to become a central leader candidate, but nomination alone provides no guarantee for the future of the candidates. A nominee must convince most of the top leaders that he both shares their core values and principles, and he has the capability to perform. As such, excellent performance at the provincial level becomes necessary for anyone to be nominated and eventually promoted as a top leader. Although this requirement may not be codified formally, without a single exception, from 1992 to 2008 every president, every premier, and every newly elected Politbureau Standing Committee member of the four CCP congresses ${ }^{30}$ during this period was promoted from a provincial position; i.e. none of them were from a ministerial or other central agency position. The appointment of sub-national level officials follows a somewhat similar consensus-based selection processes, with intensive interactions between upper and lower-level governments. In addition to major impacts on both the sub-national officials' career paths and the pool of future top national leader candidacy, these procedures also act as institutions which balance national and regional interests.

Supported by commonly-shared collective interests among most national and sub-national officials, the central leadership enjoys considerable authority over potentially disobedient regional leaders. With this authority, the central government takes a tough stand to make the subnational governments comply on the most important issues, such as national (or political) unity and macro stability. Personnel control is often used as the last resort for enforcement to guarantee the implementation of central policies. ${ }^{31}$

At the same time, as previously discussed, on regional economic issues the central government is often fairly hands-off. Sub-national governments are granted sizeable de jure control rights and endowed with even greater de facto control rights over most economic issues and resources within their jurisdictions. Together with a highly incomplete personnel control regime - although it is highly structured and effective, it is ambiguous on many issues and there are gaps in other issues - the delegation of power to regional governments is also highly incomplete (a la Pistor and $\mathrm{Xu}, 2004$ ). For most issues, as long as the central government does not have an explicit policy, by default the regional governments would be in the position to make decisions within their jurisdiction. However, the central government retains the power to intervene. The incompleteness of personnel control and power delegation is partly a result of compromises, and partly a design for encouraging more local initiatives from local governments, while still remaining open to central control. At the same time, this regime also makes it possible for sub-national governments to maneuver against, rather than to simply comply, with policies of the central government.

To understand the distinctive feature of China's RDA regime, such as the enablement of local governments, it is worthwhile to point out its origin and its robustness in history. The basic governance structure of China's RDA regime is originated from the birth of the Chinese empire and has evolved over two thousand years, which has supported the empire to last so much longer than all other empires in the world history, ${ }^{32}$ and has a long lasting impact on the governance of today's China. ${ }^{33}$

\footnotetext{
${ }^{30}$ A common practice of the CCP is to put the selected next top leader(s) into the Politbureau Standing Committee.

${ }^{31}$ When a few regional leaders defy the central government and challenge the power of the central government, they are punished severely. Recent examples include the dismissal and imprisonment of the former mayor of Beijing, Chen Xitong, in 1995, and the former mayor of Shanghai, Chen Liangyu, in 2006.

${ }^{32}$ It is well known that institutions of most of the countries in the world have a European origin through their imperial histories, e.g. the UK and France; or colonial histories, e.g. the Americans, Africa and South Asia; or
} 
Designed at the beginning of the Qin Dynasty (221 BC), sub-national government officials were appointed by the Emperor (Sima, 1993 [109 BC]). This assures the strategic control of emperor over the nation. Given the primitiveness in communication and transportation at that time, most local affairs were delegated to sub-national governments, conditional on their loyalty to the Emperor. To enable sub-national governments' effective control they are assigned with self-contained functions that each of them was able to coordinate operations within its jurisdiction. This is true at all levels of sub-national governments. To illustrate the self-contained governance structure at every level of sub-national governments, the following Figure 3 depicts a stylized structure similar to that of imperial China during the Ming and Qing dynasties (13681910), in which the empire divided the central government's functions into six ministries. The most important ministry was Personnel, which determined the appointment and promotion of central and provincial officials. This structure extends to the bottom administrative level, the county level. Just like in the central government and at the provincial level, a typical county (xian) government controlled the six corresponding offices within its jurisdiction (Bai, 1996). ${ }^{34} \mathrm{~A}$ caveat is in order that during imperial times there was no political party, such as the CCP, which makes today's RDA regime historically unique.

Fig. 3. Stylized Governance Structure of Imperial China

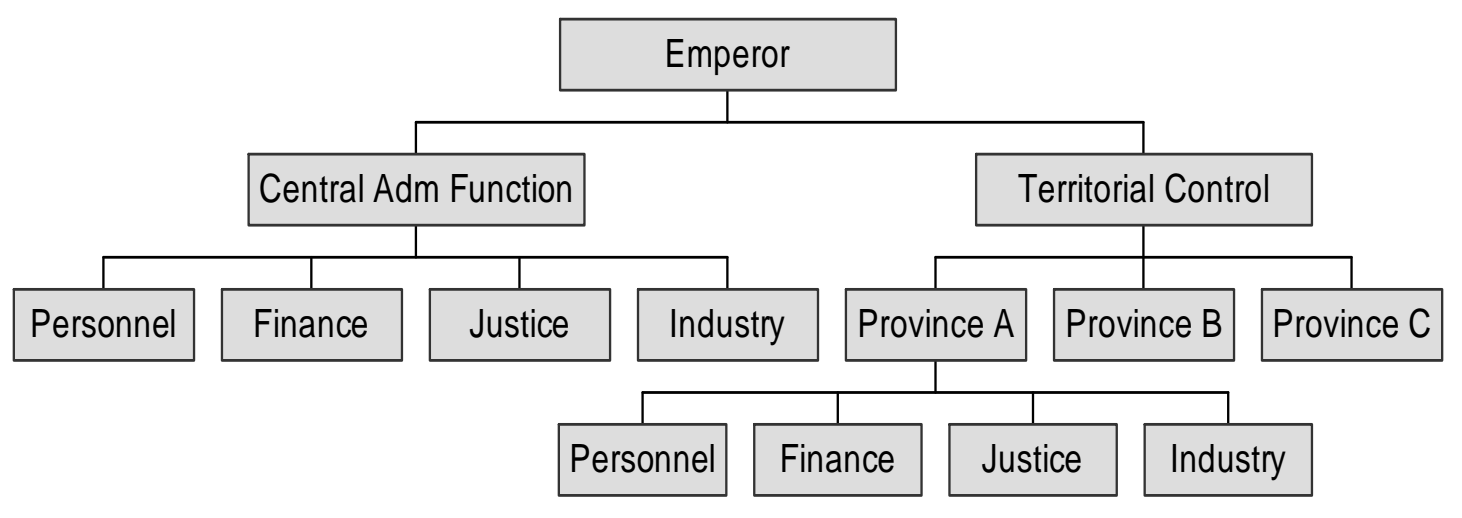

The consensus-based decision making process and personal control system of the RDA regime provide mechanisms for upholding a balance between economic decentralization and political compliance. These mechanisms allow the regime to evolve while keeping the centralregional relationship basically stable. ${ }^{35}$ There were deep worries that delegating economic

voluntary adoptions of the European institutions, e.g. Russia, Japan. But it is well noticed that China has neither been colonized by Europe nor adopted European institutions systematically before the 1950s, when it adopted an institution from the Soviet Union. This is the underlying reason why on many facets China looks inconsistent with the regularities discovered in cross country studies.

${ }^{33}$ Indeed Mao frequently referred to the governance approach of imperial times, perhaps more than his discussions on Marxism and the Soviet System.

${ }^{34}$ The six ministries at the central government are Ministries of Personnel $(l i)$, Finance $(h u)$, Civil Service Exam and Foreign Affaires (li), Military (bing), Justice (xing), and Manufacturing (gong), i.e. li-hu-li-bing-xing-gong liu-bu. The six similar offices at each county government are li-hu-li-bing-xing-gong liu-fang. Here, bu and fang are in bold to highlight the difference between the central government (six ministries, liu-bu) and a local government (six offices, liu-fang).

${ }^{35}$ It has been reported that during the reform era, in a period of more than two decades, the provincial share in the Politburo of the CCP increased slightly; meanwhile, the provincial share in the Central Committee of the CCP declined by a similar magnitude (Sheng, 2005). 
powers to regions undermined the capacity of the central power (Wang, 1995). And in the early period of the reform, the time associated with much regional decentralization, the central government's share of national total fiscal revenue declined substantially. When the economy was growing rapidly and some regional governments enjoyed high surpluses, the national government ran deficits and had to borrow from some provinces. Moreover, central power could be further weakened by the enfranchisement of regional leaders in Party institutions during national-level successions (Shirk, 1993) ${ }^{36}$. It was argued that capacity of the central government was undermined so severely during the reform era that this weakened capacity threatened Chinese political unity in a manner similar to the situation before the disintegration of Yugoslavia (Wang and $\mathrm{Hu}, 2001$ ). Responding to the worse central fiscal capacity and weakened central control over bank lending - which led to central government deficits, excessive lending, and inflation in the early 1990s - the central government increased its political and administrative control over provincial government leaders to co-ordinate and implement national economic policies (Huang, 1996a,b; Naughton and Yang, 2004; Landry, 2008). During this time, the central government took away some powers from sub-national governments. Tax collection was re-centralized in 1994, and control over bank lending was also shifted away from sub-national governments (Tsui and Wang, 2004). However, this fiscal recentralization did not fundamentally change the RDA regime and did not terminate regional decentralization. These should instead be viewed as efforts to maintain a balance between the interests of national and sub-national governments. Regional governments' losses in tax revenue were compensated by other means, such as extra-budgetary and non-budgetary revenues (Wong, 1997), and their losses in controlling bank lending were compensated by stronger controls over land and state assets within their jurisdictions (subsection 6.1 discusses consequences of these changes).

\subsection{General Remarks}

The decision-making process of China's RDA regime relies on building consensuses among the top leaders - often including provincial leaders - and regional experiments, which keeps a balance between national and regional interests. This mechanism generates outcomes which are somewhat similar to what occurs through negotiations in a legislative body. Moreover, together with the selection process of national and sub-national leaders, these mechanisms nurture interest groups of market-oriented and growth-oriented reforms within the party, which contributes to stable market reforms over several decades.

Although China's RDA regime is evolved from China's unique history (e.g. the longest imperial history in the world and the unprecedented events of the Cultural Revolution), which makes its policy lessons less relevant directly for other countries, there are important general lessons for debates on decentralization. Firstly, for developing and transition economies, focusing on fiscal decentralization can be misleading for both understanding and policies. Secondly, extreme decentralization in general may not be optimal. If China went down a path of extreme decentralization in which all provinces became completely autonomous except in military and foreign affairs, even assuming away potential political instability, without an active central government all the benefits from the combination of collective decision-making and regional experimentation would disappear; negative externalities cross regions would become

\footnotetext{
${ }^{36}$ Shirk (1993) argues that the content and sequencing of China's economic reforms are determined by the ongoing succession struggles of the Party, whereas devolution gave central politicians the opportunity to win the gratitude and the political support of officials from the provinces.
} 
prevailing; and no one would take care of positive externalities across regions. Moreover, the nature of regional competition and regional experiments would be fundamentally weakened (to be discussed in Sections 3 and 4).

\section{Regional Competition and Sub-national Governments' Incentives for Reforms}

A distinctive feature of China's reform is the vital roles played by highly motivated subnational governments. Governors Zhao Ziyang of Sichuan and Wan Li of Anhui initiated land reform experiments in a few localities within their jurisdictions in the late 1970s when the national policy, including the Party's "reform" manifesto, did not allow any ownership change to collective farming. Similarly, governor Xi Zhongxun of Guangdong proposed the special economic zone reform while some top central leaders were hostile to this reform plan (sections 4 will elaborate on this below). Later, when those locally initiated reforms were endorsed by the central government as national policies, the reforms were implemented by all levels of government nationwide. After the initial success of the regional reforms, these reform pioneers were all promoted to national level posts. Zhao and Wan became the premier and executive deputy premier of the state council, respectively, responsible for national reform; Xi became a vice Chairman of the National People's Congress.

As the pioneers and architects of regional reform, the political risks they faced were substantial. The key issue I will address in this section is how sub-national government officials are motivated to initiate and to implement reforms. Without a solution to incentive problems of government officials at all levels of government, reform would not be carried out successfully or potentially not even be attempted. There is no question that some reformists have intrinsic personal motivations (a la Prendergast, 2007) to push forward reforms. For those officials with intrinsic motivations to reform, the only incentive that needs to be devised is to give them the power to initiate and to implement reforms. However, extra incentives, i.e. extrinsic incentives, are necessary for most sub-national officials to take risks and to work hard for reforms. Furthermore, very often well-devised extrinsic incentives can induce stronger intrinsic incentives and vice-versa, so that the two incentives often reinforce each other at equilibrium (a la Benabou and Tirole, 2003). By the same logic, poorly devised or destructive extrinsic incentives could weaken or even destroy intrinsic motivations for reforms. In this section, I will focus on the extrinsic incentives provided to Chinese sub-national officials. My major argument is that interregional competition has motivated sub-national officials to push forward reforms. Chinese regions (provinces, municipalities, counties and townships) compete against each other for performance rankings; ${ }^{37}$ and regional officials' careers are linked to their performance in the "tournaments."

As bureaucrats appointed by their upper level governments, most Chinese sub-national officials are very much motivated by their career concerns, which are basically about climbing ladders within the government hierarchy. Through this channel the central government affects the ultimate incentives of the sub-national officials. It is noteworthy that this mechanism is fundamentally different from the well-known jurisdictional Tiebout competition, or in general fiscal jurisdictional competition in the fiscal federalism literature. The latter has nothing to do

\footnotetext{
37 The most popular performance indicators used in regional rankings are GDP (total or per capita), GDP growth rate, and FDI etc. In addition, some other indicators, such as regional competitiveness in various aspects, are also widely reported. For example, in a recent ranking Shanghai, Beijing and Guangdong were ranked as the first, second and third most competitive regions in China in 2007, which is unchanged from those in 2006; whereas inland provinces Anhui and Hubei improved their rankings significantly (Xinhua, 10/03/2008).
} 
with the internal promotion of the local government officials. Instead, local officials are driven by their fiscal motives, e.g. maximizing property values within their jurisdictions by attracting additional residents (Tiebout, 1956; Oates, 1999); or by winning votes from their constituencies (Epple and Zelenitz, 1981).

3.1 The Institutional Foundation for Regional Tournament Competition

In this subsection I elucidate how China's RDA institution creates the conditions for regional competition, as well as the tradeoffs of this regional competition. When the reform era started in the late 1970s, regional governments were encouraged to find ways to develop faster than other regions. Policies on special economic zones and other economic development zones were implemented, enabling sub-national governments' competition for investments. Regions compete for economic growth, and for attracting FDI etc. Since the mid-1980s, many better-performing counties were upgraded to the municipal level, which further enabled and empowered these local governments. At the same time, this city status upgrading also provides high incentives to all the county governments to compete for the opportunity to be promoted. Government statistics and mass media regularly publish rankings of regional performance, which become an important part of evaluations for determining sub-national government officials' promotions.

In contrast to the prevalence of regional competition and initiatives taken by sub-national governments in Chinese reforms, officials in other reforming countries or other transitional economies were not given similar competitive incentives and they were in general less active in taking initiatives than their Chinese counterparts. Yet, decentralization does not automatically create strong incentives to regional officials for regional economic growth, as can be seen in most other countries. What makes China special in providing strong incentives to regional officials for economic development? Furthermore, there is serious potential problems associated with decentralization, such as regional protection and regional environment problems, etc. What are the conditions under which regional competition leads to desirable outcomes?

To address the first question, let me start with a summary of the major features of Chinese institutions which facilitate regional competition. First, Chinese sub-national officials are subject to incentive schemes managed by the central government. With centralized personnel management for sub-national officials, regional competition under this institutional structure is qualitatively different from fiscal federalist regional competition, in which local officials are elected (Epple and Zelenitz, 1981). Second, the Chinese national government not only possesses superior powers of appointment, promotion and dismissal of subordinate government officials, but it is also strong enough to eliminate collusions between lower level sub-national governments. This preserves tournament-like regional competition, since collusion among subnational officials can make competition impossible. Third, Chinese regions, particularly county level or higher level regions, have historically been and remain relatively self-sufficient in that each region contains multiple economic sectors. Therefore, most Chinese regions are alike in their economic structures, which is a critical condition for tournament like competition to function (discussed in more detail below). Moreover, this greatly weakens interdependence among Chinese regions, and enables sub-national governments to coordinate most of the economic activities within their jurisdictions. Finally, Chinese sub-national governments are both enabled and empowered to take responsibility for economies within their jurisdictions. They are granted a fairly high degree of autonomy on economic activities. Enablement and empowerment themselves are vital sources of incentives. Ultimately, incentives for officials can play important roles only when those officials are enabled and empowered to take reform initiatives or growth- 
enhancing measures, etc.

The theoretical model of Maskin, Qian and Xu (2000; MQX, hereafter) highlights the relationship between China's RDA regime and high-powered incentives associated with regional competition, which includes tournament-like competition. ${ }^{38}$ The stylized hierarchical organization modelled by MQX captures the feature of the RDA regime. ${ }^{39}$ There are two types of authoritarian structures considered in the model: a multi-regional organizational form (M-form), such as China, in which there are two unspecialized sub-national regions, each of which is assigned to manage similar tasks such as manufacturing and agriculture; and a unitary form (Uform), such as the former Soviet Union before 1991, in which there are two specialized subnational units - ministries - each of which is assigned with managing a specialized task such as manufacturing or agriculture. In contrast with China, in those economies there were no ministerial or regional competitions in reform measures or growth-enhancing efforts, even though they started reforms much earlier than China. The MQX model focuses on incentive issues of sub-national officials in order to address the following questions: What is the specific mechanism that makes regional competition effective in China? And what prevented the FSUCEE countries from deploying a similar approach?

As in any incentive theory, the outcomes of the tasks are determined jointly by the managing efforts of the relevant officials and outside random factors. The officials' efforts are not observable to others and are costly to them; therefore, when there is no proper incentive scheme, there will be no reform efforts. It is known that when facing unobservable efforts, tournament competition can motivate agents better than other incentives schemes (e.g. Lazear and Rosen, 1981). However, an effective tournament competition requires that the tasks of the agents should be similar, and that the outside random factors faced by the agents should follow the same distribution. The rigidness of these conditions makes these models hard to apply directly to real-world institutions.

The MQX model extends the basic idea of tournament competition to different institutions organized in different ways, which determines how tasks are assigned and how information is used by each official. These in turn determine the effectiveness of different incentive schemes for the officials in the regime. Given that Chinese regions are alike in their economic compositions, which implies that shocks to regions are highly correlated, by assigning similar tasks to regional officials and delegating power to them in order to carry out regional reforms, regional competition among them can serve as an effective incentive scheme. To understand the mechanism, let us suppose a governor performs poorly and tries to blame the outcome on bad luck in his region. This excuse is unconvincing, however, if all other similar regions are prospering. Therefore, facing the comparison (or competition) with other regions should force every governor to work hard.

On the contrary, if sub-national units are highly specialized so that they are not comparable, or if tasks assigned to every official are idiosyncratic, which implies that shocks to these tasks are not correlated, such as ministries in former Soviet Union and Central-Eastern Europe before 1989, it is easy for a minister to blame a poor outcome on bad luck in his industrial sector and it is difficult to object to his excuse, given that performance is imperfectly correlated with officials' efforts. That is, ministerial tournament will not be efficient when tasks

\footnotetext{
${ }^{38}$ Interpreting the MQX model as a mechanism of the RDA regime is my personal view.

${ }^{39}$ In addition to authoritarian regimes, the MQX model also applies to large corporations. This is not coincidental as the Chinese authoritarian regime is sometimes regarded as corporate technocrat-ship or corporatism in the literature (e.g. Oi, 1999).
} 
and information of ministries are sufficiently different from each other. Therefore, although distributions of industry-specific shocks and of region-specific shocks are exogenous, they affect officials' incentives differently under different organizational forms.

Two types of incentives are analysed in the MQX model: the absolute performance incentive, which ties an official's compensation to his own outputs, and the relative performance incentive, which links an official's compensation to other's outputs in a negative way. The absolute performance incentive is inversely related to the noise level of each official's own performance, while the relative performance incentive is positively related to the correlation between the performances of two officials. In summarizing the two factors, the incentives of officials in any regime depend on the variance-covariance matrices of the exogenous random shocks. Fortunately, the essential information of variance-covariance matrices can be sufficiently compressed into a scalar, the conditional variation measurement. A smaller conditional variation implies a smaller variation and a larger correlation, i.e. a higher quality of information for incentive purposes.

In a highly simplified version of the model, for an economy organized in U-form, the middle officials will be ministries responsible for industries 1 and 2; and the corresponding industrial shocks are denoted as $\varepsilon_{1}$ and $\varepsilon_{2}$. The information relevant to the incentives of the two ministers is summarized by the conditional variances $\operatorname{Var}\left(\varepsilon_{1} \mid \varepsilon_{2}\right)$ for minister 1 and $\operatorname{Var}\left(\varepsilon_{2} \mid \varepsilon_{1}\right)$ for minister 2. For an economy organized in $\mathrm{M}$-form, the middle officials are governors responsible for regions $\mathrm{A}$ and $\mathrm{B}$, and the corresponding regional shocks are denoted as $\varepsilon_{A}$ and $\varepsilon_{B}$. The information relevant to the governors' incentives is summarized by the conditional variances $\operatorname{Var}\left(\varepsilon_{A} \mid \varepsilon_{B}\right)$ for governor $\mathrm{A}$ and $\operatorname{Var}\left(\varepsilon_{B} \mid \varepsilon_{A}\right)$ for governor $\mathrm{B}$.

Therefore, if $\operatorname{Var}\left(\varepsilon_{1} \mid \varepsilon_{2}\right)>\operatorname{Var}\left(\varepsilon_{A} \mid \varepsilon_{B}\right)$, then the information quality for evaluating governor $A$ in the $\mathrm{M}$-form is higher than that for minister 1 in the U-form. In general, if $\operatorname{Var}\left(\varepsilon_{i} \mid \varepsilon_{j}\right)>$ $\operatorname{Var}\left(\varepsilon_{r} \mid \varepsilon_{s}\right)$ (hereafter this condition will be referred to as Condition A), for all $i, j=1,2$ and for all $r, s=A, B$, we will conclude that, everything else being equal, regional competition with relative performance evaluations under the $\mathrm{M}$-form is more effective than ministerial competition under the U-form. Therefore, the M-form will be able to provide better incentives to their governors than the U-form for ministers. Of course, if Condition A is reversed for every pairwise comparison, the conclusion will be reversed. Therefore, ultimately, whether regional decentralization is more beneficial than a centralized regime is an empirical matter, and the MQX model provides a methodology to test it.

\subsection{Evidence}

Three forms of systematic evidences on the relationship between China's RDA regime and regional competition will be presented in this subsection. The first evidence concerns whether or not China's RDA regime provides better conditions, in terms of Condition A, for jurisdictional competition than a centralized authoritarian regime. Then, I survey evidence that regional competition provides incentives to regional officials. The last evidence suggests that China's RDA regime has made a significant contribution to China's growth.

Using a firm-level dataset of Chinese state-owned enterprises from 1986 to 1991, MQX finds that Chinese regions are indeed 'alike' in the sense that regional competition should work better than ministerial competition. The dataset contains industry classification codes and location codes for each firm, and industry-specific shocks and region-specific shocks are estimated by running the log-linear Cobb-Douglas production function. This allows for 
calculation of regional and industrial conditional variations. In their sample, $70 \%$ of the results satisfied Condition A and there is no single case that the Condition A is reversed.

To address the question of whether relative performance evaluations are actually used in China, MQX investigates the relationship between the promotion of regional officials and regional economic performance. They use regional representation in the CCP's Central Committee as a proxy for the promotion chances of officials in that region and measure the economic performance of a region by its growth rate in national income. Then they investigate how the improvement of a region's performance relative to other regions would later affect the promotion of this region's officials. Specifically, they constructed a national ranking index of each province's representation at the 11th Party Congress in 1977 and in the 13th Party Congress in 1987, and constructed a national ranking index of provincial economic performance lagged by one year, as measured by growth rates in the year before the Party Congress, that is, in 1976 and in 1986. The evidence shows that officials from relatively better-performing regions have a better chance of being promoted, suggesting that tournament-like regional competition is at work.

Similarly, using data covering 344 top provincial leaders (187 party secretaries and 157 governors) from China's 28 provinces for the period from 1979 to2002, Chen, Li and Zhou (2005) find that provincial officials' performances relative to the national average and to their immediate predecessors had significant impacts on their promotions (columns 5 and 6 in Table 3). The left-side variable of all the regressions in the Table 3 is turnover, i.e. the probability of termination, staying at the same level, or promotion.

Using a panel dataset covering 254 provincial leaders (provincial party secretaries and governors), who served in 28 Chinese provincial units from 1979 to 1995 , Li and Zhou (2005) find that regional officials' promotions are determined by the performance of their jurisdiction relative to the national average. Everything else being equal, for those provinces that surpass the average growth rate by one standard deviation from the mean, their leader would increase the probability of his promotion by $33 \%$ of the average probability of promotion; and, those that performed worse than the mean by one standard deviation would increase the probability of termination by $30 \%$ of the average probability of termination (columns 3 and 4 in Table 3). In the table, the punishment for the worst performers is shown as an estimated coefficient with cutoff point 1. Overall, the marginal effects of growth performance on turnover are large.

By separating provincial party secretaries from governors, Sheng (2009) finds evidence that provincial GDP growth mattered for the political fortunes of governors but not those of party secretaries. This may capture the division of labour between party secretaries and governors in the RDA regime given that the former were responsible for party affairs, such as personnel control etc., whereas the latter were put in charge of running the provincial economy. Nevertheless, considering the fact that most provincial party secretaries served previously as governors, their records on provincial economic performance must have already played a role in their promotion to become secretaries.

Of course, the promotion of regional officials is not solely determined by their performances in economic affairs. In most columns of Table 3, many of the non-economic performance factors are controlled. One of them is the impact of regional officials' connections with the central government on their promotion, which is measured by their previous or current work experience in the central government. The central connection indicator has a positive and significant impact. Comparing columns 3 and 4 with columns 1 and 2 of Table 3 indicate that promotion and termination appear more sensitive to the average growth rate than to the annual growth rate. They suggest that the long-run or average measure weigh more in turnover decisions than those 
of short-term shocks.

Table 3. The Effect of Economic Performance on the Turnover of Provincial Leaders (Ordered Probit Regressions)

\begin{tabular}{|c|c|c|c|c|c|c|}
\hline & \multicolumn{6}{|c|}{$\begin{array}{l}\text { dependent variable: turnover ( } 0=\text { termination, } 1=\text { same level, } \\
2 \text { =promotion })\end{array}$} \\
\hline & (1) & $(2)$ & (3) & $(4)$ & (5) & $(6)$ \\
\hline $\begin{array}{l}\text { Provincial annual GDP } \\
\text { growth rate }\end{array}$ & $\begin{array}{l}1.615 * * \\
(2.05)\end{array}$ & $\begin{array}{l}1.581 * \\
(1.87)\end{array}$ & & & & \\
\hline $\begin{array}{l}\text { Provincial average } \\
\text { GDP growth rate }\end{array}$ & & & $\begin{array}{l}\text { 4. } 727 * * * \\
(4.34)\end{array}$ & $\begin{array}{l}\text { 4. } 540 * * * \\
\quad(3.90)\end{array}$ & & \\
\hline $\begin{array}{l}\text { Provincial average } \\
\text { per capita GDP growth }\end{array}$ & & & & \multicolumn{3}{|c|}{$\begin{array}{l}3.001 * * \\
(2.10)\end{array}$} \\
\hline $\begin{array}{l}\text { Provincial average } \\
\text { per capita GDP growth } \\
\text { rate of the immediate }\end{array}$ & & & & \multicolumn{3}{|c|}{$\begin{array}{l}-3.584 * * \\
(2.36)\end{array}$} \\
\hline$(\mathrm{A})-(\mathrm{B})$ & & & & & & $\begin{array}{l}3.309 * * * \\
(3.41)\end{array}$ \\
\hline \multirow{2}{*}{ Age } & & $-0.026 *$ & & $-0.023 *$ & $-0.071 * * *$ & $-0.070 * * *$ \\
\hline & & $(-1.91)$ & & $(-1.68)$ & $(6.81)$ & $(6.77)$ \\
\hline \multirow{2}{*}{ Age65 } & & $-0.974 * * *$ & & $-0.976 * * *$ & $-0.303 * *$ & $-0.303 * *$ \\
\hline & & $(-5.27)$ & & $(-5.25)$ & $(2.07)$ & $(2.07)$ \\
\hline \multirow{2}{*}{ Education } & & 0.154 & & 0.187 & 0.183 & 0.184 \\
\hline & & $(0.96)$ & & $(1.17)$ & $(1.48)$ & $(1.5)$ \\
\hline \multirow{2}{*}{ Central connection } & & $0.384 * * *$ & & $0.404 * * *$ & 0.082 & 0.085 \\
\hline & & $(2.79)$ & & $(2.89)$ & $(0.74)$ & $(0.77)$ \\
\hline \multirow{2}{*}{ Tenure } & & $-0.053 *$ & & $-0.055 *$ & $-0.062 * *$ & $-0.062 * *$ \\
\hline & & $(-1.74)$ & & $(-1.78)$ & $(2.44)$ & $(2.45)$ \\
\hline \multirow{2}{*}{$\begin{array}{l}\text { Lagged per capita GDP } \\
\quad(\text { million yuan) }\end{array}$} & & 0.080 & & 0.010 & & \\
\hline & & $(0.43)$ & & $(0.05)$ & & \\
\hline Cutoff point 1 & $\begin{array}{l}-1.320 * * * \\
\quad(-3.67)\end{array}$ & $\begin{array}{l}-3.162 * * * \\
(-2.98)\end{array}$ & $\begin{array}{c}-2.850 * * * \\
(-2.64)\end{array}$ & $\begin{array}{c}-2.850 * * * \\
(-2.63)\end{array}$ & $\begin{array}{c}-6.992 * * * \\
(8.42)\end{array}$ & $\begin{array}{c}-6.929 * * * \\
(8.66)\end{array}$ \\
\hline \multirow{2}{*}{ Cutoff point 2} & 1. $621 * * *$ & 0.106 & 0.455 & 0.455 & $-3.736 * * *$ & $-3.662 * * *$ \\
\hline & (4.63) & $(1.01)$ & $(0.43)$ & $(0.43)$ & $(4.64)$ & $(4.7)$ \\
\hline Number of & 864 & 864 & 864 & 864 & 1227 & 1227 \\
\hline
\end{tabular}

Note: The numbers in parentheses are t-ratios based on robust standard errors. The significance levels of $1 \%, 5 \%$ and $10 \%$ are noted by $* * *, * *$ and *. All regressions include the provincial and year indicators. Columns (1)-(4) are based on Li and Zhou (2005), and columns (5) and (6) are based on Chen, Li and Zhou (2005).

In addition to providing incentives through appointment and promotion within the hierarchical structure, the decentralization-based reforms also further delegate autonomies to sub-national governments through various channels. One of those is the city status upgrading scheme. In the city status upgrading scheme, municipal governments are granted more administrative authority and the political position of a city is raised, thus more strongly incentivizing its officials. One of these kinds of practices is to upgrade some county governments as city governments (county-to-city upgrading). From 1983 to 2001, 430 county-level cities were established, mostly by upgrading (Li, 2009). Another method is to upgrade some prefecture level municipalities to the deputy provincial rank city, which is officially called separately-itemized 
cities (jihua danlie), meaning that they enjoy substantial autonomy and are treated separately from the province in which they are located. Since 1984, 14 cities have obtained deputy provincial rank (Shi and Zhou, 2007).

Using a large panel data set covering all counties in China from 1993 to 2004, after controlling for the official upgrading requirements, such as industrialization, population and fiscal strength, Li (2009) finds that, everything else being equal, counties with a higher growth rate were more likely to get city status. He interprets this as evidence that upgrading is used by the central government as an incentive mechanism to align regional interests with the national ones. Shi and Zhou (2007) show that everything else being equal, cities obtaining deputy provincial rank, i.e. a greater degree of autonomy, increased per capita GDP by an additional $9.3 \%$, per capita FDI by more than $50 \%$, and per capita investment by about $80 \%$. This indicates that enabling and empowering sub-national governments by granting them more autonomy power together with high-powered incentives enhances regional economic growth effectively.

All of the above surveyed papers do not pay special attention to the potential reverse causality problem, except for applying some time-lags. One might challenge these findings by imagining that a governor who was already picked to assume important positions in the central government in the future being assigned to a province with fast economic growth to show his performance. That is, instead of career concern motivating regional development, the findings may be interpreted as placing favourable future leaders into easy performing regions to justify their later promotion.

Indeed, a clear-cut econometric study which rules out a reverse causality has yet to be done. Nevertheless, if we combine all the results from the literature, the overall picture should be reasonably convincing that a reverse causality is not most likely. First, to improve the chance of being promoted, a governor not only should perform better than average (LZ result); but also should be better than his/her immediate predecessor (CLZ results), which makes the reversed causality argument uneasy. Second, if a governor performed really poorly for several years, the likelihood of his/her losing the governorship is substantially increased. It is hard to imagine that poor performance for many years is unrelated to this governor's own actions.

Finally, in the analysis and evidence discussed in Sections 3.1 and 3.2 the government is focused on economic growth, or growth enhancing reforms. Under this condition, tournamentlike regional competition creates powerful positive incentives to sub-national officials. However, when the government's task is expanded to many other potentially conflicting tasks, such as managing inequality, protecting environment, and maintaining social stability etc., regional competition may create strong negative effects. This is discussed in Section 6.

\subsection{Chinese Regional Competition and the Debate on Fiscal Federalism}

There is a large literature that debates whether the quality of public fiscal policy can be improved through regional competition or fiscal federalism in general. The seminal Tiebout model (1956) shows that jurisdictional competition among sub-national governments can make the provision of public goods more efficient. Along this line of thinking, a market-preserving fiscal federalism develops an argument which says that, under certain conditions, fiscal federalism is self-enforcing and is market-preserving. The core mechanism is the commitment mechanism created by certain fiscal federalism which prevents the national government from intervention, which in turn provides proper incentives to government officials at all levels to encourage market growth (Weingast, 1995). China is often seen as a major example of marketpreserving fiscal federalism (Montinola, Qian and Weingast (MQW), 1995; Qian and Weingast, 
1997; Jin, Qian and Weingast (JQW), 2005).

At the same time there is also a fairly sizeable literature that challenges fiscal federalism on many aspects. First, inter-jurisdictional competition for capital may lead to a 'race-to-the bottom' in local tax rates, or in reduced provision of some local public goods (Keen and Marchand, 1997). It may prompt local governments to exploit possible spill-over to other jurisdictions, exporting taxes or pollution to their neighbors (Gordon, 1983; Oates and Schwab, 1988), and central government intervention may be necessary to solve such problems (Cumberland, 1981; Gordon, 1983; Rivlin, 1992; Wildasin, 1989). Without a strong central government, fiscal federalism alone will not lead to efficient results and will not be market-preserving (Blanchard and Shleifer, 2001). Second, interregional competition for capital may encourage sub-national governments to act in ways that corrode the capacities of the central state such that fiscal federalism will not be market-preserving (Cai and Triesman, 2004, 2006).

Evidence from cross-country studies is mixed: fiscal federalism in many countries often is found to be inefficient (Fornasari, Webb, and Zou. 1999; Rodden, 2002; Rodden and RoseAckerman, 1997). Furthermore, arguments have been made and evidence has been found to show that Chinese fiscal decentralization is neither self-enforcing nor market-preserving (Wong, 1991; Cai and Triesman, 2006; Tsui and Wang, 2004).

However, this kind of debate could be misleading if one ignores the fundamental difference between the Chinese RDA regime and a federal state. In the Tiebout branch of fiscal federalism theory the economic gains to sub-national officials from attracting additional residents is central (Tiebout, 1956; Oates, 1999), voice or exit. In a more general version of fiscal federalism subnational government officials are elected, and they are accountable to their constituencies (Epple and Zelenitz, 1981). In contrast Chinese officials face no pressure due to voice, exit or election, suggesting they should perform poorly. Yet, they face strong incentives to meet the promotion criteria defined by higher officials. Under certain conditions these promotion incentives could be strong enough to replace the incentives derived from voice, exit or election. But this is not always the case as some later sections will discuss.

Moreover, the condition of market-preserving fiscal federalism requires that " $[\mathrm{t}]$ he allocation of authority and responsibility has an institutionalized degree of durability so that it cannot be altered by the national government." ${ }^{40}$ This requirement "provides for credible commitment to the federal system and thus for limits on the national government's discretionary authority. Not only must there be decentralization, but that decentralization must not be under the discretionary control of the national government." This is "a necessary component of federalism's marketpreserving qualities" (MQW, 1995). However, under the Chinese constitution and in line with general Chinese government policies - both de jure and de facto - the central government preserves its discretionary power over regions, and this power has been exercised during the reform era (the PRC Constitution, 1982, 2004; Mertha, 2005). A prominent example in which this basic condition of market-preserving fiscal federalism is violated is the recentralization of tax collection power after more than a decade of fiscal decentralization. Facing a decline on the central government's fiscal revenue while the economy was growing rapidly (Wong, 1991), in 1994 a reversal of the fiscal decentralization took place in central government's attempts to overcome this problem (Tsui and Wang, 2004). As a result, the share of sub-national governments' tax revenue in national tax revenue was reduced substantially from $70 \%$ to $40 \%$ (World Bank, 2002). This implies there is no commitment to limiting the central authority's power in fiscal policy.

\footnotetext{
${ }^{40}$ Tsai (2004) argues that China violates basic assumptions of market-preserving federalism.
} 
In addition to the nature of the basic institution, there is an important technical assumption necessary for Tiebout competition to work: factor mobility. Similarly, one of the five fundamental conditions of market-preserving fiscal federalism requires that "[t]he national government has the authority to police the common market and to ensure the mobility of goods and factors across sub-government jurisdictions" (MQW, 1995). However, when reforms started regions competed fiercely without factor mobility, and factors gradually became more mobile as a result of the reform - not as a starting point of the reform. For example, labor in China has only become partially mobile since the mid 1990s (Whalley and Zhang, 2004). Moreover, capital is even more immobile than labor, and segmentation of capital markets is still a problem today (Gordon and $\mathrm{Li}, 2003$ ). Although the direction of the trend of trade barriers across regions and the direction of the trend of factor mobility are debatable subjects, the existence of severe factor immobility and regional trade barriers in China is indisputable (Young, 2000; Naughton, 2003; Bai et al., 2004).

Within the theoretical framework of fiscal federalism, a violation of factor mobility makes inter-jurisdictional competition among regions impossible. Without factor mobility, citizens would not be able to "vote with their feet", and thus there would be no Tiebout competition. Similarly, in the framework of market-preserving fiscal federalism, inter-jurisdictional competition would fail to serve as an important incentive device without a national common market and factor mobility (JQW, 2005). However, economic development and the development of a national common market could be characterized as something of a chicken-or-egg dilemma. Therefore, a recipe for economic development conditional on the existence of a common market or factor mobility would be difficult to apply usefully to real-world situations. ${ }^{41}$

What happened during the Chinese reforms is that when factors were highly immobile, i.e. when Tiebout conditions were violated, Chinese regions started to compete fiercely with each other. Moreover, not only did the RDA regime manage regional competition in a growthenhancing manner, but also allowed factors gradually to become more mobile, thus encouraging the evolution of a national common market. The key point here is that factors became more mobile as an outcome of the reforms, rather than as a precondition for them.

Finally, it is important to note that fiscal federalism theory is based on the very feature of market economies which requires that the economic roles of local governments be restricted to fiscal policies. Thus, the key issues of fiscal federalism theory revolve around fiscal policies such as taxation and the provision of public goods by local governments. However, Chinese subnational governments are responsible for much broader roles in the economy, of which fiscal policies are only a subset. Therefore, applying fiscal federalism models which focus on fiscal policy alone will miss large parts of the reforms and will not be able to explain China's economic reform and growth. This point is also valid for most transition economies, at least during the process of transforming the economy into a market economy.

\section{Regional Institutional Experiments}

Regional experimentation is an essential part of the central decision-making process in China (Section 2.2.1). Starting from 1978, almost every major step on the path of reform was tried out by a few regions first before being launched nationwide. This is well echoed by the

\footnotetext{
${ }^{41}$ In almost all developing economies, factor mobility is limited and a national common market has yet to be developed; this makes people doubt the usefulness of the fiscal federalism model for economic development (Bardhan, 2002).
} 
well-known "slogan" of the Chinese reforms: "crossing a river by touching the stones." To some extent, the "stones" are reform measures and these "stones" are "touched" through regional experiments.

Sub-national governments play a critical role in attempting reforms due to the uncertainty of new reforms. One of the major uncertainties is related to the challenges of political resistance, because reforms create winners and losers in changing institutions. The political economy of institutional changes affects paths and strategies of reforms. Under certain conditions, regional reform experiments are used as a strategy to weaken political resistance and to reduce the uncertainties that come from a new reform. A successful experiment outcome not only provides information on which reform program works, but also can be used to support the reform and to persuade the unconvinced. Moreover, compared with a nationwide full-scale reform, when a regional experiment fails the drawbacks may be contained to the experimenting region. In addition, some compromise policies or compensation schemes aimed at opponents of a given policy may be attempted as a way to ease the opposition towards starting a reform. That is, the option value carried with regional experimentation may bear weight to tip the political balance in favour of those reforms which may otherwise have been discarded.

However, it seems that China is unique in deploying regional experimentation as a reform strategy, while it is usually agreed that Eastern Europe and the former USSR followed the "big bang" strategy. Moreover, this difference of approach is usually regarded as an explanation of why China's reforms performed so differently than those of Eastern Europe (McMillan and Naughton, 1992; Sachs and Woo, 1997). Yet, the experimental approach was in fact utilized in the pre-1989 reforms in Eastern Europe and the Soviet Union, but failed miserably. ${ }^{42}$ Those failures led to a discrediting of the experimental approach in reforms and to the adoption of the big bang approach. Ironically, to a large extent, China followed many of Eastern European-style gradual reforms with experiment as an essential ingredient in the earlier stages of its reforms. A fundamental question is: what are the conditions that make China special in deploying regional experiments successfully? And, what makes the experimental approach work in China but not in Eastern Europe?

The key potential benefit of experimenting is to reduce the uncertainties of reforms. However, this potential benefit will be realized only when results can be obtained through experiments which do not disturb the rest of the economy, particularly in case of experiment failures. It turns out that how an experiment is coordinated determines whether an experimental approach will be fruitful, and in turn, the way experiments are coordinated is determined by the way the economy and the government is organized.

Conventional economic wisdom may lead people to wonder why a market should not be used to coordinate a reform experiment. However, it has been argued that essential coordination tasks have to be carried out through non-market mechanisms, even in developed market economies (Coase, 1937; Weitzman, 1972; Williamson, 1975). For economies carrying out reforms aimed at transforming a centrally-planned economy into a market economy, this is particularly true since markets there have yet to be developed. In his Nobel Lecture, Coase (1992)

\footnotetext{
42 An interesting example is Khrushchev's "Sovnarkhoz” reform (decentralization reform) launched in 1957 and 1958 through a trial-and-error process, which eventually established 105 "Sovnarkhozes" in the territory of the USSR (Swearer, 1961). The reform delegates full authorities to regional party secretaries over appointing SOE directors in their jurisdictions (Ballis, 1961). Regional leaders were encouraged to try reform measures and strong incentives are linked to their performance (Swearer, 1962). But this "Sovnarkhoz" reform failed due to serious cross-region coordination failures (Gregory and Stuart, 1998), which leads to the removal of Khrushchev in 1964. Markevich and Zhuravskaya (2009) document this failed reform.
} 
argued that the function of management in a firm "was to co-ordinate" beyond the markets. He asked: "Why was it needed if the pricing system provided all the co-ordination necessary?" His answer was that "[t]o have an efficient economic system it is necessary not only to have markets but also areas of planning within organizations of the appropriate size." When an organization is large, such as a multi-national company or a national government, a related key issue is "the appropriate size" of the sub-organization which coordinates, or who should coordinate what within an organization. In the spirit of Coase, to some extent different ways of allocating authorities within a government, or different ways of decentralization, is an institutional design issue which addresses the question: what is the boundary of different levels of government?

In reality, the success or failure of coordinating reform experiments is deeply entangled with the political economy of reforms. To make the analysis tractable, in the following subsection I simplify important political economy issues into a reduced form as parameters of a model. This allows me to focus on analysing coordination problems. Then, in subsection 4.2, I bring political economy issues back to real cases of regional experimentation.

\subsection{The Institutional Foundation for Regional Experiments}

Appropriately devised and implemented reform experiments may reduce uncertainties substantially. However, a reform experiment often involves several complementary subprograms, so a reform experiment will fail if its related sub-programs are not coordinated satisfactorily. ${ }^{43}$ The role of the government, particularly local governments, in initiating and coordinating local experiments is particularly vital in cases where many markets are missing or ill-functioning.

There are many reasons why it is important to let local governments initiate and coordinate local experiments. These are best seen by exploring an alternative approach, which would be to let the central government initiate and coordinate reforms. "Local knowledge" and "local information" (Hayek) are the basic reasons why decentralized experimentation is superior to centralized experimentation. The central government does not know every thing; without information on local preferences, local technology and local institutional conditions, it is hard for a centralized regime to come up with a concrete, implementable idea which satisfies local demand (preferences). Moreover, implementing a reform requires detailed local knowledge. As a matter of fact, in China's 30 years of reform, most reform ideas did not come from the central government.

A closely related disadvantage of centralized experimentation is the incentive problem. Without autonomous power, unmotivated local officials would be passive at the best and would not take initiatives to observe and to resolve potential problems. Delegating the power to conduct reform experiments to local governments converts local officials into entrepreneurs. A major feature of China's economic reforms is that local officials make efforts to find market niches, initiate inventive ideas, try new approaches, etc. Without this widespread entrepreneurship and their institutional innovations, most of China's successful reforms would not have been attempted.

However, not all governance structures are conducive to regional reform experiments. A challenging question to be addressed here is the institutional foundation for coordinating regional experiments. As discussed previously, a typical Chinese region is relatively self-contained and a sub-national government is responsible for most economic activities within its jurisdiction. That

\footnotetext{
${ }^{43}$ Here, the central importance of complementarity among different reform dimensions is in odds with the simplistic view that a single factor determines economic development.
} 
is, sub-national governments are assigned with the power and the resources to initiate and to coordinate regional reform experiments. Moreover, given that interregional dependence is relatively weak in China, when a regional experiment fails, its impact on the rest of the national economy is minimal (Qian and $\mathrm{Xu}, 1993){ }^{44}$

QRX (2006; also 1999, 2007) developed a theory to explain how the Chinese RDA regime creates conditions that alleviate coordination problems in reforms and that allows for flexible experimentation. ${ }^{45}$ In this theory a reform program is consisted of some complementary sub-programs. Each sub-program of the reform is characterized by its own individual attributes, and these complementary sub-programs must ultimately be fit together in order to be integrated properly. A reform is completed successfully only if the characteristics of each attribute of the various sub-programs are matched successfully. A failure in the matching of attributes implies a breakdown of economic order, i.e. a drastic failure. To simplify the matter, suppose a reform program is ex ante well designed in the sense that all the attributes are matched by those in the blueprint of the program. However, some of the attributes may not suit local conditions ex post, and adjusting these attributes may lead to mismatches with the attributes of other tasks, which will then require further adjustments.

To illustrate the basic idea, let us look at the following example. Suppose a reform has two sub-programs: an enterprise restructuring program (involving a lay-off of excess workers) and the creation of a social safety net (involving unemployment benefits). The attributes of the enterprise restructuring program include the number of laid-off workers and their individual characteristics, such as: age, seniority, family composition, length of residence, sex, type of contract, current wage, history of employment, etc. The attributes of the unemployment benefits in the social safety net include the rules of eligibility, such as: length of employment, special circumstances (i.e. veterans)), the status of enterprises, the rules of the benefits such as size and length, the types of benefits (monetary or not), the technical support of computers, administration, budget, etc. If some attributes of the two tasks are not matched, many laid-off workers may not be compensated appropriately, so they may strike and the ensuing social disorder will make the reform a failure.

Therefore, a successful reform requires both a good reform blueprint and proper implementation (i.e. coordination). The uncertainty of the quality of a reform program can be reduced to form an expression of two factors: a) the political support for, or resistance to, a reform; b) the technical quality of the proposed reform. A program with many political challenges is more uncertain, and a reform program that incites strong political opposition will fail in spite of how "good" the program looks from an outsider's perspective. Therefore, a program without political support will be regarded as bad regardless how good the program is in theory or in practice in another country. In addition, a program can be technically uncertain. For example, a mechanical transplantation of the case law from the US to China would be highly technically uncertain given the linguistic, historical and cultural differences between the two countries. In a simplified theory, a bad reform program always leads to a failure, however well coordinated in the implementation. Yet, without a test it is not known for sure ex ante whether a reform program is good or not.

\footnotetext{
${ }^{44}$ Provincial officials of Anhui and Guangdong argued that a failed experiment in an isolated locality would not affect the province's performance when they initiated regional experiments related to land reform and special zone reform in the late 1970s (for more details see Section 4.2).

${ }^{45}$ In the QRX papers Chinese economy is modelled as M-form organization. All the political economy interpretations associated with the RDA regime discussed here may or may not be shared by my co-authors.
} 
On the other hand, a good reform program needs to be implemented or coordinated correctly. The quality of coordination depends on the quality of the information available to decisionmakers in the organization. Regional officials enjoy a local information advantage (a la Hayek, 1947), in that they have first-hand observations on the site; whereas for others, any on-site information would require communication, which is subject to imperfect transmission. The QRX framework assumes that information transmission is imperfect. To capturing the reality fully, this assumption should be interpreted as a reduced-form expression of two noises: a) political noise; and b) technical noise. Political noise occurs when information is transmitted through political skeptics or opponents, while technical noise arises from the fact that two officials can have different knowledge and different interpretations of the same message, or for some other technical reasons.

In China's RDA regime, where each region is self-contained and regional officials are assigned the power to coordinate, reform experiments can be coordinated locally. Relying on first-hand local knowledge directly, without involving upper-level officials, local coordination will not be subject to political interference and technical noises, and will be easier to accommodate. Most importantly, flexibility in reform experiments makes it possible to try a reform in one region (or a few regions) first and extend the experiment to other regions later if the first experiment is a success. In the case of a failure, although the failed experimenting region's payoff will be reduced, the payoff for the non-experimenting regions will remain constant. This flexibility weakens resistance to reform proposals and encourages attempts of many different reforms, which may otherwise not be tried at all.

In contrast, in an economy where specialized ministries are responsible for implementing tasks, because ministries are complementary, reform experiments have to be coordinated by the central officials. This makes both political and technical noise inevitable, thereby making coordination failure more likely. One of the worst features of this economy is its rigidity, which prevents a regional experiment or a small-scale experiment from being beneficial. A fundamental institutional problem here is that because complementary tasks are grouped separately into specialized ministries, and therefore coordination across ministries must be provided by the centre. In coordinating a small-scale experiment, the central government has to carry it out in multiple steps involving all relevant ministries. These complications in coordinating regional experiments not only incur deadweight losses (as shown rigorously in QRX), but also makes it easy to sabotage an experiment in the process.

In general, when there are more political suspicions surrounding a reform program, and when political opposition within the government is stronger, therefore causing coordination failure to occur more often, the advantage of the RDA regime becomes more apparent. These points are illustrated by case studies in the following subsection.

\subsection{Regional Experiments on Land Reform and Special Economic Zones (SEZs)}

China's land reform and SEZ reform were both made possible by the efforts of reformoriented sub-national governments facing stiff political resistance at national level. Successful regional reform experiment outcomes created bases for forging consensus among the central leaders, which made large-scale diffusion of the reform programs possible at a later date. Ex ante the reduced uncertainties of regional experiments gave reformers better chances to try controversial programs. Ex post successful experiment outcomes - even those that were only partially successful - could be used as evidence to convince undecided politicians and to accumulate momentum and political support for the reforms. 
Chinese land reform started in the late 1970s, and is officially known as the household responsibility system (HRS). It is regarded as "a major social experiment in the design of institutions in which a system emphasizing social values has been replaced by a system relying on economic incentives" (McMillan et al., 1989). During the period of the HRS reform between 1978 and 1984, output in the Chinese agricultural sector increased by over 61 percent. Seventyeight percent of the increase in productivity in Chinese agriculture in this period of time was due to the changes brought about by the HRS reform (McMillan et al., 1989). By examining many other factors, Lin (1992) disentangled the contribution to output growth of the HRS reform from those of other reforms, as well as from that of increased input availability. He confirms that the dominant source of agriculture output growth during 1978-1984 was the change from the production-team system to HRS, which was directly responsible for 49 percent of the output growth. Moreover, the change in crop patterns, from grain to non-grain crops, also had a positive impact.

Although it may be a bit of an exaggeration to call the introduction of the HRS "the design of institutions," it is pretty accurate to regard this process as "a major social experiment." A key point I want to highlight here is that this major social experiment was initiated and carried out by sub-national governments without an design at the national level; this is the way to overcome the political resistances and risks associated with land reform.

Similar to what happened in Central-Eastern Europe before the 1989 reforms, or in the former Soviet Union during perestroika, political/ideological resistance to land reform were strong in China. Any change which could lead to de-collectivization was seriously challenged, and any failure associated with land reform would be utilized by the conservatives for political reasons. Thus, minimizing the political and technical uncertainties of land reform was critically important for the survival of the reform, as well as the reformers themselves.

In the late 1970s, "proto-types" of the HRS were tried by a handful of local officials in a few provinces such as Anhui, Sichuan and Guangdong. One of the best known examples of initiative by local government was in Xiaogang village, in Fengyang county of Anhui. In those localities, land and output quotas were contracted out from local governments (Communes) to individual households. The experiments were carried out under high risks, given that people who were involved in the 1960s' land reform were heavily penalized not long ago. ${ }^{46}$ At that time, land reform was unconstitutional (as stated in the 1978 Constitution of China), and was officially banned by the Communique of the Third Plenum of the $11^{\text {th }}$ Central Committee of the CCP, which is often quoted officially and in the literature as the first milestone of the post-Mao reform (Kelliher, 1992; Naughton, 1995). The State Council and the Party's news paper, the People's Daily, issued decrees and commentaries on behalf of the central government to stop any land reform attempts with political threats based on the ban of the Communiqué (Wu, 2009). Deng Xiaoping was quiet until some obvious successful experiment results came out.

Facing the daunting challenges of carrying out the land reform, in 1979 Zhao Ziyang and Wan Li, then the governors of Sichuan and Anhui respectively, decided to experiment with different land contracting schemes in a few counties within their jurisdictions. According to Tian Jiyun, a Vice-Premier of the State Council between 1983 and 1993, Dangtu county was one of the counties picked up by Wan in 1979 and about seventeen percent of rural households there participated in the land contracting experiment. ${ }^{47}$ All of the land reform experiments were

\footnotetext{
${ }^{46}$ Land reform was tried in many Chinese regions during the early 1960s but reforms were banned, and officials and peasants involved in the experiments were punished severely during the CR.

${ }^{47}$ Similar experiments were also carried out in Guangdong in 1978 under the leadership of governor Xi Zhongxun at
} 
coordinated locally.

In 1980, validated by the successful regional experiment results, Wan and Zhao reported to the central government and rallied for expanding reform experiments into more regions throughout the nation. Supported by their successful experiment results, in late 1980 the central government decided to allow for regional land reform experiments spread-out nationwide. Zhao and Wan were promoted to be the Premier and Vice-Premier of the State Council, respectively, in order to carry out the nationwide reform experiments (Tian, 2008). After this, the nationwide land reform experiment propagated quickly, so that in 1981 about $45 \%$ of rural households participated in the reform. Subsequently participation increased to $80 \%$ in the next year, and finally, reached $99 \%$ in 1984 (Lin, 1992). Thereafter, agricultural reforms in general and land reform in particular were further progressed and were consolidated through numerous further reform measures. Similarly, most of those are based on successful regional experiment results. ${ }^{48}$

In sharp contrast, at the onset of Chinese reforms, all Soviet farming tasks were coordinated by the central government through specialized ministries (e.g., Ministries of Agriculture, Trade, Cereal and Grain Production, Tractors and Farm Machinery, Food Industry, Rural Construction, Fertilizer, Land Reclamation and Water Resources, and Fruit and Vegetable Farming etc.). The tasks of providing inputs to the farmers, of managing their operations, storage, processing, transport, and road infrastructure were all allocated to separate agencies over which neither collective farms nor regional governments had any control, and thus it would have been extremely difficult to experiment without support from all relevant ministries. In 1989 Gorbachev launched his comprehensive agriculture reform in a manner such that all relevant ministries were included. In the reform, peasants could lease land with long-term contracts. Although the goal seems similar to the Chinese reform, the farmers encountered grave coordination problems. As a result, there were serious problems in implementation, such as waste during the storage, transport and processing stages due to failures in coordination between production units, transport and storage (Wädekin, 1992).

Another famous Chinese reform is the special economic zone (SEZ) development and the subsequent meteoric rise in foreign direct investment (FDI). Thanks to this reform, even though China started with virtually zero FDI and almost negligible trade and foreign reserves in 1978, in a quarter of a century China has become one of the largest FDI recipient countries in the world, with the world's largest foreign reserves, and also one of the largest trading countries in the world. It is clearly shown in the following Table 4 that FDI in China and Chinese exports are essentially driven by the SEZs. When China first opened up and began attracting FDI and trade, $37 \%$ of FDI was located in SEZs in 1985, and $89 \%$ of the national exports came from the SEZs in 1985. In 2005, when China became the largest FDI recipient country in the world, 93\% of FDI was located in SEZs, and 93\% of China's exports came from the SEZs. It is not an exaggeration to claim that it is the SEZ that made China the country with the largest foreign reserves in the world, as well as the country with the largest trade surplus with the US and the EU. Therefore, among all the Chinese reform measures, the SEZ has had the greatest direct impact on the global

that time but were stopped due to political pressure from the conservatives in the central government (Cai et al., 2008).

${ }^{48}$ Although rural households enjoy the residual income and residual control rights over what they do with the land, under the HRS the control rights of allocation and management of land resources are kept with the local officials. Thus, most cultivated land in rural China remains partially collectively owned. Jacoby, Li and Rozelle (2002) show the existence of inefficiencies caused by this partial privatization. However, they also show that the inefficiency level was not high. 
economy.

Table 4. The Impacts of SEZs on National FDI and Exporting

\begin{tabular}{|c|c|c|c|c|c|c|c|}
\hline year & $\begin{array}{c}\text { Number } \\
\text { of SEZs }\end{array}$ & $\begin{array}{c}\text { Nat'l Exports } \\
\text { (mil US\$) }\end{array}$ & $\begin{array}{c}\text { SEZ Exports } \\
\text { (mil US\$) }\end{array}$ & $\begin{array}{c}\text { SEZ share of } \\
\text { Exports }\end{array}$ & $\begin{array}{c}\text { Nat'l FDI } \\
\text { (mil US\$) }\end{array}$ & $\begin{array}{c}\text { SEZ FDI } \\
\text { (mil US\$) }\end{array}$ & $\begin{array}{c}\text { SEZ share } \\
\text { of FDI }\end{array}$ \\
\hline 1980 & 4 & 18119 & 278 & $1.5 \%$ & 145 & 51 & $34.9 \%$ \\
\hline 1985 & 77 & 27350 & 24327 & $89.0 \%$ & 1956 & 728 & $37.2 \%$ \\
\hline 1990 & 290 & 62091 & 44602 & $71.8 \%$ & 3487 & 2551 & $73.2 \%$ \\
\hline 1995 & 341 & 148780 & 124692 & $83.8 \%$ & 37521 & 33694 & $89.8 \%$ \\
\hline 2000 & 341 & 249203 & 228779 & $91.8 \%$ & 40715 & 38796 & $95.3 \%$ \\
\hline 2005 & 342 & 761953 & 709373 & $93.1 \%$ & 60325 & 56397 & $93.5 \%$ \\
\hline
\end{tabular}

Sources: China statistical yearbooks 1986-2006; China Urban Statistical yearbook 1986-2006; China Urban Forty years; Provincial Statistical yearbooks 1996-2006; State Council documents.

Although by conventional wisdom it seems obvious to suggest SEZ reform policies in order to improve trade and attract FDI, initiating and carrying out these reforms was a great challenge at the beginning of the reform era. There was strong political opposition to the idea of renting land to foreign firms or multi-national firms, as these kinds of practices were regarded as 'selling the nation'. Indeed this kind of reform was unconstitutional at that time. The political risk would be too high for a reformer to bear if one had to confront the convention of the planning apparatus at a national level or to confront the constitution head-to-head. Thus, those concerned with how to attract FDI to China faced tremendous political and economical difficulties and uncertainties. Moreover, when the constitution (including the Party's constitution) did not protect private property rights, how would one convince foreign investors to invest? When imports/exports were all controlled by government agents - national and regional - how could China accommodate foreign and domestic firms to develop trade-intensive businesses?

Facing these tough constraints, the central leadership was, at best, not able to build a consensus to move forward (Cai et al., 2008; Zhao, 2009). The idea of setting up SEZs to attract FDI and to develop export-oriented industries was initiated and experimented by sub-national governments. The strategy of regional experimentation played a vital role in dealing with the ensuing difficulties and uncertainties. According to the archives (Cai et al., 2008), the idea of conducting municipal experiments to attract FDI was proposed by officials of Guangdong province in 1979. The proposal suggested to authorize Shenzhen and Zhuhai as experimenting municipalities, and required that conditional on the success of the first experiment other cities will follow similar experiments in the next step. A major part of the experiment involved trying new sets of institutions, legislation and rules for the purpose of attracting FDI, and furthermore municipality governments were made responsible for implementation. Moreover, the proposal asked for greater regional autonomy, particularly for decision-making power in regional experiments.

The skepticism towards the SEZs was strong at the top level of the central government (Zeng, 1984). There had been fierce debates in the central government and within the party apparatus on the desirability and the nature of SEZs, and on the paths of development the SEZs should take. ${ }^{49}$ As a compromise, approval was given by the State Council for small-scale

${ }^{49}$ Chen Yun, a top leader of the CCP, cast deep doubts on the SEZs. The idea of setting up the SEZs was regarded as 
experiments in four remote cities in 1979 (The Central Government Circular No.50, 1979, Zhongfa (1979) 50).

Together with authorizing the experiments for SEZs, the central government also granted the Guangdong government, and particularly the experimenting municipal governments, more autonomy in regional planning, in enterprise management and in policies related to FDI. In August 1980 the People's Congress approved the State Council's proposal of setting up four SEZs in Guangdong and Fujian and passed the first legal rule on the SEZs: "the Regulation for Guangdong SEZs." This was the first kind of regional law tested, which was drafted with the help of legal experts sent from the central government (Cai et al., 2008). When the experiment was expanded into other provinces, they also adopted and modified this law accordingly.

Supported by the initial achievements of the first group of SEZs in 1984, the central government endorsed another 14 cities to experiment with SEZs, and the experiment was further expanded to more cities in 1985. In the early 1990s, the extremely fast growth of export and FDI validated the success of the SEZs. The opposition to the SEZs is subdued and encouraging SEZ development becomes a national policy. In 1992, SEZs comprised all the capital cities of inland provinces and autonomous regions, 15 free trade zones, 32 state-level economic and technological development zones, and 53 new- and high-tech industrial development zones. Currently, SEZs encompass more than 100 national economic and technological development zones, 15 national bonded areas and 14 border trade and co-operation regions in the broadest sense.

One of the major features of the small scale regional experiments, such as the HRS and SEZ reforms, is that for a certain period of time the non-experimenting regions remain unchanged until diffusion commences. The co-existence of two systems, experimenting vs. nonexperimenting or reforming vs. non-reforming, in the reform process is sometimes called "the dual track system." The dual track system has been used to describe both small scale and full scale reform experiments in which all regions implement a reform experiment at the same time, while keeping the non-experimenting system for a certain period of time. A major example of a full scale experiment is the dual track price system. The most important benefit of the dual track system is to reduce resistance to a reform by substantially reducing the number of losers through keeping the non-reforming system at earlier stages of the reform (Lau, Qian and Roland, 2000). However, there are essential conditions to be satisfied to make the dual track approach beneficial in reforms. If the state is weak in enforcement and as a result parties are able to siphon resources away from low-priced existing transactions to high-priced new transactions, the dual track approach may fail to function (Che and Facchini, 2007). Thus, the sub-national governments' enforcement capability to regulate firms' strategies is vital in order for the dual approach to be efficiency-improving.

In addition to locally initiated reform experiments, almost all important reforms sponsored by the central government in the past three decades were also tried and implemented through regional experiments, such as the state sector reforms (Heilmann, 2008). The bankruptcy reform in the mid 1990s illustrates this phenomenon. Although there was collective support from the top leaders for restructuring the state sector drastically through enforcing the bankruptcy law, there was no consensus on how to do it. After it issued general guidelines on the basic priorities and general approaches in 1994, the central government encouraged local governments to experiment with innovative solutions for debt restructuring, mergers, closures, and employee

equivalent to a "rented territory" or "the selling of the nation," which would be a revival of the semi-colonial era. The other objection charged that the SEZs would exacerbate inequalities (Zhao, 2009). 
resettlement. Eighteen municipalities were picked up by the central government "to test new methods for dealing with the resettlement of employees in insolvent industrial enterprises." Each experimenting municipality was responsible for coordinating all the relevant aspects within its jurisdiction, such as land-use rights and using the proceeds for resettling the laid-off workers etc. (Heilmann, 2008). This reform finished in the mid 2000s.

\subsection{Incentives of Experimenting}

Regional experimentation is a major strategy for moving a reform forward before central decision-makers are able to build consensus for the reform. Experimenting involves high risks for regional officials who conduct the experiments, and it also creates large positive externalities at the costs of experimenting regions. Moreover, conducting reform experiments often requires officials take initiatives and make extra efforts to deal with unexpected contingencies. Without the initiative to solve problems, experiments would easily fail. Therefore, in addition to previously discussed conditions, setting up proper incentives is essential for inducing subnational officials to conduct experiments. ${ }^{50}$

It is relatively straightforward to design incentives for central government-sponsored local experiments. Often, the central government provides generous compensation to experimenting local governments (Heilmann, 2008). However, for locally-initiated experiments, the incentive mechanism is subtler. It turns out that the regional competition-based promotion system is one of the mechanisms that create motivations for regions to be entrepreneurial in experimenting. In the RDA regime, regional officials are appointed, and initiating or implementing successful regional experiments can lead to substantial promotions. Thus, although experimenting involves risks and externalities, experimenting also creates chances not only to outperform others, but also more importantly, to lead others, which implies getting unusual promotion opportunities. That is, the benefits associated with promotions will correct disincentives from positive externalities.

In addition to the costs of experiments, another critically important issue is who decides what to experiment and who conducts the experiment. By being granted a broad range of control rights over regional economic affairs, the regionally decentralized structure converts many regional bureaucrats into entrepreneurial officials. Regional officials are active in identifying reform experiment opportunities. If, after someone's initiative, other regions follow an experiment, it implies that this reform experiment was a success, and therefore the chance of getting a substantial promotion is higher. Perceiving this, officials with greater career ambitions would initiate reform experiments on their own, sometimes even taking high risks. That is, the centralized personnel control may internalize some of the externality problems of regional experiments. The HRS and SEZ experiments discussed in the previous subsection are the most visible examples of this process. In those examples, the pioneers of the HRS and SEZ reforms were promoted substantially when the experiments were recognized by the central government as models for the nation to follow.

Moreover, it is observed that a common practice in reform era is to promote officials from more developed municipalities, where many reform experiments were tried out earlier, to leading provincial posts, particularly in less developed regions. Chien and Zhao (2007) document that from the late 1990 s to the early 2000 s there were three former heads of Suzhou city who were promoted to become governors of Jiangsu, Shaanxi and Jilin respectively; a former Shenzhen

\footnotetext{
${ }^{50}$ In a Tiebout federal system, where officials are elected from their constituencies, the value dilution due to the positive externalities will dis-incentivize regional officials and lead to too few experiments (Gordon, 1983; Cai and Triesman, 2005).
} 
mayor was appointed as the governor of Hunan, and a mayor of Wenzhou became the governor of Sichuan. These three cities pioneered many reform experiments on their own and are among the best reforming municipalities in China.

By using a panel data consisting of thirty provincial regions between 1978 and 2005, through a diff-in-diff approach to control for groups with and without transfer of governors and before and after transfer of governors, $\mathrm{Xu}$ et al. (2007) found that, everything else being equal, cross-regional governor transfer increased regional GDP growth rate by $1 \%$. In the more recent period of 1992 to 2005, the effect was enlarged to $2 \%$. By constructing a panel data consisting of thirty provincial regions between 1978 and 2004, with a similar approach, Zhang and Gao (2007) find that the effect of cross regional governor transfer on regional GDP growth rate was significant for the period of 1990 to 2004.

\section{Regional Competition and Regional Experiments in Some Major Reforms}

This section discusses some major economic reforms which have had substantial impacts on China's economic growth over the past three decades. This discussion serves two purposes: first, it is important to understand the mechanisms by which these reforms operate for their own sake; and in addition, these reforms act as concrete examples of the conceptual discussions above about the mechanisms of regional competition and regional experimentation.

\subsection{The Township-Village Enterprises (TVEs) and the Non-State Sector}

Large-scale entry and fast development of the non-state sector is a distinctive feature of China's reforms. ${ }^{51}$ The pace of growth of the non-state sector is so quick that the state sector is unable to compete. Without a conventional form of privatization of the state sector, i.e. privatizing existing SOEs, the market share of China's state sector in the national economy shrunk from $78 \%$ in 1978 to $53 \%$ in 1991 . The most important non-state sector until the mid1990s was the TVE. By the early 1990s, TVEs accounted for about $4 / 5$ of the output of the nonstate sector. Between 1981 and 1990, the total industrial output of TVEs grew at an average annual rate of $28.1 \%$, while the rate for the state sector was $7.7 \%$. As a comparison, China's average annual GDP growth rate was $8.7 \%$ between 1979 and 1991. Moreover, TVEs had substantially higher TFP growth rates than the state sector in those years (Xu, 1995).

More importantly, the TVE actually served as a major stepping-stone in changing China's institutions. A typical TVE is a collectively-owned enterprise located in a township/village. All the people in the township/village which "sets up" the TVE own the firm collectively. The community government of the township/village "represents" the communal collective owners, and is the de facto executive owner of the TVE (Byrd and Lin, 1990). The property rights of the TVE are vaguely defined. From a viewpoint based on 'conventional wisdom', the governance of these firms appears deficient and should result in unproductive firms. Therefore, the spectacular performance of the TVE sector poses major challenges to economics (Weitzman and Xu, 1994). This is particularly true before the mid-1990s.

Several complementary explanations are proposed in the literature, and most focus on the role of the community government. The strong incentives created by regional competition are one of the institutional reasons for the rapid development of TVEs. Moreover, the relatively selfcontained nature of regional economies gave TVEs opportunities to grow. There are broad

\footnotetext{
${ }^{51}$ To some extent Hungary, Poland and Vietnam are the other transition economies that shared this feature and they all enjoyed better performances than other transition economies.
} 
ranges of products which the TVEs can produce to meet local demand, and there are often sufficient local semi-products to supply to TVEs as inputs. Close links between TVEs and local SOEs often facilitated the transfer of technology and management know-how (Xu and Zhuang, 1998).

Concerning the relatively effective governance of the community government over TVEs, most conceptual discussions emphasize the second-best nature of TVEs when there is weak or no legal protection of private property rights (Chang and Wang, 1994; Li, 1996; Oi, 1999). That is because township-village governments had access to resources, whereas community citizens did not. Moreover, when the firm is owned by the community government, the community government faces less state expropriation because part of the revenue is used to finance the local provision of public goods, which addresses the state's concerns and also enhances the firm's future earning potential (Che and Qian, 1998). These arguments are supported by empirical evidence collected from villages (Chen and Rozelle, 1999).

Another major feature of the TVEs is the prevailing of the informal institutions, such as implicit contractual relationships between community governments and TVEs, between TVE employees, and between TVEs. Weitzman and Xu (1994) conjectured that local cultural or social norms may be an important factor behind informal institutions. This conjecture shares the same spirit of the evolutionary repeated game theory of social norms (Axelrod, 1984; Fudenberg and Maskin, 2008) and is closely related to the literature on the evolution of social norms, culture and human behaviour. Empirically, it sheds light on substantial regional differences in TVE development, including powerful informal institutions in post-TVE developments (Xu and Zhang, 2009), which reflects the diverse history of China's regional economic development. ${ }^{52}$

As protection of private property rights improved (Clarke, Murrell and Whiting, 2006) and asset markets developed, many benefits of TVEs are diminished. Moreover, associated with large-scale migration since the mid 1990s, an increasing numbers of TVE employees, including TVE top managers, have become migrant workers. This also contributes to changes in the governance of TVEs. ${ }^{53}$ A large percentage of TVEs were privatized since the mid 1990s (Kung and Lin, 2007; Park and Shen, 2003; Li and Rozelle, 2004).

Although TVEs have declined, the institutional legacy of TVEs in China's economic development and corporate governance is extensive. Important mechanisms that prevailed in TVEs, e.g. the intimate involvement of community governments in business and informal institutional arrangements, are still at work today, and their impacts on the rise of entrepreneurship in China are far-reaching, such as on the fast growth of clusters of large number of small private firms in coastal provinces.

With clustering of a vast number of small specialized firms, many Chinese townships have become national or world "factories" for certain products. It is these townships which made China "the world's factory". ${ }^{54}$ In a typical industrial cluster, thousands of highly specialized

\footnotetext{
${ }^{52}$ Most TVE employees and managers lived in the same community for generations when there was almost no migration before the early 1990s. Under certain conditions, close long-term interactions among community members (virtually infinitely repeated overlapping-generation relationships) might foster a social norm within the community which may facilitate informal institutions. In contrast, SOEs are not organized based on natural communities, such as villages; therefore, many of the informal mechanisms found in TVEs would not function in SOEs.

${ }^{53}$ In the terminology of evolutionary game theory, there were lots of mutants which invaded the repeated games and that would change the equilibrium strategy of the game (Fudenberg and Maskin, 2008).

${ }^{54}$ For example, Datang township makes one-third of the world's socks; $40 \%$ of the world's neckties are made in Shengzhou township; more than $70 \%$ of the buttons for clothes made in China come from Qiaotou township; Songxia township produces 350 million umbrellas every year; and Puyuan township produced $60 \%$ of China's
} 
family owned entrepreneurial firms are worked together with infrastructural and regulatory support of township governments. The small firms in a cluster are closely coordinated, similar to workshops within an integrated firm, whereas they are also highly competitive, as in markets. These specialized small firms are linked together by networks of informal arrangements, such as implicit contracts, so that every final product is jointly produced by a collection of many firms. Repeated interactions among the workshops and among the agents help reduce the monitoring and enforcement costs. The township government affects the overall and long-run strategic direction of the cluster without direct involvement in the daily operations of the thousands of small workshops. ${ }^{55}$ To a large extent, some important features of TVE institutions, particularly the importance of entrepreneurial local governments to local business development, remain in this post-TVE development. The clusters are strategically managed by township governments, although they have no ownership of the assets of the workshops and are not involved in their financing, except for most of the land and some of the buildings. They provide infrastructure, secure property rights, regulate quality, train labourers, and provide favourable policies.

All of these make the township government similar to the headquarters of a conglomerate. Moreover, to a large extent, due to the way that they coordinate with each other, the behaviour of those privately-owned specialized workshops are more like workshops within an integrated large firm than independent small firms in a market (Xu and Zhang, 2009).

The evolution of TVEs and the subsequent clustering of modes of production are institutional responses created by entrepreneurs, including local entrepreneurial officials, to overcome constraints such as weak legal protections for property rights, weak contract enforcement, as well as credit and technical constraints, etc. When the political, legal, and economic conditions improve, a firm's organization and organizational structure may change as well. Less viable forms of organizational structures are eliminated through competitive pressures in a decentralized setting, whereas it will be hard to prescribe the optimal path of firm evolution beforehand. This makes regional experiment-based decision-making important. Overall, the success of TVEs and post-TVE developments is due to the regional decentralization which allows for the full use of individual talents through introducing various institutional and organizational innovations to cope with constraining factors.

\subsection{State Sector Reform: Centrally Sponsored Local Experiments}

Similar to other transition economies, at the onset of the reform the Chinese economy was dominated by the state sector, and therefore state sector reform was the most important. Yet, as opposed to other transition economies, most of the SOEs in China were "owned" by sub-national governments. China's state sector reforms have been very much driven by regional competition and regional experiments. Two major aspects of early SOE reforms have been discussed in the literature. The first aspect concerns appointment or selection of SOE managers. Before privatization (to be discussed later), sub-national governments were responsible for selecting SOE managers within their jurisdictions. Under the pressure of regional competition and the importance of local SOEs to regional economies, sub-national officials became very performance-conscious when considering the appointment of SOE managers (Groves, Hong,

\footnotetext{
cashmere sweaters, of which China is the world's largest producer (Xu and Zhang, 2009).

${ }^{55}$ Take Puyuan Township (Zhejiang province), the largest cashmere sweater production centre in the world, as an example. There were six thousand family-owned highly specialized workshops and three thousand private trading shops in the cluster coordinated strategically by the township government (Xu and Zhang, 2009).
} 
McMillan, and Naughton, hereafter abbreviated as GHMN, 1995). The second aspect of the early reforms involved managerial incentives (GHMN, 1994; Zhuang and Xu, 1996).

As regional SOEs were owned by regional governments, to a certain extent, a region's state sector is like a state-run regional conglomerate in which sub-national governments functioned like the headquarters of regional conglomerates (Oi, 1999). This is particularly true for municipalities and counties. The regional governments, functioning like the personnel department of a regional conglomerate, selected managers, made decisions on promotions and demotions, maintained dossiers and tracked managerial records etc. In response to regional competition, also under the encouragement of the central government's reform guidelines, subnational governments experimented with various "managerial responsibility systems" in which managers were delegated power to make many decisions, and employees were given financial incentives tied to enterprise performance.

By using firm-level panel data, GHMN (1994, 1995) and Li (1997) evaluated the outcomes of some major SOE reform experiments in the 1980s. In their sample, over $80 \%$ of the managers were appointed by sub-national governments, and their careers were determined by the evaluations of their bureaucratic superiors; and the majority of SOEs were in the regional experiments of delegate more authorities to SOE managers, which allowed SOEs to keep a large proportion of their profits and to use the retained funds for worker bonuses, worker welfare facilities, and enterprise investment, etc. Moreover, performance responsibility contracts for SOE managers were experimented with in many regions. The contracts specified performance indicators, such as profit, reinvestment, and compensation structure. Most of the SOEs' managers in the GHMN sample signed the contracts. GHMN (1994) investigated how SOE managers responded to their increased autonomy and how firm productivity was affected. They found that with more autonomy in output decisions and with higher marginal profit-retention rates, SOEs increased their use of bonuses and hired more fixed-term contract workers. Moreover, the strengthened incentives were positively correlated with higher productivity.

Another important experimental SOE reform was the system of management selection by competitive auctions. About 14 percent of the managers in the GHMN sample were selected through competitive auction. The usage of this reform peaked in the late 1980s - 1987 and 1988 accounted for $57.4 \%$ of the competitive auctions in the GHMN sample. Auction procedures varied among regional experiments. In general, a typical SOE was put up for auction by its superior municipal government. The most important part of a bid was the promise of profit to the municipal authority in the near future. In most cases, bidders also made promises to reinvest, etc. The municipal government as the owner of the SOE then chose the winning bidder on the basis of promised profit delivery and the management plan etc. The top manager often signed a management contract and frequently was required to put up a security deposit, which could be forfeited if the manager failed to meet the promised performance.

Based on their firm level data, GHMN indicated that the managerial labor market was functioning in China's state sector such that SOE managers changed jobs frequently. They found both demotion/promotion of the previous manager and the conditions of the new manager's appointment can be partially explained by the corresponding firm's performance. Moreover, they found that SOE managers' total compensation is positively related to firm profits. In their sample, overall, SOE per worker output rose 67\% (in constant prices) for the decade of the 1980s. As a result, in that period of time TFP growth contributed to $73 \%$ of output growth; moreover, over $87 \%$ of the TFP growth was attributable to improved incentives, intensified product market 
competition, and improved factor allocation ( $\mathrm{Li}, 1997)$, which is confirmed by researches based on national census data (Jefferson et al, 1996).

Nevertheless, the early SOE reforms failed to solve some basic problems of the state sector. While productivity was increased, facing fierce competition from the non state sector and losing monopolistic position in most product markets, the financial performance of the state sector worsened rapidly. The total losses in the state sector kept worsening between 1993 and their peak in 1998, when the state sector made a net loss of 285 billion RMB (Table 4) and the government kept pumping financial aid into this sector for bailouts. ${ }^{56}$ The record-breaking losses of the state sector led to an unprecedented number of non-performing loans (NPLs) in China's banking sector. These were manifestations of a serious soft budget constraint syndrome (SBC), a major moral hazard problem prevalent in all centralized economies and transition economies. ${ }^{57}$ The severe SBC problem and the well-known consequences of SBC created deep worries about the sustainability or even the survivability of the Chinese regime. The SBC syndrome is caused by the lack of a credible commitment from the government to allow loss-making SOEs to fail (Kornai, 1980, 1992; for surveys see Maskin and Xu, 2001; Kornai, Maskin and Roland, 2003). ${ }^{58}$ The key to hardening a budget constraint is to make bankruptcy threats to SOEs credible.

To a large extent, since the late-1990s, the state sector bankruptcy reforms and privatization (to be discussed in Section 5.3), have hardened budget constraints, which turned the state sector to profitable since the year 2000 (Table 5). The effectiveness of these reforms constitutes a big surprise for many experts. ${ }^{59}$ Indeed, as it is for other transition economies, hardening budget constraints and bankruptcy reform were some of the most difficult reforms in China. Given the close interrelation between SOE debt and the state banking system, and between SOEs and social safety nets, radical bankruptcy reform or SOE restructuring could lead to massive social unrest and bankruptcy of state banks (Booth, 2004; Heilmann, 2008). Moreover, state firms carry many types of policy burdens, such as employment and social security etc. (Shleifer and Vishny, 1994;

\footnotetext{
${ }^{56}$ GHMN $(1994,1995)$ reported no evidence that budget constraints for state-owned firms were hardened in the 1980s. In studying the "fiscal contracting system" operating between the central and provincial governments from 1980-93 JQW also found that the central government was not able to keep its commitment to restrain from offering ex post subsidies to sub-national governments.

${ }^{57}$ Yet, the TVEs did not suffer much from the SBC syndrome, as millions of them went bankrupt in 1989, even though they were supported by community governments and many of them also had policy burdens for community employment and social security. This is because at the bottom level of the hierarchy, community governments, as well as local branches of rural credit cooperatives, have limited financial resources available in their disposal. Moreover, their access to subsidies and credits from the central government is restricted by law. These limitations have prevented community governments from bailing out loss-making TVEs (Qian and Xu, 1993). Moreover, given local governments' limited financial resources, they face high opportunity costs for bailing out failing firms. When regional competition is tougher, the opportunity cost becomes higher and local governments would be less willing to bailout their failing firms (Qian and Roland, 1998).

${ }^{58}$ Concurrent with increased state sector losses, between 1993 and 1995, inflation also worsened. A loss of control over monetary policy due to decentralization in credit control was blamed as the cause (Wang, 1991; Huang, 1996). Sharing a similar perspective, Brandt and Zhu (2000) argue that facing competition from the non-state sector, the central government was forced to rely on money creation to finance the state sector, since the central government supports the employment and investment of the state sector. This not only softened budget constraints of the state sector but also caused inflation.

${ }^{59}$ Around that time, some authoritative China experts, such as Nicolas Lardy (1998), worried that with a continued increase of the number and value of NPLs, the Chinese financial system would collapse soon, which would lead to economic disaster.
} 
Lin, Cai, and Zhou, 1998). With the policy burdens, the state is accountable for the losses incurred from policy burdens, and thus it has to bailout insolvent SOEs (Lin and Tan, 1999). ${ }^{60}$

There were intense political controversies in drafting, updating and finalizing the bankruptcy law from the 1986 version to the final 2006 version (Booth, 2004). ${ }^{61}$ Facing vast difficulties and political risks, China's bankruptcy reform was carried out through local experiments to deal with the social and fiscal consequences of SOE insolvencies, and was used by central policymakers in their debates, decisions and lawmaking etc. (Heilmann, 2008).

Table 5. Losses and Layoffs in the State Sector, 1991 to 2005

\begin{tabular}{|l|l|l|l|l|}
\hline & Losses (bi1) & $\begin{array}{l}\text { Profits } \\
\text { (bil) }\end{array}$ & Layoffs (mi1) & $\begin{array}{l}\text { Net } \\
\text { (bil) }\end{array}$ \\
\hline 1991 & 92.59 & 74.5 & & -18.1 \\
\hline 1992 & 75.68 & 95.5 & & 19.8 \\
\hline 1993 & 46.94 & 166.7 & & 119.8 \\
\hline 1994 & 62.45 & 160.8 & & 98.4 \\
\hline 1995 & 80.21 & 147.0 & & 66.8 \\
\hline 1996 & 112.7 & 87.7 & 5.42 & -25.0 \\
\hline 1997 & 142.09 & 54.0 & 6.34 & -88.1 \\
\hline 1998 & 306.65 & 21.4 & 5.95 & -285.3 \\
\hline 1999 & 214.49 & 114.6 & 6.53 & -99.9 \\
\hline 2000 & 184.6 & 283.4 & 6.57 & 98.8 \\
\hline 2001 & 199.36 & 281.1 & 5.15 & 81.8 \\
\hline 2002 & 180.25 & 378.6 & 4.10 & 198.4 \\
\hline 2003 & 281.98 & 476.9 & 2.60 & 195.0 \\
\hline 2004 & 303.06 & 736.9 & 1.53 & 433.8 \\
\hline 2005 & 331.39 & 958.0 & 0.61 & 626.6 \\
\hline
\end{tabular}

Sources: China Fiscal Yearbook, 1996-2006; China Accounting Yearbook, 1995-2006; China Labor and Social Security Yearbook, 2006; China Labor Economic Yearbook, 1997-98.

Losses: the total losses in the state sector; Profits: the total profits from the profitable SOEs; Layoffs: the accumulated number of employees laid-off by the state sector.

One of the most contested political and legal issues in China's bankruptcy reform was about who should be assigned with priority protection in the liquidation of assets. Should that be given to creditors (state banks, i.e. government assets) or to employees (the source of potential social unrest)? (Heilmann, 2008). The first bankruptcy law, the "Experimental Bankruptcy Law" passed in 1986, was more creditor-friendly. Instead of being a law to be enforced nationwide, however, this law only served as a guideline for central government-sponsored local experiments. Very importantly, in experiments, local governments deviated from the law substantially. To prevent local social problems, the administrative practice of local governments in dealing with insolvent enterprises favored employees (Heilmann, 2008). The early reform progressed fairly

\footnotetext{
${ }^{60}$ In this logic, Lin and Li (2007) argue that even privatization will not necessarily harden budget constraints. This is because bearing policy burdens, to provide the same policy service a private enterprise will demand more ex post subsidies from the government than an SOE due to more agency problems between the state and private firms.

${ }^{61}$ Controversies revolved around safeguarding state assets in liquidations; containing the social and financial consequences of SOE insolvencies; dealing with unemployment and rearranging the social safety net function of the SOEs (pensions, health care, housing, etc.) (Heilmann, 2008).
} 
slowly, so that between 1989 and 1993, among tens of thousands of chronicle loss-making SOEs there were only 1,150 bankruptcy cases nationwide.

Pressured by rapidly growing SOE debts and mounting state bank-held NPLs, bankruptcy reform emerged as a top-priority issue in the 1990s. The central government sponsored new waves of local bankruptcy experiments. ${ }^{62}$ In the peak years of restructuring and bankruptcy reforms, from 1996 to 2001, every year there were more than 5 or 6 million SOE employees laid off nationwide relatively peacefully (Table 5). Summarizing local experiment practices, the 2002 and 2004 versions of the bankruptcy law gave workers first priority over the rights of secured creditors; and the burden of providing compensation to the employees of insolvent enterprises was put on local governments. As a result, the state sector was significantly transformed, from losing 285 billion RMB in 1998 to profiting 99 billion RMB in 2000 and 627 billion RMB in 2005, when bankruptcy and layoffs became negligible (Table 5). SOE productivity in the corresponding period also improved significantly (Brandt, Hsieh and Zhu, 2008; Jefferson, Rawski and Zhang, 2008). ${ }^{63}$

Experimental bankruptcy reform processes helped "to conceal and manage fundamental political-ideological controversies that were at the heart of the delayed law-making. Policy experimentation over 23 years allowed recurrent adaptations in the application of the basic priority scheme and thereby helped to avoid open policy conflicts" (Heilmann, 2008). When the bankruptcy reform was carried out by local experiments, the law was only "provisionary" and formal bankruptcy proceedings in courts played a minor role. Generally, corporate rescue measures were undertaken through a variety of flexible, inconsistent, but less painful policies which were experimented with locally (Heilmann, 2008). The final version of the Bankruptcy Law (2006) was not passed until the reform experiments were over and the number of bankruptcy cases dropped drastically. However, the final version of the law goes back to the protection of creditors and did not retain those policies in favor of protecting workers vis-à-vis creditors.

\subsection{Privatization: Locally Initiated Experiments}

Although there is no empirical work that decomposes factors contributing to the turnaround of the state sector from chronicle loss-making to a profitable sector, perhaps the most effective reform was privatization, which sold most of the loss-making firms to private owners. In sharp contrast to other transition economies, where privatization was pushed through by the central governments as a high priority at the beginning of the transition, privatization was and is a highly controversial subject in China due to ideological and political reasons. As a result, privatization has been postponed by the Chinese government as much as possible. Moreover, the Chinese privatization scheme is not based on a rational design; instead, it is a result of political games given existing institutions. Due to this delay, at the time of privatization, even though the state sector was loss-making and was deeply in debt, the national economy was in a better shape and conditions for privatization were more ready than all other transition economies when they

\footnotetext{
${ }^{62}$ In 1994 the State Council issued a circular on trial implementation of new insolvency procedures and sponsored experiments in 18 cities. Two years later trial implementations of new merger and insolvency procedures were tested in 56 cities. In the next year the State Council sponsored experiments in 117 cities for trial implementation of merger, bankruptcy, and reemployment procedures.

${ }^{63}$ Of course, given that many reform measures were taking place in the same period of time, such as privatization, layoffs, change of corporate governance, market competition, large scale FDI and lower interest rates, it is a challenge for researchers to find out what specific reform measure has exactly contributed by how much to the improvements of productivity and profitability of Chinese firms.
} 
launched privatization. The non-state sector had already surpassed the state sector in the national economy, while the market had already replaced most of the planning related to resource allocation, including the product, capital, labour, and managerial labour markets, etc. Moreover, the improved productivity of the state sector through earlier reforms, as discussed in Section 5.2, might also have played an important role in making the transition smooth. Furthermore, the Chinese privatization has been carried out by municipal governments at their discretion, under regional competition for economic growth. That is, they have opted not to privatize if doing so would hurt their regional growth. As a result, China is an exceptional case among all transition economies which did not suffer from recessions as CEE-FSU economies did during their privatizations (Estrin, Hanousek, Kočenda and Svejnar, 2009; hereafter abbreviated as EHKS). Instead, China's privatization is associated with a high growth rate.

Privatization was officially banned, and in practice it was not encouraged by the central government until the late 1990s. However, given the local "ownership" of most of the Chinese SOEs and pressures faced by local governments, de facto privatization was tried quietly without official permission from the central government in the process of restructuring local SOEs before the mid-1990s. Even in the late 1990s, it is still a city government's decision whether or not to privatize and how to privatize within their jurisdictions (Garnaut et al, 2001, 2005; Gan, Guo and $\mathrm{Xu}, 2010$, hereafter abbreviated as GGX). Moreover, even by then, due to political and ideological constraints, privatization has occurred in a camouflaged form such that the term "privatization" is officially disguised as "transforming the system" or "gaizhi" in Chinese (Garnaut et al., 2001, 2005). Nevertheless, in 2005, about two-thirds of the Chinese SOEs and COEs with annual turnover of more than 5 million RMB Yuan (about \$620,000) have been privatized and the total asset value involved in the process was about 11.4 trillion RMB (or 1.63 trillion USD) in 2005 (Guo, Gan and Xu, 2008). ${ }^{64}$ Due to its recentness and the lack of data, the research on China's privatization is still very limited (EHKS).

One of the early major reforms attempted by many cities in the late 1980s, and which lead to privatization later, was the leasing of SOEs. The top managers of small- or medium-sized SOEs leased the firms by paying the sub-national government a fixed proportion of the firms' profits. This reform gradually led to de facto privatization, since after some years of leasing the share value of a manager would outweigh that of the city government, the "state owner". The other major reform initiative, which facilitated privatization later, was incorporation. Although officially incorporation was restricted to the exchange of shares among the SOEs, private shareholding was allowed in some cities. The first reported cases were in Guangzhou in the late 1980s, when employees of some SOEs bought substantial amount of shares of the firms where they worked. Under severe political and ideological constraints, to contain the risks of privatization, a prevailing privatization strategy chosen by most Chinese city governments is to sell the ownership of SOEs and COEs to their employees. This is because employee ownership is least controversial politically and ideologically.

Similar to the situation of the bankruptcy reform, the most important impetus for privatizing SOEs was the large amount of debt built up by the state sector in the 1990s. Distinctively different from the central government's sponsorship of the bankruptcy reform, however, privatization was initiated by city governments. The central government tolerated this by turning a blind eye to the actions of city governments. One of the first regional privatization experiments was in Zhucheng, a city in Shandong province. In that city, more than two thirds of the SOEs were loss-making in 1992, with losses amounting to the city government's total fiscal revenue

\footnotetext{
${ }^{64}$ Based on the data collected from a nationwide random survey of all Chinese industrial firms conducted in 2006.
} 
over 18 months. The city government sold many SOEs to their employees. Another representative example is the municipal government of Shunde in Guangdong. The Shunde city government also encountered a serious debt problem when it privatized most of its state and collective firms in 1992 (Garnaut et al., 2005).

As a result of successful local experiments with privatization and the severity of SBC problems in the state sector, privatization was gradually accepted by the central government through several steps, from an explicit "tolerance" policy to some proactive guidelines on privatization. ${ }^{65}$ Finally, a green light was given by the CCP's 15th Congress (1997), which granted de jure ownership of local SOEs to local governments. By default, this implies that the centre has authorized the 'owners,' mostly city governments, of smaller SOEs to try everything on their own, including privatization, although this has never been explicit. With this major change, the scale of privatization gradually enlarged after 1997.

China's regional experiments on privatization have adopted multiple approaches. These approaches include share issue privatization (SIP), joint ventures with foreign firms, management buyouts (MBO), and sales to outsiders. Privatization in China has created concentrated private ownership and about half of privatized firms in China were sold to managers, i.e. through $\mathrm{MBO}$, which has greatly changed corporate governance and corporate performance (GGX).

Not every privatization approach was effective. Based on their nationwide random sampling survey data, by controlling for privatized and not privatized firms; before privatization and after privatization, based on a nationwide random survey, GGX found that among all privatization methods, only $\mathrm{MBO}$ had statistically significant positive impacts to the restructuring, corporate governance and performance. One of the most important changes associated with MBO is that the state has retreated from firms after privatization. That is, after buying out the firm owner-managers became the decision-makers of their own firms on issues like hiring, layoffs, wages, compensation, production, marketing, and investments etc. Moreover, MBO firms substantially restructured in a deeper way than other privatized firms. As a result, MBO had a statistically significant positive impact on improving firm performance. ${ }^{66}$ In contrast, governments still kept substantial controls over those firms privatized through other methods, and these privatization strategies failed to improve performance (GGX).

It is the decision of a given municipal governments whether to privatize and, if so, how to privatize. According to a nationwide random survey, MBO was chosen mostly by those cities that had stronger fiscal discipline and/or were less concerned about shedding labour, such as fast growing coastal cities like Ningbo, Wenzhou, Hangzhou, Changzhou and Wuxi etc. Meanwhile, non-MBO approaches were chosen mainly by those city governments that had weak fiscal discipline and a concentration of the state sector, such as heavy industrial cities like Changchun,

\footnotetext{
${ }^{65}$ In 1993 , the $3^{\text {rd }}$ Plenum of the $14^{\text {th }}$ CCP Congress endorsed the creation of a modern enterprise system, which approved the development of diversified forms of ownership including private ownership. Although much of the political constraints on privatization were still in place, this created a more tolerable environment for local privatization experiments. In 1995, the central government announced the policy of "retain the large, release the small" (zhuada fangxiao), i.e. the state was to keep the largest few hundred SOEs in strategic industries and to give local governments full control rights to local SOEs.

${ }^{66}$ Without differentiating between $\mathrm{MBO}$ and non-MBO privatization, by examining formerly state-owned large and medium-size enterprises for the period from 1994 to 1999 nationwide, Jefferson and Su (2006) found that privatization increased productivity and investments in research and development. Similarly, based on firm level data collected from one city, Dong, Putterman and Unel (2006) found that privatization has significantly improved productivity and profitability for urban firms.
} 
Jinzhou, Handan and Xian, etc. (GGX).

The process of privatization illustrates the importance of regional experiments in advancing China's reforms. To make this picture sharper, it is important to point out that MBO was never favoured by the central government. In fact, the mass media, which has been tightly controlled by the central government, was hostile to MBO. In contrast, the central government-sponsored major ownership reforms, such as share issuing privatization, failed to improve the performance of SOEs. ${ }^{67}$

\subsection{The Impacts of Regional Decentralization on Growth}

It is a major challenge to study the impact of regional decentralization on economic growth empirically. One of the most difficult issues is how to measure regional decentralization. The Chinese regional decentralization involves much more than simply fiscal decentralization. But how to measure statistically non-fiscal elements of regional decentralization is an unsettled subject. Moreover, regional decentralization captures only part of the operations of China's RDA regime. The effectiveness of regional experiments and regional competition is often conditioned on effectiveness of central control. That is, centralization is an essential part of the picture. In addition to the conceptual and theoretical problems in the literature, the lack of statistics on broadly defined decentralization is another major problem yet to be resolved. Given the difficulties, most of the empirical literature concerning the impacts of regional decentralization on growth is restricted to fiscal decentralization.

Lin and Liu (2000) (abbreviated as LL hereafter) and Jin, Qian and Weingast (2005) (abbreviated as JQW henceforth) found that fiscal decentralization contributed to regional growth in general, and to the development of the regional non-state sector in particular. Zhang and Zou (1998) found a negative relationship between fiscal decentralization and regional economic growth in China, but LL and JQW suggested potential data and methodological problems in Zhang and Zou.

LL uses provincial data from 1970 to 1993 to study the impact of fiscal decentralization on regional economic growth. Their regressions are based on a Solow type of growth model. Economic growth is decomposed into growth of per capita investment and growth of total factor productivity. All the major reforms included in the regression models are related to regional decentralization. The major focus of the paper is fiscal decentralization. In addition, other reforms included in the regression model are the HRS reform; and the share of non-SOEs' output in the total industrial output. As discussed in previous sections, the HRS reform and non-state sector development are all consequences of regional decentralization. Therefore, together with fiscal decentralization these variables capture a large part of regional decentralization. At the same time, their regression models also control for the growth rate of per capita investment, the financial strength of a region, the impacts of urbanization and the size of the population on economic growth, and price liberalization. All of these control variables have insignificant impacts to regional growth.

LL discovered that, everything else being equal, the growth rate of per capita provincial GDP would increase by $3.62 \%$ in response to an increase of the marginal retention rate of regional fiscal revenue from 0 to $100 \%$. Moreover, the impact of the HRS on regional growth rates was similar to that of the fiscal decentralization. Furthermore, among all regional decentralization variables, the one with the largest impact was the non-state sector development. Everything else

\footnotetext{
${ }^{67}$ It has been shown that China's share issue privatization has failed to contain costs and improve profitability (Sun and Tong, 2003; Deng, Gan, and He, 2008).
} 
being equal, the regional GDP growth rate would increase by $14.2 \%$ if the share of the non-state sector increased from 0 to $100 \%$.

Consistent with LL, by using provincial data from 1980 to 1993, JQW found that stronger fiscal incentives are associated with faster development of non-state enterprises and with greater reforms in state-owned enterprises. Furthermore, JQW found provincial governments in China faced stronger ex post fiscal incentives after the reform. Specifically, they found a strong correlation between the current provincial budgetary revenue and its expenditure for the period of 1982-91 when the "fiscal contracting system" was implemented. The JQW discovery is echoed by a literature which argues that the different fiscal federalist approaches used by China and the FSU are related to well/poorly defined tax rights for sub-national governments and strong/weak fiscal incentives for sub-national governments. Some of this literature claims that these shed light on the performance gap between China and Russia (Shleifer, 1997; Berkowitz and Li, 2000; Zhuravaskaya, 2000).

However, the results of both LL and JQW are based on data up to 1993. As discussed previously, fiscal policy was substantially recentralized after 1994. This makes these results vulnerable to challenges (Tsui and Wang, 2004; Mertha, 2005).

Nevertheless, the LL-JQW evidence constitutes a valuable step in understanding the impacts of regional decentralization on regional growth. After all, fiscal decentralization is an important part of regional decentralization, which includes land reform, SEZs and non-state sector development, etc. The period before 1994 is one in which fiscal decentralization is fully consistent with regional decentralization in general. Thus, fiscal decentralization may be a good proxy for regional decentralization in that period of time. However, the contribution of non-fiscal reforms to economic growth is pooled together with fiscal decentralization so that the contribution of each remains entangled. That is, the identification problem has yet to be resolved in this literature.

Last but not least, it should be pointed out that although taxation has been recentralized since the mid 1990s, it is not clear that regional decentralization has been reversed completely in general. Firstly, in the same period of 'fiscal recentralization' sub-national governments gained more power in some non-fiscal spheres. Endorsed by the $15^{\text {th }}$ Party's Congress in 1997, subnational governments' de facto ownership over regional SOEs has been transformed into de jure or nearly de jure ownership. ${ }^{6}$ Together with other major changes, this endorsement paved the road for sub-national governments to privatize SOEs and COEs (Garnaut et al., 2005). Moreover, sub-national governments were authorized to sell land within their jurisdictions. Secondly, these changes in turn have had impacts on fiscal matters, so that the revenues of sub-national governments in more developed regions created through privatization and selling land in the past years could sufficiently offset losses of their tax revenue. Control rights over land give subnational government important leverage over regional development, regional industrial policy and over macro control of the region (to be further discussed in Section 6.1). To summarize, although the share of sub-national governments' tax revenue in national tax revenue was reduced substantially, sub-national governments' importance in regional governance and in national economic development remains essential. The central government still relies on sub-national governments to govern the bulk of the Chinese economy and sub-national governments still

\footnotetext{
${ }^{68}$ In 2005, sub-national governments owned about thirty-one thousand SOEs plus control of a huge number of COEs (NSB, 2006) whereas the central government owned 166 firms (the State-Owned Assets Supervision and Administration Commission, or SASAC: http://www.sasac.gov.cn/gzwgk/gzwgk_jj.htm).
} 
dominate regional economic affairs, including fiscal and non fiscal matters, such as allocating critical resources to firms, dealing with contract enforcement and property rights protection, etc.

\section{Tradeoffs of Regional Decentralization}

Rent-seeking behaviour and general conservatism are inherent features of an authoritarian regime, therefore making them difficult to reform. However, under the RDA regime, rents could be eliminated if sub-national governments face fierce regional competition: given the importance of winning the competition, if losing a competition implies losing a position, which is the necessary condition for enjoying rents. Moreover, as discussed in Section 2, regional experimentation and regional competition can alleviate the problem of conservatism, enabling reforms to move forward.

However, regional competition and regional experimentation are effective only when subnational governments' tasks can be summarized by a single indicator, e.g. economic growth. If sub-national governments face multiple tasks that cannot be encompassed under a single objective, regional competition and regional experiments may become focused on tasks, which are more measurable, while less measurable tasks are ignored. In that case, high-powered incentives created through regional competition may lead to undesirable consequences. Even worse than this, sub-national governments may be induced to race to the bottom, i.e. regions may compete in or may experiment on some policies which may benefit regional officials but damage most other citizens, or may benefit the region but damage other regions.

At earlier stages of the reform, it was commonly agreed by the central government, subnational governments and citizens that economic growth was the most important objective of China's economic reform. Under that consensus, other objectives can be overlooked so long as the economy grows rapidly. Thus, regional competition and regional experiments faced easier tradeoffs. Moreover, at earlier stages of the reforms, most growth-enhancing policies and institutional changes avoided immediate conflicts among stakeholders. The land reform (HRS reform) distributed land equally among rural households. The TVE development and other nonstate sector developments, including SEZs, were less intrusive to rural stakeholders' interests, such as land.

However, after a quarter century's fast economic growth, the multi-task nature of subnational governments' duties has become more pronounced and the general consensus on the importance of economic growth has broken down. Many major growth-enhancing reforms implemented since the mid-1990s generated immediate conflicts among stakeholders. A prominent example is firm restructuring and privatization, which started in the 1990s. In those reforms, a large number of SOE employees were laid off, whereas new private owners obtained huge amounts of wealth through management-buy-outs. Another example is associated with large-scale rapid urbanization, which converts arable land for non-agricultural developments and creates a great number of landless peasants. This often leads to sharp conflicts between those who lost land without receiving proper compensation, and property developers who profited immensely from the transactions, and are usually closely associated with sub-national governments.

\subsection{Law and Regulation}

Under the RDA regime, Chinese sub-national governments play significant roles in both law enforcement and lawmaking. The aforementioned provincial law on SEZs, "the Regulation for 
Guangdong SEZs" illustrates that sub-national legislation can also serve as the experimental basis for new national legislation. Sub-national governments were endowed with lawmaking power since the PRC's founding in 1949. Although most of their de jure lawmaking power was taken away during the centralization movement of the 1950s, sub-national governments kept some de facto lawmaking powers. At the onset of the reform, sub-national governments regained much of their lawmaking power (http://www.china.com.cn/zhuanti2005/txt/200302/27/content_5283965.htm), and these gains were institutionalized by the 1982 constitutional amendment. In addition, the central government from time to time experimented with giving additional lawmaking powers to sub-national governments, such as "authorized lawmaking power" (shouquan lifa) or "beforehand lawmaking power" (xianxing lifa). As a result, more than six thousands laws have enacted by sub-national governments nationwide since 1978. Conflicts that arise between regional laws and national laws is one of the major concerns of this system, although in principle whenever there are conflicts the national law overrules.

However, the starting point of China's legal reform is among the weakest of all transition economies, since during the CR China dismantled its formal legal system. As a result, China has had to build its legal system virtually from scratch during the reform era. Moreover, ideological and political constraints delayed major legal reforms, such as the protection of private property rights, etc. Together with the lack of judiciary independence, China was in a weaker position than average transition economies in terms of legal reforms. It is not surprising that a lack of proper law and law enforcement can lead to serious problems, and I will discuss some of the most serious problems related to Chinese law later in this subsection. However, the coexistence of very fast-growing businesses, including the private sector, and a very weak formal legal sector is puzzling. The solution to this puzzle lies in the fact that regionally decentralized administrative measures step in as substitutes for law and law enforcement (Pistor and $\mathrm{Xu}, 2005) .{ }^{69} \mathrm{In}$ the past, this has sometimes helped avoid governance vacuums, as private businesses were at times disguised by sub-national governments. Indeed, many of the initiatives and protections provided by sub-national governments to private firms flew in the face of the constitution. Thus, strong incentives given to sub-national governments played essential roles for them to take the risks associated with their unconstitutional actions.

The roles of the municipal governments of Taizhou and Wenzhou of Zhejiang province in developing private sectors ahead of relevant legal developments illustrate this point. The municipal governments offered "red heads" to private firms within their jurisdiction to conceal their vulnerable legal status, thereby giving the outsiders the illusion of official government sanction. Thanks to this kind of development in many regions where sub-national governments provided similar protections, the private sector in China experienced double-digit growth for more than a decade without full legal protection. To some extent it is this spectacular development of the private sector which catalyzed the legalization of private property rights. When the constitutional protection of private property rights was enacted in 2004 the private sector was already the dominant sector in Zhejiang and one of the largest sectors in China.

Concerning regulation, given its weakness in legal institutions, under the RDA regime, China introduced an administration-based regulatory decentralization scheme. In this scheme, the

\footnotetext{
${ }^{69}$ It is worthwhile to note that there are many cases in which business practice preceded relevant laws in European and American history. For example, important securities laws (US 1933/34 Acts) were developed decades behind major developments in US securities markets. However, in Europe/US, there were functioning legal systems that effectively enforced general laws, such as contract law, tort law etc., on new business practices (Xu and Pistor, 2008). But in Chinese reforms, a basic functioning legal system itself is under construction. Thus, sub-national governments are essential as substituting mechanisms to fill in the governance gap (Pistor and $\mathrm{Xu}, 2005$ ).
} 
central regulatory authorities break down the regulatory tasks and delegate them to sub-national governments. Together with regional competition, this system sometimes is able to implement some national regulatory goals; sometimes fails to do so. The regulatory scheme evolved in recent twenty years relies essentially on sub-national governments' assistance and cooperation for enforcement of its regulations ( $\mathrm{Du}$ and $\mathrm{Xu}, 2008)$. In this system, one of the major instruments that are deployed is the quota system.

The bank credit quota system, which was utilized by the People's Bank of China (PBC) to control the aggregate money supply until 1998, is an example of one such quota ( $\mathrm{Du}$ and $\mathrm{Xu}$, 2008). The PBC formulated the national credit plan and allocated credit quotas to the headquarters of all major state banks, which in turn reallocated these to their regional branches and subsidiaries. The regional allocation of bank credit quotas depends largely on regional banking performance, measured in ways such as the amount of deposits taken by regional banks in the previous year; regional economic performance; and a variety of other metrics. The bank credit quota system was a major instrument for implementing macroeconomic policies in general and monetary policy in particular until market-based credit allocation mechanisms were somewhat deployed in the late 1990s.

Another major example is the evolution of Chinese financial market regulation. China's securities markets, the Shanghai and Shenzhen stock exchanges, initially emerged as selfregulated regional markets with supervision from the corresponding municipal governments (Green, 2004). The quota system of equity share issuance was introduced to the Chinese equity market in 1993, and was designed to control the size of financial markets to maintain balance among the regions and to preserve the dominant position of public ownership. The central government would determine the total number of shares to be issued in the nation and then would allocate stock issuance quotas to regions and ministries. Sub-national governments in turn would allocate quotas to selected SOEs for going public through IPOs or to listed companies seeking SEOs. The sub-national governments would collect information on these firms and submit it to the China Securities Regulatory Commission (CSRC), the national regulatory agent. After reviewing the company information, the CSRC would give its approval to companies to issue shares in the public equity markets. The quota system was officially in place from 1993 to 2000; however, it actually governed financial markets up until around 2003 (Pistor and Xu, 2005).

Although the quota system was not designed for dealing with informational or incentive problems, several bodies of evidence indicate that it has played a significant role in creating incentives for regional competition and decentralized information collection in stock issuance. Based on the data of all listed firms from 1993 to 2004, after controlling for political factors, macro variables etc., $\mathrm{Du}$ and $\mathrm{Xu}$ (2008) find that firms located in regions with better performance obtained more quotas in subsequent periods. In explaining firm-level quotas by provincial performance, this result essentially rules out the possibility of reverse causality, since none of the firms in the sample were large enough to affect provincial performance. In addition, the data demonstrate that everything else being equal, listed firms from provinces that disclosed information better were rewarded with more stock quotas in the ensuing periods. Moreover, the quality of regional information disclosure was substantially more important than other factors, such as regional corporate or macro performances, in determining how quotas were allocated. These findings suggest that provinces which performed better in various aspects previously would be given a higher stock issuance quota later from the central government. That is, the quota allocation functioned as a de facto incentive device that induced sub-national governments 
to select better-performing firms for initial public offerings (IPOs) or seasoned equity offerings (SEOs). Finally, detailed evidence from 23 provincial-level regions suggests that the majority of IPO firms selected by sub-national governments had been better-performing state-owned enterprises before they went public ( $\mathrm{Du}$ and $\mathrm{Xu}, 2009$ ). This further indicates that the Chinese regulatory decentralization is somewhat effective at the IPO stage.

However, administration-based regulatory decentralization is not always effective, and it is not a long-term substitute for law enforcement. There are several conditions that must be met for decentralized admin measures to function well as a substitute for conventional legal institutions. Firstly, sub-national governments must have substantial control rights over the regulatory subjects; otherwise, sub-national governments would not play a major regulatory role (e.g. the quota system does not work effectively for non-state-owned firms and cannot ensure adequate corporate governance of listed companies). Secondly, sub-national governments must have strong vested interests in the subjects of regulation; otherwise, sub-national governments would not be motivated to participate. Finally, the central government must have direct control over the resources to be allocated by a quota system; otherwise information problem will disable the system. For example, the quotas systems used for bank credit control and for environment protection did not work well since these quotas are nominal that the financial resources and pollutant emissions are directly controlled by local governments and they can easily manipulate the information.

In order to prevent excessive conversion of arable land for non-agricultural uses, the Chinese government has applied a land quota system to regulate local governments' land conversion. Each region is allocated a land-use quota for each year and regions violating the land-use quota would face a deduction in future quota allocation, together with other penalties. Moreover, an official's compliance with quotas is taken as part of the criteria for evaluating his work. However, because this quota system violates all the three aforementioned conditions, the land quota system fails to work.

In fact, the land problem is one the most serious social problems in China and it can be used as an illustration how China's RDA system makes troubles to the economy. Deeply-flawed laws governing land ownership and fiscal recentralization "collectively" incentivize local governments to ignore the quota system (Kung, Xu and Zhou, 2009; hereafter abbreviated as $\mathrm{KXZ}$ ). Arable land in China is de jure collectively-owned, and in this system, the commune authorities before the reform, and the village authorities afterwards, represent the collectives. Although rights of use and income over land have been reassigned to the farm households since the land reform of the early 1980s, the farmers have no right to alter the land's usage, or to transfer it to another party. The crucial right to transfer these rights has remained in the hands of the state and, in part, of the village authorities. Yet, the collective owners have no right to convert arable land into non-arable usages. Nationalization has been the only legal mechanism by which farmland can be converted into non-arable usages since any non-arable usage of collective farmland requires a change from collective to state ownership (Articles 63 and 43 of the Land Management Law of 1999). Moreover, the law confines farmers' rights in land to basically an "agrarian" usage when land use is changed to non-agrarian and ownership converted (from collective to state). In other words, farmers would only be compensated according to the value of crop production after conversion, even though the land post-conversion may be far more valuable. Apart from the minimal compensation which is legally protected, China's farmers are subject to the whims of local authorities in the process of land conversion (KXZ).

As discussed previously, the fiscal recentralization of 1994 reduced the share of local 
governments' entitlement to most tax sources. To compensate local governments for the losses, local governments were assigned greater control rights over revenues generated by land sales within their jurisdictions. From 2002 onwards the central government further proposed to appropriate $50 \%$ of the enterprise profit tax, which greatly disincentivizes local governments' efforts to improve enterprise efficiency. The fiscal recentralization, together with the monopoly right assigned to local governments over the conversion of farmland to non-arable uses, has induced local governments to switch from a passion for industrialization to "urbanization" frenzy (KXZ).

Blessed with escalating land prices (especially for commercial and real estate developments in premium locations) on the one hand and artificially low compensations on the other, many local governments, particularly those in the rapidly-developing coastal areas, have pocketed "windfall profits" from this urbanization process. Attracted by the huge "windfall profits", land conversion has accelerated after 1999. In 2003 the state became worried that China would soon deplete its arable land below its threshold required for food self-sufficiency. In an attempt to slow down the conversion of farmland, since 2001 the central government has set land conversion quotas for all provinces for each year. But with seriously distorted incentives, the land quota assignment did not work. Much worse, in the process of land conversion local authorities have triggered serious conflicts with the farmers, as a large number of farmers lost their primary source of livelihood with minimal compensation. They feel that they have been robbed of the bundle of rights assigned to them at the outset of the reform. Opposite to the harmonious atmosphere at the era of land reform, i.e. the early 1980s, now land expropriation by local governments becomes one of the worst sources of social conflicts in China (Guo, 2001; Li and O'Brien, 2008). This illustrates that without a properly developed legal system many problems cannot be resolved by regional competition, regional experimentation, personnel control and other methods deployed by the RDA regime.

\subsection{Regional protections}

Regional decentralization alone may not automatically guarantee growth-enhancing regional competition. Without checks of the central government, sub-national officials may restrict cross regional trade to protect firms within their jurisdiction. Indeed, it is oft-cited that sub-national governments opt to put up barriers to shield local firms and industries from competition. It was documented that in the mid-1980s many sub-national governments tried to retain low priced raw materials, such as wool or silk, within their jurisdictions in order to favor local manufacturers (Watson, Findlay et al. 1989; Bernstein and Lu, 2000), and this was also widely reported by both domestic and international mass media coverage. ${ }^{70}$

If there are no effective central-government policies to keep barriers in check, in addition to making factors immobile as most often emphasized in the literature, regional protection could destroy regional competition itself, one of the basic mechanisms that drive China's reform and development. Moreover, interregional trade barriers and regional protectionism can eventual lead to serious political problems, such as disintegration of the country.

Recognizing the seriousness of the problem, the Chinese central government has battled

\footnotetext{
${ }^{70}$ For example, a New York Times report illustrated trade barriers among Chinese regions. To protect their local made car manufacturers, "Tianjin local officials barred taxi companies in the city from buying Geelys," which are produced by a Zhejiang-based car manufacturer (NYT, 11/17/2006). Casual observations confirm this as a general phenomenon that most taxi cabs in many major cities, e.g. Beijing, Tianjin, Shanghai, Changchun, Guangzhou, etc., are made locally.
} 
against regional protectionism repeatedly during the whole reform period. The central government has issued decrees in 1982, 1990, and 2001 to curb regional protectionism (Holz, 2009). A State Council circular of 10 April 1982 states: "regional or departmental (trade) blockages ... are extremely harmful to China's economy in total." The State Council clarified that enterprises had the authority to sell their above-plan output anywhere in the country they wanted, and sub-national governments were not to interfere in the distribution of the above-plan output. In 1990 the State Council issued a circular on breaking inter-regional blockades. It requires that all regional trade checkpoints must be rectified, and differential tax rates based on product origin were prohibited. The State Council issued another regulation in 2001 to deal with issues of the malfunctioning of the "market order," including regional trade barriers. It contains detailed stipulations for eliminating specific kinds of regional trade barriers (Holz, 2009). The great efforts of the central government in containing regional protectionism demonstrate the stubbornness of the problem and the determination of the central government to contain the problem. It also underscores the "checks-and-balances" between the central government and subnational governments in the context of regional competition.

Whether or not the central government's efforts in confining regional protectionism and whether or not regional fragmentation has worsened during the reform have been debated intensively in the literature. There is abundant literature about, statistical evidence of, and mass media coverage of the fast growing inter-regional trade (Holz, 2009). Indeed, one of the most important early reforms in the early 1980s was the legalization of cross-region trade carried out by state and non-state merchants, including private traders. Lau, Qian and Roland (2000) contend that the "dual-track system" introduced during the reforms promotes interregional trade, because under this system, local officials can "sell" the rights to purchase a certain percentage of raw materials and final products at lowered planned prices. Since opening up the market to other regions may significantly increase the market price, this system is beneficial for local officials.

In an ideal situation with perfect national markets, all factors would be mobile, and therefore their productivities across regions would be equalized; regional economies would utilize their comparative advantages, their production would be specialized, and regional prices for the same products would converge. Based on this idea, taking the first best case as the benchmark, it has been argued that Chinese economy has become fragmented regionally, and that the situation was getting worse. Young (2000) reported widespread convergence in the regional structure of production during the reform period, and a rise in the interregional variation of prices during the 1980s. Moreover, there was a divergence of regional relative factor allocations and labour productivities. These findings were interpreted as evidence of industrial duplication across regions caused by regional barriers. Based on this he claimed that regional protection in China was worsening, and that Chinese reforms resulted in a fragmented internal market with fiefdoms controlled by local officials. To some extent, similarly, by studying capital mobility across provinces, Boyreau-Debray and Wei (2005) found great discrepancies in regional marginal capital productivities, and from this concluded that the Chinese financial system was regionally fragmented.

However, by using more diverse and recent data than that of Young (2000), Bai, Du, Tao and Tong (2004) found that regional specialization has increased and has become dominant over the forces of regional protection in recent years. Moreover, with a data set that consists of 93 products in 36 cities over more than ten years, Fan and Wei (2006) provided evidence of market integration during the reform period. They found an overall price convergence in China that indicates that markets across different cities are indeed integrated. Furthermore, they found that 
the products for which interregional trade was more likely to be restricted by local officials for rent-seeking purposes tended to converge to a greater degree of absolute price parity. This finding suggests that local protectionism might be a less important obstacle to inter-regional trade in China than some other factors, such as transportation costs.

Yet, there are serious concerns regarding the methodologies used to study trade barriers. Specifically, focusing on measuring regional specialization alone may not be most helpful in understanding regional protection, since it does not have the warrant of a theoretical foundation. As Naughton (2003) points out, without an underlying theory and without a cross country comparison, i.e. without knowing proper benchmarks, looking at one country's regional specialization alone might be misleading. Indeed, state manufacturing sectors in the U.S., an integrated national economy, became less specialized than before 1987, and they became more similar than they were in the past (Kim, 1995). Moreover, by using a similar approach, Holz (2009) finds that Chinese provinces are similar to American states in their degree of regional specialization. Echoing this finding, Fan and Wei (2006) also find the convergence trend in China is similar to those discovered in the US and Canada. In these three economies, many prices follow relative price convergence rather than absolute price convergence. Obviously, it will not be convincing to claim that market development in China is at a similar level of the US given this evidence. However, it would be even harder to claim, based on this methodology, that Chinese economic reforms have moved the economy further away from markets.

In fact, it is quite likely that applying a similar approach, regional specialization in Russia, or more generally in the CIS and Central-Eastern European countries, is much higher than that in China before 1990. But it would be misleading to interpret this as evidence for more-developed markets in these locations. Indeed, based on the theories discussed in Sections 3 and 4, an economy with overly-specialized regions would hamper regional competition and experimentation. Of course, in those theories, the composition of regional economies is exogenous. A more complete theory has yet to be developed to analyse dynamics of regional competitions when both the composition of regional economies and scale economies are endogenously chosen by players.

\subsection{Regional disparity}

In light of record-breaking rapid and prolonged growth, the quickly-increasing disparity of wealth in China has become a major concern. It is commonly agreed in the literature that inequality in China has substantially worsened since the reforms, mainly in the past two decades. Based on household data from nine provinces, Benjamin, Brandt, Giles and Wang (2009; hereafter abbreviated as BBGW) find that the overall (combined urban-rural) Gini coefficient of China probably exceeds 0.50 , which is approaching that of some of the most unequal countries in the world, e.g. South America. Based on provincial level aggregate data, Kanbur and Zhang (2005) found that, associated with the increase of GDP and trade, the Gini coefficient has increased from 0.29 in 1978 to 0.37 in 2000 . To what degree regional decentralization has contributed to this increased inequality is a hotly-contested subject in the literature.

The relationship between growth and inequality is a subject of debate in the literature (for a survey sees Aghion, Caroli and Garcia-Penalosa, 1999). In the classical view, inequality is regarded as necessary and transitional in the process of industrialization or growth (Kuznets, 1955). Moreover, an increase of inequality may not be so bad even for the poor when an economy grows quickly, since the poor benefit more from increasing aggregate growth than from reducing inequality through redistribution (Dollar and Kraay, 2001). China's rapidly increasing 
per capita income came together with rises in inequality and is used as a major example to illustrate the above point (Quah, 2003). This line of thought would argue that the reform policy in the first two decades of Chinese reforms enabled some people to become rich first. Driven by this policy and implemented within the framework of regional decentralization, arguably, in the last quarter of century, China has experienced the largest scale of poverty reduction in human history. The Chinese population in absolute poverty (defined as $\$ 1 /$ day income) has dropped from $50 \%$ to $7 \%$ in twenty years, while the number of individuals in absolute poverty was reduced by almost 400 million. This number is nearly three-quarters of poverty reduction in the whole developing world (World Bank, 1995).

On the other hand, however, it is argued that inequality has impacts on politics, investment, etc. which in turn can harm stability and growth in general (e.g., Alesina and Rodrik, 1994); and high levels of inequality can even lead to the disintegration of a nation (Bolton and Roland, 1997). Concerning China's growing inequality, it has been warned that increased regional inequality in China may threaten economic and political stability, and national unity (Hu, Wang and Kang, 1995). Is the Chinese duo of high growth and increasing disparity a 'normal' development path prescribed by the well-known Kuznets curve? Will worsening inequality hurt China's economic growth? To what extent is the widening disparity related to regional decentralization? These are issues still under debate in the literature.

Although empirical findings unequivocally show rapidly increasing inequality, particularly during the recent twenty years of reforms, findings on the relationship between inequality and reforms, including decentralization, are divided. Based on a Chinese household survey dataset, with about one million households in the period between 1980 and 2002, Ravallion and Chen (2007) found that inequality was not always related to growth-enhancing reforms, and that there was no overall evidence of an aggregate growth-equity tradeoff in China. They found that higher growth in rural areas, which corresponds well with HRS reform and TVE development, brought inequality down. It reduced inequality within both urban and rural areas, as well as between them. Moreover, provinces with worse disparities, both within rural areas and between urban and rural areas, were less able to speed up rural economic growth. However, urban economic growth was positively correlated with inequality. Moreover, they found that the increases in public spending reduced poverty but not inequality. And, the increases in public spending tended to come from sub-national governments, not the central government. Finally, they found substantial regional variations such that provinces with a more rapid rise in inequality usually made less progress in poverty reduction.

Based on rural household-level data collected in nine provinces during 1986 to 1999 , Benjamin, Brandt and Giles (2005) made qualitatively similar conclusions. They found that initial inequality affects growth, whereas rising inequality is not related to the growth trajectory. Specifically, they found that villages with higher inequality initially - i.e., in 1986 - in their sample, grew more slowly over the next thirteen years. However, in village fixed-effects specifications, there is no statistical relationship between inequality and growth. They believe this suggests that the mechanism linking growth to inequality operates "in the long run." They also found that more unequal villages had the slowest non-agricultural development. Part of the explanations for the long-run impacts of inequality on growth may be related to their other findings. That is, low inequality is related to the effect of village education, which leads to higher income growth, especially of non-farm incomes.

Yet, worries over ever-increasing inequality are increasing, and the impact of regional decentralization on inequality has been hotly debated. Some scholars even argue that the rapid 
widening of regional disparity caused by regional decentralization can lead to the disintegration of China (Hu, Wang and Kang, 1995). Kanbur and Zhang (2005) claim that fiscal decentralization is responsible for the rise of nationwide inequality.

Based on provincial level aggregate data, Kanbur and Zhang (2005) use the GE (the generalized entropy index) inequality coefficient, which increased from 0.14 in 1978 to 0.25 in 2000, and decompose Chinese inequality into three components: inland-coastal and rural-urban. They suggest that regional decentralization has contributed to about one-third of Chinese inequality. Consistent with some earlier literature (e.g. Tsui, 1993; Chen and Fleisher, 1996; Kanbur and Zhang, 2001) they contend that regional disparity in general, and inland-coastal disparity in particular, is a key dimension of increased inequality in the reform era. From 1978 to 2000, the inland-coastal GE component increased by nine times, from $0.4 \%$ in 1978 to $3.8 \%$ in 2000. They argue that this rapid widening of the gap between coastal and inland regions is mainly due to FDI and trade since the two regions have different opportunities. On the other hand, the rural-urban GE coefficient component increased from $11 \%$ in 1978 to $13.9 \%$ in 2000. Although this raise looks marginal, there was an inverse trend, as the number had bottomed out at $6.4 \%$ in 1984 when the HRS reform was completed. ${ }^{71}$ They argue that the worsening of the rural-urban disparity was also related to FDI and exporting.

Based on provincial-level data, Lin and Liu (2005) and Fleisher and Chen (1997) also claimed that widened regional disparities were related to regional decentralization. Lin and Liu (2005) emphasize different sub-national governments' strategies and their effectiveness in economic development, whereas Fleisher and Chen (2005) attribute the widened disparity to the central government's policies of favoring the development of coastal regions, as most important reform policies favoring coastal regions are FDI- and export-related policies. Similarly, Yao and Zhang (2001), Demurger (2001) and Fu (2004) all claim that these reforms contribute to regional inequality. They report that both exports and FDI have significant and positive impacts on growth in coastal regions, but not in inland regions.

Fiscal recentralization was proposed as a policy remedy to ease regional disparities. However, based on county-level data, Tsui (2005) and Zhang (2006) find that the regional fiscal disparities have worsened since the 1994 fiscal recentralization. Regional disparities in per capita fiscal expenditures (and by implication, the provision of services) are extraordinarily large across rural governments, and they were persistent since the peak reached in the late 1990s. Among the 2,800 county-level jurisdictions, in 2003 the richest spent 48 times as much as the poorest - a gap that is unusually large compared to that of other countries (Wong, 2007).

Yet, one has to be careful about real mechanisms behind the so-called fiscal decentralization or fiscal centralization as most of the empirical work in the literature is based on aggregate data and is carried out in a reduced form. As we discussed previously, at certain times fiscal decentralization is concurrent with regional decentralization such that a correlation with fiscal decentralization in such a period could capture some things other than fiscal decentralization. On the other hand, since the mid-1990s, in addition to fiscal recentralization there have been many changes in regional decentralization. Thus, further research should be done to study the impacts of regional decentralization and various specific reforms on inequality.

Based on household data from nine provinces, BBGW found that the contribution of regional disparities to household inequality was increasing and peaked in the mid-1990s, when fiscal policy was recentralized, and since then it has declined. They find after the mid 1990s, most of the inequality in China is within the villages and cities in which Chinese households live

\footnotetext{
${ }^{71}$ Ravallion and Chen (2007) report a similar trend of Rural-urban disparity over this period of time.
} 
and work; that is, most of the inequality was due to differences of income among households in the same province.

Concerning the disparity between coastal and interior regions, BBGW found that during the 1990s the difference in average incomes between the two regions widened considerably. However, much of the increase in the gap appears to be the result of a growing difference in incomes between rural households in the coastal and interior provinces. By 2000, rural incomes in the coastal provinces were about 50\% higher than they are in the interior, whereas the urban income gap between the two regions did not widen much. Consistently, inequality in the coastal provinces increases only slightly (from 0.35 to 0.39 ), whereas increases are larger in the interior (from 0.39 to 0.48 ). The significantly larger increase in the interior is attributed to the increase in inequality in rural areas in the interior (increases from 0.40 to 0.49 ) compared to the coastal provinces, which remains under 0.40; and a widening rural-urban income gap in the interior (which widened from 1.58 to 1.85 ) compared to the coastal areas (which fell from 1.60 to 1.32).

BBGW's findings suggest a strong link between inequality and regional decentralization, but due to a different mechanism than many other proposed. Instead of regional disparity, they argue that economic opportunity for citizens varies across regions, and this affects the development of rural areas. Thus, local institutions and differences in the opportunities for people living in the same community explain most of the rising inequalities. Concretely, they contend that at the outset of the reforms, the role of the state sector was significantly more important in the interior than in the coastal provinces. During the reform, the growth of the non-state sector in the interior provinces has been much slower. This has handicapped the growth in rural incomes in both the urban and rural sectors. In contrast, growth in the non-state sector in coastal provinces has provided opportunities to rural households, which has prevented a sharp deterioration in rural inequality like that observed in the interior.

\subsection{Resolving China's Institutional Problems}

The lack of an independent judiciary, rent-seeking behaviour, and unresponsiveness to citizens' preferences etc. are some of the intrinsic deficiencies of an authoritarian regime, and China's RDA regime is no exception. As discussed previously, some of those problems might be mitigated under the RDA regime when economic growth is an overwhelming objective, because the multiple tasks of a regional government can be effectively converted into a single task, achieving a high GDP growth rate. Under this condition, regional competition can alleviate many problems.

However, when there are many tasks which are not well-defined by quantitative targets, regional competition may lead to problems, such as regional protection and ignoring tasks that are not directly growth-enhancing, etc. It has been widely reported that there has been a severe deterioration of China's environment as a result of its rapid economic growth. $\mathrm{SO}_{2}$ emissions increased from 19.9 million tons in 2000 to 25.5 million tons in 2005 making China the largest emitter of $\mathrm{SO}_{2}$ (World Bank, 2007). Moreover, this deterioration was closely related with a lack of interest from sub-national government officials, who found that enforcing environmental regulations detracted from their ability to provide regional economic growth (Li, 2006).

Theoretically, if all tasks and their outcomes could be well measured, then by assigning a policy weight for each task it might be possible to construct a comprehensive index to summarize an official's achievement of all tasks. In this way, a multi-task problem could be reduced into a single-task problem, and regional competition and experimentation over the comprehensive index would function well. The "Green GDP" proposal of the Chinese 
government is an endeavour in this direction (Economy, 2007). However, most provincial governments who initially joined this 'Green GDP' project have withdrawn from it due to a conflict of interests (between growth and other objectives) and disagreements on technical issues related to its measurement. Indeed, this idea is fundamentally flawed and the problem can be traced back to the Lange vs. Hayek debate on the feasibility/infeasibility of centralized information collection. The GDP measurement is market-based, and therefore market transactions have already solved a large share of the associated incentive and information problems. The difficulties in measuring non-market activities, i.e. beyond GDP measurement, are notoriously difficult due to incentive and technical problems. If there existed a general way to measure economic activities without using markets, or to measure non-market activities accurately and efficiently, a centralized economy would be able to resolve all incentive and information problems at least as well as a market economy.

It is known that assigning high-powered incentives, through methods such as tournament competition, to sub-national officials can be harmful when they are responsible for multiple tasks (Holmstrom and Milgrom, 1991). However, without regional competition, sub-national officials under the RDA regime would not make efforts to initiate reforms or undertake growth-enhancing activities, which would deeply affect China's future development. In the following I briefly discuss some principles to handle this dilemma.

First, the multi-task problem can be mitigated by redefining tasks assigned to ministries and provincial governments. The scope of tasks to be carried out by sub-national governments should be narrowed down. For example, responsibilities for activities with strong cross-region externalities should be centralized and regulated by ministries. Moreover, to reduce the multitask problem at the central level, tasks to be handled by the central government should be handled by specialized ministries, special courts, and specialized regulatory bodies. Second, many monitoring and law enforcement functions, including regulation, should be separated from sub-national governments, i.e. should be carried out by an independent press and an independent judiciary. This will not only reduce the multi-task problem of sub-national governments effectively, but also greatly enhance neutrality, objectiveness, justice and thus effectiveness in monitoring and law enforcement. Third - and this would further entrench reforms - most market activities should be carried out by firms and should be separated from sub-national governments. This will not only narrow the tasks of sub-national governments, but it would also preserve strong incentives for firms for economic development even when incentives of sub-national governments are weakened.

I must make it clear that some of the most serious and fundamental problems intrinsic to the RDA regime cannot possibly be resolved without a fundamental institutional change. The multitask problem faced by sub-national governments is fundamentally associated with the fact that officials are accountable to their bosses, who face inherent and difficult informational problems in performance evaluation, not to mention the legitimacy problems of the central leadership (Section 2). The ultimate solution to those problems lies in transforming the RDA regime into a democratic federal system in which sub-national officials are elected and are accountable to their constituencies, so that their multi-task problem will be converted into a single-task election problem. Arguably, to some extent this transformation is on its way, but very slowly, in a bottom-up fashion. In the past decade, most village heads (O'Brien and $\mathrm{Li}, 2000 ; 2006$ ) and some township heads (Li, 2002) in China were elected; and systematic evidence shows that elected officials provide better public services and are more harmonious with their constituencies than appointed ones (Brandt and Turner, 2006; Rozelle et al., 2009). If China is unable to meet the 
serious challenges of managing the institutional transformation into a democratic federal system, China's political stability and long run development could be put in jeopardy.

Another closely related, fundamental, and challenging problem China has faced is law and law enforcement. To some extent, by deploying a regulatory decentralization regime as a substitute, China has mitigated or postponed serious problems associated with the absence of the rule of law, and has therefore won itself some time to reform its law and legal institutions. However, arguably, reform in this area is among the slowest and weakest, and this slow pace has caused and will continue to cause severe socio-economic problems. As the private sector and markets become fundamentally important to the economy, the negative impacts of bad laws and the absence of the rule of law will become even more manifest. The lack of an independent judiciary is one of the most serious problems; additionally, this is an intrinsic problem of the RDA regime, and therefore an ultimate resolution depends on institutional transformation. Following successful experiences in previous reforms, China should start to establish an independent judiciary system at the county level - the bottom sub-national level - and expand the reform upwards. Without substantial legal reforms, the absence of the rule of law could lead entrenched interest groups, particularly corrupt officials, to block the reform, obstruct development, and even threaten the political stability of the nation.

\section{Concluding Remarks}

In this paper I argue that the regional competition and experimentation governed by China's regionally decentralized authoritarian (RDA) regime have effectively alleviated potential incentive and informational problems. By linking regional performance to officials' promotion, tournament-like regional competition provides high-powered incentives to sub-national officials to initiate and to implement market-oriented reforms, while simultaneously limiting corruption ${ }^{72}$ (Section 3). Therefore, to some extent, competition among sub-national governments encouraged or forced them to create implicitly the institutions essential for a well-functioning market (Section 5). Furthermore, by incorporating regional experimentation into the central government's decision-making process, reforms are less likely to be blocked, and the political and technical risks of reforms are greatly reduced (Section 4).

Nevertheless, the very same institution, the RDA regime, and the solutions created and implemented by the RDA regime - as highly imperfect substitutes for "standard" solutions - also have created serious problems (Section 6). Yet, given the political and economic context of China's reforms (Section 2), many "standard" approaches were and are politically and institutionally infeasible, and it could be even worse for China's reforms if a reform fails as a result of implementing an infeasible approach. In this sense, the regional competition and regional experiments implemented by the RDA regime are second-best solutions.

To highlight the major features of the RDA regime, the following Table 6 compares the characteristics of China's RDA regime with the federal state and the Soviet system.

As it evolved from a unique history, China's RDA regime is itself somewhat unique. Therefore, many reform policies that fit with this regime could not be easily transplanted as a package to other countries. However, there are still some general lessons that can be drawn from China's reforms and development for other developing countries.

The first general lesson is our understanding of "institutions" and their relationship with

\footnotetext{
${ }^{72}$ My prediction is if there was no fierce regional competition, corruption would collapse Chinese government and Chinese economy.
} 
development. During its process of transition and development, China has changed its institutions at a large scale and has created market-supporting institutions in an evolutionary way, i.e. new institutions have gradually replaced old institutions when the new is ready. It would be mistaken to advise transition economies or developing countries to abandon their existing institutions in a rush by copying stylized "best practice" or "good" institutions without a careful understanding of the operation of both inherited and new institutions. As a matter of fact, the sophisticated market-supporting institutions observed in today's developed world were not created overnight ${ }^{73}$; instead, they historically co-evolved with markets. Thus, for a country with many missing "good institutions", like China, it is inevitable to use existing institutions, such as the government, as a starting point to pave the road for institutional evolution.

Table 6. Characteristics of China's RDA Regime Compared with Other Regimes

\begin{tabular}{|l|l|l|l|}
\hline & China's RDA Regime & Soviet System & Federal State \\
\hline $\begin{array}{l}\text { Composition of } \\
\text { national decision- } \\
\text { making body }\end{array}$ & $\begin{array}{l}\text { Central, regional and } \\
\text { ministerial officials } \\
\text { pecision-making } \\
\text { process }\end{array}$ & $\begin{array}{l}\text { Central and ministerial } \\
\text { bargaining; Consensus } \\
\text { building; Local } \\
\text { experiments as a strategy }\end{array}$ & $\begin{array}{l}\text { Top-down; SOE- } \\
\text { Ministry bargaining } \\
\text { representing regional } \\
\text { constituencies }\end{array}$ \\
\hline $\begin{array}{l}\text { Sub-national officials' } \\
\text { incentives }\end{array}$ & $\begin{array}{l}\text { Promotion: absolute and } \\
\text { relative performance; } \\
\text { Accountable to } \\
\text { superiors; Personnel } \\
\text { control }\end{array}$ & $\begin{array}{l}\text { Promotion: absolute } \\
\text { performance; } \\
\text { Accountable to } \\
\text { superiors; Personnel } \\
\text { control }\end{array}$ & $\begin{array}{l}\text { Federal-state bargaining } \\
\text { Independent from the } \\
\text { federal government; } \\
\text { Accountable to local } \\
\text { constituencies }\end{array}$ \\
\hline Regional competition & $\begin{array}{l}\text { Tournament-like } \\
\text { competition; } \\
\text { Competition affects } \\
\text { governor's promotion }\end{array}$ & Not important & $\begin{array}{l}\text { Fiscal (Tiebout) } \\
\text { competition; } \\
\text { Competition affects } \\
\text { governor's re-election }\end{array}$ \\
\hline Regional experiment & $\begin{array}{l}\text { Local experiments as } \\
\text { part of central decision- } \\
\text { making; Experimental } \\
\text { results may become } \\
\text { national policy }\end{array}$ & Not important & $\begin{array}{l}\text { States are "laboratories" } \\
\text { for policy; Voluntary } \\
\text { adoption of experiments } \\
\text { by states }\end{array}$ \\
\hline
\end{tabular}

Overly simplistic, black-and-white views of government are detrimental to reforms and economic development. There is a popular view that reforms in transition and developing economies should focus on confining the government, such that the role of the government should be restricted to the protection of property rights and contract enforcement. However, it has been well argued that reform and economic development involves complementary institutional changes to be carried out by the government. China's reforms in particular, and the experience of East Asian development in general (Japan, South Korea, Taiwan, Singapore, Hong Kong) illustrate this (Lin, 2007); the history of market development in pre-industrial revolution Britain also illustrate this (Smith, 1763). The government is the most important institution in any country (Stiglitz, 1989) and its involvement is essential for market development (Smith, 1776),

\footnotetext{
${ }^{73}$ Ironically, the on-going catastrophic financial crisis makes it crystal clear how problematic the legal (regulatory) and financial institutions are in the most advanced market economies. If we economists had a standard universal recipe on the shelf for institutional building, as offered to transition and developing economies, why do not we apply the recipe to fix these problems in advanced market economies?
} 
and this has borne out yet again during the market reforms in China. In addition to macro and political stability, national reform strategies, a functioning national government also determines effectiveness of decentralization, which is the next point I want to make.

The second general lesson is to use regional decentralization as an approach to solve incentive problems imbedded in reforms. China's reforms illustrate that the ability to reform institutions is endogenized as a result of the incentives of the stakeholders of existing institutions; while existing institutions are endogenized as a result of a country's history, social norms, culture, endowment and technology, etc. These facts make institutional reform and policy design fundamentally different from engineering design. The primary reason why many reforms with comprehensive plans failed was a lack of understanding of details of existing institutions, and of stakeholders' incentive problems with newly designed institutions, particularly when those were designed by outside "experts", who are not informed on those incentive problems. A thorough understanding of the details of existing institution in general, and the incentive problems of the stakeholders of a reform program in particular, is the foremost factor in determining the fate of a given reform.

Although at an abstract level there may exist commonly agreed-on goals for reforms or economic development, it is often not very helpful to prescribe a universal policy recipe in detail. This is because any effective policy recipe must take into account the interests of stakeholders in the existing institution, which varies from country to country and from context to context. When China 'ignored' standard advice, what they ignored was mainly the details, particularly when these were not incentive-compatible with Chinese stakeholders, and thus would not work. Sometimes they have also 'ignored' basic principles of standard advice due to political considerations, which is another type of incentive compatibility problem. Most of the details of Chinese reform policies were not designed ex ante, but instead evolved during the process of the reforms when incentive problems were resolved.

The importance of decentralization is not only due to heterogeneous local preferences, (Oates, 1999) but also due to heterogeneous local incentive problems and local institutional arrangements which can be handled more properly locally. Economic reforms and economic development are path-dependent, and this is true not only at the national level, but also at the sub-national level. A local history determines what interests stakeholders have nested into the existing institution there and how those affect institutional reforms in the locality. The typical approaches deployed in Chinese reforms evolved as a result of dealing with local incentivecompatible problems explicitly. ${ }^{74}$ Regional competition and regional experiment facilitate this approach, thus making reform easier. A large number of reforms in China were locally-initiated responses to local problems. The greatest benefit of this decentralized approach is that it evolves within the existing institutional framework. Therefore, it is easier for a reform to be incentivecompatible, the reform will fit better with local conditions, and when new problems arise, officials will have better incentives and information to find solutions.

However, what is the limitation of decentralization? Or what is the boundary of a national government? Pushing decentralization to the limit, if every city is completely decentralized and becomes an independent country, each city-state will have substantial powers and responsibilities and each will subject a hard budget constraint, should this be optimal? Applying the analytical framework of this paper (Sections 2, 3 and 4), I would argue that in addition to social costs of breaking up of a nation (depending on the procedure these costs may vary from extremely high,

\footnotetext{
${ }^{74}$ The Pareto-improving requirement (a la Lau, Qian and Roland, 2000) is the strongest criterion, whereas the incentive-compatible requirement is weaker and more general.
} 
e.g. anarchy or a civil war, to almost zero, e.g. a peaceful referendum and an orderly change), there are "pure" economic reasons that under certain conditions an integrated nation with regional decentralization can dominate a nation's breaking up. This is because the central government in an integrated nation is in a good position to address externalities among regions, such as strong positive externalities created by a few local experiments in a nation.

The last, but not the least, general lesson from China's reform is the importance of subnational governments. Decentralization is important for reforms and economic development in all countries, except city-states. To make decentralization work, sub-national governments should not only be empowered, but also enabled. The literature on decentralization and federalism emphasizes empowering sub-national governments, but hardly discusses enabling sub-national governments. Enablement does not come automatically with empowerment. Without enablement, sub-national governments would not be able to take policy actions, and decentralization would not work even when they are legally empowered. Moreover, enablement is a necessary condition for commitment to, and institutionalization of, decentralization. This point illustrates again that the overly simplistic view of confining government's resources and functions without a careful study of the context can be harmful to policy. Indeed, in many decentralized developing economies, sub-national governments are not enabled. For example, under-funding of required expenditures on local infrastructure or social services has been common in most decentralized developing countries (Bardhan, 2002; Bardhan and Mookherjee, 2006). In contrast, all major reforms were initiated and carried out by Chinese sub-national governments since they not only had the incentives to do so, but also they have the resources to proceed even if a given reform was not fully endorsed, i.e. not completely empowered. ${ }^{75}$ This may explain partly why "China is the only country [in the world] where the local governments have played a leading role in increasing rates of growth" (Bardhan and Mookherjee, 2006). A country's history determines to what extent sub-national governments are enabled, and which government is enabled. This implies that except for general principles, standard policy-recipes may not work uniformly even within a country. This is another reason to support decentralization.

\footnotetext{
${ }^{75}$ Many Chinese local governments in less-developed-regions also suffered severe under-funding problems for local public services, particularly after the 1994 fiscal recentralization (Wong, 2007).
} 


\section{Reference}

Acemoglu, Daron and Simon Johnson (2005), "Unbundling Institutions," Journal of Political Economy, October 2005, v. 113, 949-995.

Aoki, Masahiko (1990), "Toward an Economic Model of the Japanese Firm," Journal of Economic Literature, March 1990.

Axelrod, R. (1984), The Evolution of Cooperation, Basic Books.

Aghion P, Caroli E and Garcia-Penalosa C (1999) Inequality and Economic Growth: The Perspective of the New Growth Theories, Journal of Economic Literature. Vol. 37, No. 4. (Dec., 1999), pp. 16 15- 1660.

Alesina, Alberto and Dani Rodrik. 1994. "Distributive Politics and Economic Growth," Quarterly Journal of Economics, 109:2, pp 465-90.

Bai, C.-E., Y. Du, Z. Tao and S. Y. Tong (2004). "Local protectionism and regional specialization: evidence from China's industries." Journal of International Economics 63(2): 397-417.

Bai, Gang (1996), The General History of China's Political Institution (Zhongguo Zhengzhi Zhidu Tongshi), Volume I, Beijing: People's Press. 1996.

Ballis William B. 1961. Political Implications of Recent Soviet Economic Reorganisations. The Review of Politics, 23 (2) : 153-171.

Bao, Tong (2009), "On the three decades' reform (yetan gaige sanshi nian)," 22/12/2008-1/1/2009, Radio Free Asia (http://www.rfa.org/mandarin/yataibaodao/Baotong-12222008093954.html).

Bardhan, Pranab. 2002. "Decentralization of Governance and Development," Journal of Economic Perspectives. 16(4): 185-205.

Bardhan, Pranab and Dilip Mookherjee (2006), "The Rise of Local Governments: An Overview," in Bardhan and Mookherjee (eds.), Decentralization and Local Governance in Developing Countries: A Comparative Perspective, Cambridge: MIT Press, 2006.

Benjamin, Dwayne, Loren Brandt, and John Giles. 2005. "The Evolution of Income Inequality in Rural China." Economic Development and Cultural Change, 53:4, pp. 769-824.

Benjamin, Dwayne, Loren Brandt, John Giles and Sangui Wang (2009), "Income Inequality During China's Economic Transition," in Loren Brandt and Thomas Rawski (eds.), China's Economic Transition: Origins, Mechanisms, and Consequences, forthcoming.

Berkowitz, Daniel and Wei Li (2000), "Tax rights in transition economies: a tragedy of the commons?" Journal of Public Economics 76 (2000) 369-397

Bernstein, T.P. and $\mathrm{Lu}^{\prime \prime}$, X., 2000. Taxation without representation: peasants, the central and the local states in reform China. China Quarterly 163, 742- 763.

Blanchard, Oliver and Andrei Shleifer (2001) "Federalism With and Without Political Centralization: China vs. Russia" IMF Staff Working Papers, Special Issue, 2001.

Bolton, Patrick and Gerard Roland (1997), "The Break-Up of Nations: A Political Economy Analysis", Quarterly Journal of Economics 113, 1057-1090.

Booth, Charles D. (2004), "Drafting Bankruptcy Laws in Socialist Market Economies: Recent

Developments in China and Vietnam," Columbia Journal of Asian Law, Vol.18, No.1 (Fall 2004), pp.94147.

Boyreau-Debray, Genevieve and Shangjin Wei (2005), "Pitfalls of a State-dominated Financial System: The Case of China," NBER Working Paper, 2005.

Brandt, Loren and Xiaodong Zhu (2000), "Redistribution in a Decentralized Economy: Growth and Inflation in China under Reform," Journal of Political Economy, 108(2).

Brandt, Loren, and Matthew Turner (2006), "The Usefulness of Corruptible Elections," mimeo, University of Toronto, 2006.

Brandt, L., C. Hsieh, and X. Zhu. 2008. Growth and Structural Transformation in China, 1978-2004. In China's Great Economic Transformation, ed. L. Brandt and T. G. Rawski. Cambridge and New York: Cambridge University Press.

Burns, John P. (1994), "Strengthening central CCP control of leadership selection: the 1990 nomenklatura," The China Quarterly, No. 138 (1994), pp. 458-491 
Byrd, W. and Q. Lin (eds.) (1990), China's Rural Industry: Structure, Development and Reform, Oxford University Press, 1990.

Cai, Dongshi et al. (eds.) (2008), Xi Zhongxun Governing Guangdong (Xi Zhongxun Zhuzheng Guangdong), Beijing: Chinese Communist Party History Press, 2008.

Cai, Hongbin and Daniel Treisman (2004), "State corroding federalism," Journal of Public Economics, 88:819-843.

Chang, Chun and Yijiang Wang (1994), "The Nature of the Township and Village Enterprise." With C. Chang, Journal of Comparative Economics, 19(1994):434-452.

Che, Jiahua and Yingyi Qian (1998), "Insecure Property Rights and Government Ownership of Firms." Quarterly Journal of Economics, May 1998, 113(2), pp. 467-496.

Che, Jiahua and Giovanni Facchini (2007), "Dual track reforms: With and without losers," Journal of Public Economics, Volume 91, Issues 11-12, December 2007, Pages 2291-2306.

Chen, Hongyi, and Rozelle, Scott. "Leaders, Managers, and the Organization of Township and Village Enterprises in China." Journal of Development Economics, 60 (December 1999): 529-57.

Chen, Ye, Hongbin Li and Lian Zhou, (2005), "Relative Performance Evaluation and the Turnover of Provincial Leaders in China," Economics Letters, 88: 421-425, 2005.

Chien, Shiuh-Shen and Litao Zhao (2007), "Cross-Regional Cadre Transfer and Local Economic Development:Evidence from Jiangsu Province," 2007 Annual Conference of Association of American Geographers, San Francisco, April 2007.

Clarke, Donald, Peter Murrell and Susan Whiting (2006), "The Role of Law in China's Economic Development," The George Washington University Law School Public Law and Legal Theory Working Paper No. 187. 2006.

Coase, Ronald (1937), “The Nature of the Firm,” Economica, 1937.

Coase, Ronald (1992), "The Institutional Structure of Production" (Nobel Prize Lecture), The American Economic Review, vol.82, n²4, pp. 713-719, 1992.

Demurger, Sylvie, 2001. Infrastructure development and economic growth: an explanation for regional disparities in China? Journal of Comparative Economics 29, 95-117.

Deng, Jianping, Jie Gan, and Jia He, 2008. " The Dark Side of Concentrated Ownership in Privatization: Evidence from China," Hong Kong University of Science and Technology Working Paper.

Deng, Xiaoping (1980 [1984]), "On the Reform of the System of Party and State Leadership," in Selected Works of Deng Xiaoping, Volume II. Beijing: Foreign Languages Press. 1984.

Deng, Xiaoping (1987 [1994]), "To Uphold Socialism We Must Eliminate Poverty," in Selected Works of Deng Xiaoping, Volume III. Beijing: Foreign Languages Press. 1994.

Dickson BJ. (2003), Red capitalists in China: the party, private entrepreneurs, and prospects for political change. New York: Cambridge University Press; 2003.

Dong, Xiao-yuan, Louis Putterman and Bulent Unel (2006), "Privatization and firm performance: A comparison between rural and urban enterprises in China," Journal of Comparative Economics, 34 (2006) 608-633.

Du, Julan and Chenggang Xu (2008), "Regional Competition and Regulatory Decentralization: The Case of China," mimeo, Chinese University of Hong Kong and HKU, 2008.

Du, Julan and Chenggang Xu (2009), "What Firms Went Public in China? A Study of Financial Market Regulation," World Development. 4(37):812-824, April 2009.

Du, mingming and Xu Qingquan (2009), "Tian Jiyun on the 1992 Speech at the Central Party School (Tian Jiyun tan 1992 nian zhongyuang dangxiao jianghua)," Yanhuang Chunqiu, No.3, 2009.

Economy, Elizabeth (2007), "Green GDP: Accounting for the Environment in China," China from the Inside, http://www.pbs.org/kqed/chinainside/nature/greengdp.html.

Edin, Maria (2000), Market Forces and Communist Power: Local Political Institutions and Economic Development in China, Uppsala: Uppsala University, Department of Government, 2000.

Edin, Maria (2003), "State Capacity and Local Agent Control in China: CCP Cadre Management from a Township Perspective," The China Quarterly, 2003.

Epple, Dennis and Allan Zelenitz (1981), "The Implications of Competition Among Jurisdictions: 
Does Tiebout Need Politics?" Jounal of Political Economy,89:1197-217.

Estrin, Saul, Jan Hanousek, Evžen Kočenda and Jan Svejnar (2009), "Effects of Privatization and

Ownership in Transition Economies," Journal of Economic Literature, forthcoming.

Fan, Simon and Xiangdong Wei (2006), "The Law of One Price: Evidence from the Transitional Economy of China," Review of Economics and Statistics, 2006.

Fleisher, Belton M. and Jian Chen (1997), "The Coast-Noncoast Income Gap, Productivity, and Regional Economic Policy in China," Journal of Comparative Economics, 25(2): 220-236, 1997.

Fornasari, Francesca, Steven B. Webb, and Heng-Fu Zou. 1999. "Decentralized Spending and Central Government Deficits: International Evidence,” WP, World Bank, 1999.

$\mathrm{Fu}$, Xiaolan (2004), "Limited linkages from growth engines and regional disparities in China," Journal of Comparative Economics, 32 (2004): 148-164.

Fudenberg, Drew and Eric Maskin (2008), "Evolution, Cooperation, and Repeated Games," mimeo, Harvard University and IAS, Princeton.

Gan, Jie, Yan Guo, and Chenggang Xu (2010), "Privatization and the Change of Control Rights: The Case of China," mimeo, HKUST, PKU and University of Hong Kong, 2010.

Garnaut, Ross, Ligang Song, Yang Yao and Xiaolu Wang (2001), China's Private enterprise. Canberra : Asia Pacific Press, 2001.

Garnaut, Ross, Ligang Song, Stoyan Tenev, and Yang Yao (2005). Ownership Transformation in China, The World Bank, 2005.

Gordon, Roger and Wei Li (2003), "Government as a Discriminating Monopolist in the Financial Market: The Case of China." Journal of Public Economics, 87:283-312, 2003.

Granick, D., Chinese State Enterprises: A Regional Property Rights Analysis, Chicago: Chicago University Press, 1990.

Gregory, Paul and Robert Stuart, Russian and Soviet Performance and Structure, Harper Collins College

Publisher, 6th edition, 1998.

Greif, Avner. 2006. "Family Structure and European Institutional Exceptionalism: the Origin of Corporations." American Economic Review. Papers and Proceedings. May, 2006.

Groves, Theodore, Yongmiao Hong, John McMillan, and Barry Naughton. 1994. "Autonomy and Incentives in Chinese State Enterprises," Quarterly Journal of Economics, 109(1), 183-209.

Groves, Theodore, Yongmiao Hong, John McMillan, and Barry Naughton. 1995. "China's

Evolving Managerial Labor Market," Journal of Political Economy, 103, 873-892.

Guo, Xiaolin (2001), "Land expropriation and rural conflicts in China," The China Quarterly, No. 166 (2001).

Guo, Yan, Jie Gan and Chenggang Xu (2008), "A Nationwide Survey of Privatized Firms in China," The Seoul Journal of Economics, Vol. 21(2), 2008.

Heilmann, Sebastian (2008), "Experimentation under Hierarchy: Policy Experiments in the

Reorganization of China's State Sector, 1978-2008," CID Working Paper No. 172, June 2008.

Holmstrom, Bengt and Paul Milgrom (1991), "Multitask principal-agent analyses: incentive contracts, asset ownership, and job design," Journal of Law, Economics and Organization, Vol. 7 (1991), pp. 2452.

Holz, Carsten (2009), "No Razor's Edge: Reexamining Alwyn Young's Evidence for Increasing InterProvincial Trade Barriers in China," Review of Economics and Statistics, 91, no. 3 (Aug. 2009): 599-616.

$\mathrm{Hu}$, Angang, Shaoguang Wang and Xiaoguang Kang (1995), Regional Disparity in China (Zhongguo Diqu Chaju Baogao), Shenyang: Liaoning People's Press. 1995.

$\mathrm{Hu}$, Jiwei (2008), "Hu Yaobang Selected the Breakpoint for the Reform," Open, May 2008.

Hu, Jiwei (2009), "What is 'Reform and Open-up'? When Did It Occur?" Chengming, April 2009.

Huang,Yasheng (1996) Inflation and Investment Controls in China: The Political Economy of CentralLocal Relations During the Reform Era, New York: Cambridge University Press, 1996.

Huang, Yasheng (1996b), "Central-local relations in China during the reform era: the economic and institutional dimensions," World Development, Vol. 24, No. 4 (1996).

Hurwicz, Leonid (2007), "But Who Will Guard the Guardians?" Nobel Prize Lecture, Nobel Foundation, http://nobelprize.org/nobel_prizes/economics/laureates/2007/hurwicz-lecture.html. 
Jacoby, Hanan G., Guo Li and Scott Rozelle (2002), "Hazards of Expropriation: Tenure Insecurity and Investment in Rural China," The American Economic Review, Vol. 92, No. 5. (Dec., 2002), pp. 14201447.

Jefferson, G. H.; Rawski, T. G.; and Zheng, Y. "Chinese Industrial Productivity: Trends, Measurement Issues, and Recent Developments." Journal of Comparative Economics 23 (October 1996): 146-80.

Jefferson, Gary and Jian Su (2006), "Privatization and Restructuring in China: Evidence from Shareholding Ownership, 1995-2001." Journal of Comparative Economics, 34(2006), 146-166.

Jefferson, Gary, Thomas Rawski and Yifan Zhang (2008), "Productivity Growth and Convergence across China's Industrial Economy," mimeo, Brandeis University and University of Pittsburgh, 2008.

Jin, H., Y. Qian and B. R. Weingast (2005). "Regional decentralization and fiscal incentives: Federalism, Chinese style." Journal of Public Economics 89(9-10): 1719-1742.

Kanbur, Ravi and Xiaobo Zhang (2005), "Fifty Years of Regional Inequality in China: a Journey Through Central Planning, Reform, and Openness," Review of Development Economics, 9(1), 87-106, 2005.

Khrushehev, Nikita S. (1959), "Let Us Live in Peace and Friendship," Moscow: Foreign Language Press. 1959. Kim, S. (1995). "Expansion of Markets and the Geographic distribution of Economic Activities: The Trends in U.S. Regional Manufacturing Structure, 1860-1987." Quarterly Journal of Economics (November): 881-908.

Kornai, Janos (1972), Rush versus Harmonic Growth. Amsterdam: North-Holland. 1971.

Kornai, Janos (1980), The Economics of Shortage. Elsevier Science Ltd. 1980.

Kornai, Janos (1986), "The Hungarian Reform Process: Visions, Hopes, and Reality." Journal of Economic Literature, December 1986, 24, pp. 1687-1737.

Kornai, Janos (1992), The Socialist System: The Political Economy of Communism. Princeton University Press. 1992.

Kornai, Janos, Eric Maskin and Gerard Roland (2003), "Understanding the Soft Budget Constraint," Journal of Economic Literature, 2003.

Kung, James and Yi-min Lin (2007), “The Decline of Township-and-village Enterprises in China's Economic Transition," World Development, 2007.

Kung, James, Chenggang Xu and Feizhou Zhou (2009), "From Industrialization to Urbanization: The Social Consequences of Changing Fiscal Incentives on Local Governments' Behaviour," in Joseph E. Stiglitz (ed.), Institutional Design for China's Evolving Market Economy. Forthcoming.

Landry PF (2008), Decentralized authoritarianism in China: the communist party's control of local Elites in the post-Mao era. New York: Cambridge University Press; 2008.

Lardy, Nicholas R.. 1998. China's Unfinished Economic Revolution, Washington D.C.: Brookings Institution and Institute for International Economics, 1998.

Lau, Lawrence J., Yingyi Qian and Gerard Roland. "Reform Without Losers: An Interpretation of China's Dual-Track Approach to Transition," Journal of Political Economy, Feb 2000, 108(1), pp.120-143.

Lazear, E., Rosen, S., 1981. Rank-ordered tournaments as optimal labor contracts. Journal of Political Economy 89, S.841-S.864.

Li, David (1996), "A Theory of Ambiguous Property Rights: the Case of the Chinese Non-State Sector." Journal of Comparative Economics, v.23, n.1, pp.1--19, August, 1996.

Li, Hongbin, Rozelle, Scott (2004), "Insider privatization with a tail: The screening contract and performance of privatized firms in rural China," Journal of Development Economics, 75, 1-26.

Li, Hongbin and Lian Zhou (2005), "Political Turnover and Economic Performance: The Incentive Role of Personnel Control in China," Journal of Public Economics, 2005.

Li, Lianjiang (2002), "The Politics of Introducing Direct Township Elections in China." The China Quarterly, 171 (September 2002): 704-23.

Li, Lianjiang and Kevin J. O’Brien (2006), Rightful Resistance in Rural China, Cambridge: Cambridge University Press, 2006.

Li, Lianjiang and Kevin J. O'Brien (2000), "Accommodating 'Democracy' in a One-Party State: Introducing Village Elections in China," The China Quarterly, No.162 (June 2000), pp.465-89.

Li, Lixing (2009), "The Incentive Role of Creating "Cities" in China," Peking University, mimeo, 2009. 
Li, Rui (2008), "Li Rui’s Reflections on Reform and Open-up (Li Rui dui gaige kafang de yizhong huigu)," Yanhuang Chunqiu, No. 11, 2008.

Li, Wanxi (2006), "Environmental Governance: Issues and Challenges," News \& Analysis, Washington DC: Environmental Law Institute, 2006.

Li, Wei (1997), "The Impact of Economic Reforms on the Performance of Chinese State-Owned Enterprises," Journal of Political Economy, 105:5, 1080--1106, (October 1997).

Li, Wei and Dennis Yang (2005), "The Great Leap Forward: Anatomy of a Central Planning Disaster," Journal of Political Economy, 2005.

Lin, Justin Yifu (1990), "Collectivization and China's Agricultural Crisis in 1959." Journal of Political Economy 98.

Lin, Justin (1992), "Rural Reforms and Agricultural Growth in China," American Economic Review, 82 (March 1992):34-51.

Lin, Justin (2007), Development and Transition: Idea, Strategy, and Viability, Marshall Lectures, Cambridge University, 2007.

Lin, Justin, Fang Cai, and Zhou Li (1998), The China Miracle, Beijing.

Lin, Justin and Guofu Tan (1999), "Policy Burdens, Accountability and Soft Budget Constraint," American Economic Review: Papers and Proceedings, Vol. 89, No. 2 (May 1999), pp. 426-31.

Lin, Justin and Zhiqiang Liu (2000), "Fiscal Decentralization and Economic Growth in China," Economic Development and Cultural Change, 2000.

Lin, Justin and Peilin Liu (2005), "Development Strategies and Regional Income Disparities in China," CCER Working paper, Beijing University. 2005.

Lin, Justin and Zhiyun Li (2007), "Policy burden, privatization and soft budget constraint," Journal of Comparative Economics, 2007.

Liu, Guoguang, Zhuyuan Zhang, Zhikai Dong and Li Wu (eds.) (2006), Research Report on China's Ten Five Year Plans (Zhongguo Shige Wunian Jihua Yanjiu Baogao), Beijing: People's Press, 2006.

MacFarquhar, Roderick (1974, 1983, 1993), The Origins of the Cultural Revolution, Volumes I, II, III, New York: Columbia University Press. 1974, 1983, 1993.

MacFarquhar, Roderick and Schoenhals, Michael. Mao's Last Revolution. Harvard University Press,_2006. Markevich, Andrei and Ekaterina Zhuravskaya (2009), "Career concerns in a political hierarchy: a case of regional leaders in Soviet Russia," SSRN, 2009.

Maskin, Eric, Yingyi Qian, and Chenggang Xu (2000), "Incentives, Information, and Organizational

Form." Review of Economic Studies, April 2000, 67(2), pp. 359-78.

Maskin, Eric and Chenggang Xu (2001), "Soft budget constraint theories: From centralization to the market," Economics of Transition, 2001.

McMillan, John, and Barry Naughton (1992), "How to Reform a Planned Economy: Lessons from China." Oxford Review of Economic Policy, 8(1). Spring 1992, pp. 130-43.

McMillan, John, John Whalley and Lijing Zhu (1989), "The Impact of China's Economic Reforms on Agricultural Productivity Growth," Journal of Political Economy 97, Aug. 1989, 781-807.

Mertha, Andrew C. (2005), "China's 'Soft' Centralization: Shifting Tiao/Kuai Authority Relations," The China Quarterly, 2005.

National Statistical Bureau, 2006, China Statistical Yearbook, 2006.

National Statistical Bureau, 2006b, China Industrial Economy Statistical Yearbook, 2006.

National Statistical Bureau, 2006c, China Regional Economy Statistical Yearbook, 2006.

Naughton, Barry, Growing Out of the Plan: Chinese Economic Reform, 1978-1993, New York: Cambridge University Press. 1995.

Naughton, Barry (2003), "How Much Can Regional Integration Do to Unify China's Markets?" in Nicholas Hope, Dennis Yang, and Mu Yang Li, eds., How Far Across the River? Chinese Policy Reform at the Millennium. Stanford: Stanford University Press, 2003. Pp. 204-232.

Naughton, Barry and Dali L. Yang (eds.), Holding China Together: Diversity and National Integration in the Post-Deng Era, New York: Cambridge University Press, 2004.

Nelson, R. and S. Winter (1982), An evolutionary theory of economic change, Harvard University Press. 
1982.

North, Douglass C. (1981), Structure and Change in Economic History, W.W. Norton \& Co., New York. North, Douglass C. (1990), Institutions, Institutional Change and Economic Performance, Cambridge University Press, 1990.

Oates, Wallace E. (1999), “An Essay on Fiscal Federalism,” Journal of Economic Literature, Vol. 37, No. 3. (Sep., 1999), pp. 1 120-1 149.

Oi Jean C. (1999). Rural China Takes Off: Institutional Foundations of Economic Reform. Berkeley: Univ. Calif. Press.

Ofer Gur (1987), “Soviet Economic Growth: 1928-1985," Journal of Economic Literature, December 25(4). 1987.

Park, Albert and Shen,Minggao (2003), "Joint liability lending and the rise and fall of China's township and village enterprises," Journal of Development Economics 71, 497-531.

Perkins, Dwight (1977), Rural Small Scale Industry in the People's Republic of China, University of California Press, 1977.

Perkins, Dwight (1988), "Reforming China's Economic System," Journal of Economic Literature, Vol. XXVI, No. 2, June 1988, pp. 601-645.

Perkins, Dwight and Thomas Rawski (2008), "Forecasting China's Economic Growth to 2025," in Loren Brandt and Thomas Rawski (eds.), China's Great Economic Transformation, Cambridge University Press. 2008.

Pistor, Katharina and Chenggang Xu (2004), "Incomplete Law," Journal of International Law and Politics, 2004. pp.931-1013.

Pistor, Katharina and Chenggang Xu (2005), "Governing Stock Markets in Transition Economies Lessons from China," American Law and Economics Review, 2005.

Qian, Yingyi and Gérard Roland (1998), "Federalism and the Soft Budget Constraint," American Economic Review 88(5): 1143-1162.

Qian, Yingyi, Gerard Roland and Chenggang Xu (2007), "Coordinating Reforms in Transition Economies," Proceedings of the $5^{\text {th }}$ Nobel Symposium, Palgrave Macmillan, 2007.

Qian, Yingyi, Gerard Roland and Chenggang Xu (2006), "Coordination and Experimentation in M-Form and U-Form Organizations," Journal of Political Economy, 2006.

Yingyi Qian, Gérard Roland and Chenggang Xu (1999), "Why is China Different from Eastern Europe? Perspectives from Organization Theory," European Economic Review, 43(4-6): 1085-1094, April 1999.

Qian, Yingyi, and Chenggang Xu (1993), "Why China's Economic Reform Differ: The M-form Hierarchy and Entry/Expansion of the Non-state Sector." Economics of Transition, June 1993, 1(2), pp. 135-170.

Qian, Yingyi and Barry R. Weingast (1997), "Federalism as a Commitment to Preserving Market Incentives," Journal of Economic Perspectives 11(4): 83-92.

Ravallion, Martin and Shaohua Chen. 2007. "China's (Uneven) Progress Against Poverty." Journal of Development Economics 82 (2007) 1- 42.

Rodden, Jonathan (2002), "The Dilemma of Fiscal Federalism: Grants and Fiscal Performance around the World," American Journal of Political Science, 46 (July 2002), 670-87.

Rodden, Jonathan and Susan Rose-Ackerman (1997), "Does Federalism Preserve Markets?" Virginia Law Review, 1997.

Rodrik, Dani (2006), “Goodbye Washington Consensus, Hello Washington Confusion?” Journal of Economic Literature, XLIV, December 2006, 969-983..

Rozelle, Scott, Jikun Huang, Renfu Luo, and Linxiu Zhang (2009), "Village Elections, Public Goods Investments and Pork Barrel Politics, Chinese-style," mimeo, Stanford University, 2009.

Sachs, Jeffrey, and Wing T. Woo. "Understanding China's Economic Performance." Journal of Policy Reform, 2000, 4(1), pp. 1-50.

Sheng, Yumin (2005), "Central-Provincial Relations at the CCP Central Committees: Institutions, Measurement and Empirical Trends, 1978-2002," China Quarterly, 2005. 
Sheng, Yumin (2009), "Career Incentives and Political Control under Authoritarianism: Explaining the Political Fortunes of Subnational Leaders in China," mimeo, Wayne State University, 2009.

Shi, Yupeng and Lian Zhou (2007), "Regional Decentralization and Efficiency: A Case of Itemized Cities (Diqu Fangquan yu Jinji Xiaolv: yi Jihua Danlian Weili)," Economic Research (Jinji Yanjiu), No.1, 2007.

Shirk, Susan L. (1993), The Political Logic of Economic Reform in China, Berkeley : University of California Press, 1993.

Shleifer, A. and with R. Vishny (1994), "Politicians and Firms," Quarterly Journal of Economics, November 1994.

Shleifer, A., 1997. Government in transition. European Economic Review 41 (3), 385-410.

Sima Qian (1993) [109 BC], Records of the Grand Historian of China. Qin Dynasty. Translated by Burton

Watson. Hong Kong: The Research Centre for Translation [The Chinese University of Hong Kong]; New York, Columbia University Press.

Smith, Adam (1763), Lectures on Justice, Police, Revenue and Arms, Oxford: Clarendon Press, 1763.

Edited with introduction and notes by Edwin Cannan (1896).

Smith, Adam (1776), An Inquiry into the Nature and Causes of the Wealth of Nations, Oxford: Clarendon

Press, 1776. Eds. R. H. Campbell, A. S. Skinner and W. B. Todd. Reprinted in two volumes (1976).

Stalin, Josef V. (1931 [1947]), "Problems of Leninism," Moscow: Foreign Language Press. 1947.

Stiglitz, J. E. (1989). 'On the Economic Role of the State'. In A. Heertje (ed.), The Economic Role of the State, Cambridge, Mass., and Oxford: Basil Blackwell, 9-85.

Stiglitz, J. E. (2002), "Information and the Change in the Paradigm in Economics," The American

Economic Review, VOL. 92 NO. 3, 2002.

Sun, Q., Tong, W. H. S., 2003. "China Share Issue Privatization: The Extent of Its Success." Journal of

Financial Economics 70: 183-222.

Svensson, Jakob (2005), "Eight questions about corruption," Journal of Economic Perspectives, 19:3

(Summer 2005), 19-42.

Swearer Howard R. 1959. 'Khrushchev's Revolution in Industrial Management', World

Politics, 12 (1): 45-61.

Swearer Howard R. 1962a. 'Decentralisation in Recent Soviet Administrative Practice',

Slavic Review, 21 (3): 456-470.

Tian, Jiyun (2008), "How Economic Reforms Started (Jingji Gaige Shi Zenyang Gao Qilai de)?" Yanhuang Chunqui, No.1, 2008.

Tiebout, Charles. 1956. "A Pure Theory of Local Expenditures.” Journal of Political Economy 64: 416424.

Treisman, Daniel (2000), "Decentralization and Inflation: Commitment, Collective Action, or Continuity?," American Political Science Review, 94 (December 2000), 837-57.

Tsai, Kellee S. (2004), "Off balance: the unintended consequences of fiscal federalism in China," $J$. Chinese Polit. Sci. 9(2):1-26.

Tsui, Kai-yuen (2005). Local tax system intergovernmental transfers and China's local fiscal disparities. Journal of Comparative Economics 33 (1), 173-196.

Tsui, Kai Yuen and Youqiang Wang (2004), "Between separate stoves and a single menu: fiscal decentralization in China," The China Quarterly, No. 177 (2004), pp. 71-90.

Wädekin, Karl-Eugen. "Verlustminderung als zentrale Aufgabe der Nahrungswirtschaft in Russland und der GUS (SNG). Osteuropa, November 1992, pp. 938-950.

Wang, Shaoguang (1995), "The rise of the regions: fiscal reform and the decline of central state capacity in China," in Andrew G. Walder (ed.), The Waning of the Communist State:Economic Origins of Political Decline in China and Hungary, Berkeley: University of California Press, 1995.

Wang, Shaoguang and Angang Hu (2001, The Chinese Economy in Crisis: State Capacity and Tax Reform (Armonk, NY: M.E. Sharpe, 2001).

Wang, Yijiang (1991), "Economic Reform, Fixed Capital Investment Expansion and Inflation: A Behavior Model Based on the Chinese Experience," China Economic Review, Vol. 2 (1), pp. 3-27.

Watson, A., C. Findlay, et al. (1989). "Who Won the 'Wool War'?: A Case Study of Rural Product Marketing in China." The China Quarterly, 118: 213-41. 
Weingast, Barry (1995), “The Economic Role of Political Institutions: Market-Preserving Federalism and Economic Development," Journal of Law, Economics, and Organization 11 (April 1995)

Whalley, John and Shunming Zhang (2004). "Inequality Change in China and (Hukou) Labour Mobility Restrictions," NBER Working Paper No. 10683, 2004.

Whiting, Susan H. (2000), Power and Wealth in Rural China: The Political Economy of Institutional Change (Cambridge: Cambridge University Press, 2000)

Williamson, Oliver (1975), Markets and Hierarchies: Analysis and Antitrust Implications, The Free Press, New York, 1975.

Wong, Christine (1987), "Between Plan and Market: The Role of the Local Sector in Post-Mao China," Journal of Comparative Economics, 1987.

Wong, Christine (1991), "Central-local relations in an era of fiscal decline: the paradox of fiscal decentralization in post-Mao China," The China Quarterly, No. 128 (1991), pp. 691-715.

Wong C. 1992. Fiscal reform and local industrialization: the problematic sequencing of reform in postMao China. Mod. China 18:197-227

Wong, Christine (1997), Financing Local Governments in the People's Republic of China, Oxford University Press, 1997.

Wong, Christine (2006), "Can China Change Development Paradigm for the $21^{\text {st }}$ Century? Fiscal Policy Options for Hu Jintao and Wen Jiabao after Two Decades of Muddling through," mimeo, University of Washington, 2006.

Wong, Christine (2007), "Fiscal Management for a Harmonious Society: Assessing the Central Government's Capacity to Implement National Policies," Workshop on China's Institutional Design. Manchester, UK

World Bank (2002), China: National Development and Sub-National Finance, Washington DC: The World Bank, 2002.

World Bank (2007), Cost of Pollution in China: Economic Estimates of Physical Damages, Washington DC: The World Bank, 2007.

Woo, T.W.; Hai, W.; Jin, Y.; and Fan, G. "How successful Has Chinese Enterprise Reform Been? Pitfalls in Opposite Biases and Focus." Journal of Comparative Economics 18 (June 1994): 410-37.

Wu, Jinglian (2009), Understanding and Interpreting China's Economic Reform (Dangdai Zhongguo Jingji Gaige Jiaocheng), Shanghai: Shanghai Far East Press. 2009.

$\mathrm{Xu}$, Chenggang (1995), A Different Transition Path: Ownership, Performance, and Influence of Chinese Rural Industrial, New York: Garland Publishing. 1995.

$\mathrm{Xu}$, Chenggang, and Katharina Pistor. 2006. Enforcement Failure under Incomplete Law. mimeo, London School of Economics and Columbia Law School.

$\mathrm{Xu}$, Chenggang and Xiaobo Zhang (2009), "The Evolution of Chinese Entrepreneurial Firms:

Township-Village Enterprises Revisited," in Ronald Coase (ed.), China's Economic Transformation, forthcoming.

Xu, Chenggang and Juzhong Zhuang (1998), "Why China Grew: The Role of Decentralization," in Boon, P., R. Layard and S. Gomulka (eds.), Emerging from Communism: Lessons from Russia, China and Eastern Europe, MIT Press, 1999.

$\mathrm{Xu}$, Quanxing (1995), Theory and Practice of Mao Zedong in His Late Years (1956-76) (Mao Zedong wannian de lilun yu shijian, 1956-1976), Beijing: China Encyclopaedia Press, 1995. p.363.

Xu, Xianxiang, Wang Xianbin and Shu Yuan, 2007, "Local officials and economic growth", Economic Research (Jingji Yanjiu), September 2007.

Yang, Dali (1997), Beyond Beijing: Liberalization and the Regions in China, New York and London: Routledge. 1997.

Yang, Dali (2006), "Economic Transformation and Its Political Discontents in China: Authoritarianism, Unequal Growth, and the Dilemmas of Political Development," Annual Review of Political Science, no. 9 (2006), pp. 143-164.

Yao, Shujie, Zhang, Zhongyi (2001), "On regional inequality and diverging clubs: a case study of contemporary China," Journal of Comparative Economics 29, 466-484. 
Young, A. (2000). "The Razor's Edge: Distortions and Incremental Reform in the People's Republic of China." Quarterly Journal of Economics 115(4): 1091-1135.

Zeng, Jianhui, 1984, "A New Step in Opening Up the Economy The Emergence of an Important Policy," Liao Wang No 24, 1984.

Zhang, Jun and Yuan Gao, 2007, "Tenure/Rotation of Governors and Regional Economic Growth," Economic Research (Jingji Yanjiu), November 2007.

Zhang, Tao, and Heng-fu Zou. 1998. "Fiscal Decentralization, Public Spending and Economic Growth in China." Journal of Public Economics 67: 221-240.

Zhao, Ziyang (2009), Prisoner of the State - the Secret Journal of Zhao Ziyang, New York: Simon \& Schuster, 2009.

Zhuang, Juzhong and Chenggang Xu (1996), "Profit-sharing and financial performance in the Chinese state enterprises: Evidence from panel data," Economics of Planning, 1996. 